Florida International University

FIU Digital Commons

\title{
Students with Autism Spectrum Disorders at a Hispanic Serving Institution: A Qualitative Case Study of Students' Experiences
}

Stephen P. Loynaz

Florida International University, loynazs@fiu.edu

Follow this and additional works at: https://digitalcommons.fiu.edu/etd

Part of the Higher Education Administration Commons

\section{Recommended Citation}

Loynaz, Stephen P., "Students with Autism Spectrum Disorders at a Hispanic Serving Institution: A Qualitative Case Study of Students' Experiences" (2020). FIU Electronic Theses and Dissertations. 4400. https://digitalcommons.fiu.edu/etd/4400

This work is brought to you for free and open access by the University Graduate School at FIU Digital Commons. It has been accepted for inclusion in FIU Electronic Theses and Dissertations by an authorized administrator of FIU Digital Commons. For more information, please contact dcc@fiu.edu. 
FLORIDA INTERNATIONAL UNIVERSITY

Miami, Florida

STUDENTS WITH AUTISM SPECTRUM DISORDERS

AT A HISPANIC SERVING INSTITUTION:

A QUALITATIVE CASE STUDY OF STUDENTS' EXPERIENCES

A dissertation submitted in partial fulfillment of

the requirements for the degree of

DOCTOR OF PHILOSOPHY

In

HIGHER EDUCATION

by

Stephen Peter Loynaz

2020 
To: $\quad$ Dean Michael Heithaus

College of Arts, Sciences and Education

This dissertation, written by Stephen Peter Loynaz, and entitled Students with Autism

Spectrum Disorders at a Hispanic Serving Institution: A Qualitative Case Study of Students' Experiences, having been approved in respect to style and intellectual content, is referred to you for judgment.

We have read this dissertation and recommend that it be approved.

$\begin{array}{r}\text { Norma Goonen } \\ \hline \text { Rebekah Schulze } \\ \hline \text { Benjamin Baez, Co-Major Professor } \\ \hline \text { Kyle D. Bennett, Co-Major Professor }\end{array}$

Date of Defense: March 24, 2020

The dissertation of Stephen Peter Loynaz is approved.

Dean Michael Heithaus

College of Arts, Sciences and Education

Andrés G. Gil

Vice President for Research and Economic Development and Dean of the University Graduate School

Florida International University, 2020 
(C) Copyright 2020 by Stephen Peter Loynaz

All rights reserved. 


\section{DEDICATION}

I wish to dedicate this dissertation to my daughters, Emma \& Everly. Emma \& Everly, I don't expect you to ever read this thing all the way through, but when you are old enough to know and understand what it is and what it means to me, I hope you see it the same way I see it. This is my contribution to a subject I love-Education. Education is something that when life is breathed into it and it becomes real, it becomes something that has allowed individuals to seek a better life for themselves and their families. It allows people to create innovations that propel our society into the future, whether it be here on earth or among the stars. It is something that allows us humans to understand ourselves a little bit better and hopefully treat each other with dignity and respect, even if we don't always agree on things. It is something that allows us to understand the world around us and make sense of it, help preserve it, help cure it, help improve it. It is the thing that helps us define our goals and create a strategy to obtain them. With this contribution, I hope to make education more accessible to others. My dream is that helping others get an education will in turn help make the world around you a better place. A better place for you. I hope you come to value education as much as I do in your lives and go on to gain as much of it as possible. And remember, once you have experienced success with your education, endeavor to pass it on to the next generation so they may continue to learn and thrive from your efforts, my and your mother's efforts, and all those with us now and are no longer with us that have partaken in building the world you have inherited.

Throughout this endeavor, you have both been my guiding light, my motivation to do more and do better than the day before. I have enjoyed every minute of seeing you 
grow and develop! As I reflect on how blessed I am to have you two in my life, I wish only the best for you and promise I will always do everything in my power to give you the opportunity to become the best version of you that you can be, and this can only be done by being educated. It is the key to all our success in life-whether it comes from a university, your own studies, or being an artisan's apprentice, it will unlock whatever it is that restrains us from continuing down the path to our destiny. Just as I have made this effort to help others obtain an education, I promise that I will always support you in your endeavors and be there for you as you grow up to be strong, intelligent, independent, just, and gracious women.

I love you always, Papi 


\section{ACKNOWLEDGMENTS}

I would like to acknowledge all that have helped me accomplish this goal. My Dissertation Committee Dr.'s Kyle Bennett, Benjamin Baez, Norma Goonen and Rebekah Schulze: I cannot thank you enough for all of your guidance and support. Your dedication to my success is what has helped me cross the finish line. Thank you for patience, understanding, feedback (though I didn't always want to hear it), support during times when it didn't seem I was progressing and kind words during what was the darkest time of my life.

Amanda and my DRC Family: I seriously could not have done this without the unwavering support of my co-workers. Thank you for allowing me to breathe life into my research and allowing me to create the "Blue Panthers"! Thank you for allowing me the time and space to do my interviews and just about every part of my degree, and thank you for the moral support. Thank you, Amanda and Martha, for always helping me by reading some of my work and helping me think out loud to figure things out, despite all the responsibilities on your shoulders.

My Interview Participants: This study is only possible because of your stories. Thank you for letting me get a peek into your lives and be able to learn more about you and how we can hopefully help other students with ASD in higher education. I am forever grateful for your assistance with this venture.

Sensei Armando Martinez: The lessons you taught me so many years ago endure in me today. Without them, I would not have the mental fortitude to have accomplished this feat. Although I am not currently training, I still remember your teachings and sayings like "Gambatte Kudasai" and "Ichi-go Ichi-e." I will continue to always do my best and I 
will continue to seize every moment of the day and make the most of it. Domo Arigato Gozaimas, Sensei.

My Parents: You have both shown me what it is to have a goal and work tirelessly to achieve it and what it means to be a parent. On both sides, our family came from Cuba with practically nothing and eventually became business owners, homeowners, and achievers of the American Dream. You have been there for me through every good and bad time and have always shown me unwavering love and support as I worked to achieve my dreams and support my family. There is nothing I can say or do to say thank you and honor all the work and sacrifice you have done for me to be where I am today than to continue working towards being the best I can be in every aspect of my life.

My Wife: Despite the efforts and support of everyone who has contributed to me finishing this dissertation, the bottom line is that I would not have been able to do it without the support of my amazing wife. When I was on the verge of giving up, it was you who forced me to see past all the darkness in that time of my life and realize that I needed to finish this. During the long days and nights writing and doing literature reviews, it was you who was patient and understanding and made sure I didn't have to worry about all the parenting obligations and could just be a student. When I would forget to send an e-mail, run out of time to do something for my professors, or needed help with running our business, it was you who would step in and keep me on track. When I thought I had run out of options and was in dispair, you helped me find a way forward. Other than our daughters, you have been the rock I have leaned on to finish this. You have helped me keep my motivation and my spirit up that I will finish this. Your relentless optimism when all I could see is what could go wrong is what helped me find 
balance between school, work, and family. I don't know how I would have finished this without you. Thank you, thank you, thank you! 


\section{ABSTRACT OF THE DISSERTATION \\ STUDENTS WITH AUTISM SPECTRUM DISORDERS \\ AT A HISPANIC SERVING INSTITUTION: \\ A QUALITATIVE CASE STUDY OF STUDENTS' EXPERIENCES \\ by}

Stephen Peter Loynaz

Florida International University, 2020

Miami, Florida

Professor Benjamin Baez, Co-Major Professor

Professor Kyle D. Bennett, Co-Major Professor

The present study focuses on the experiences of students with Autism Spectrum Disorder (ASD) in higher education. It was important to conduct this study because of the rising numbers of students with ASD in higher education and the scant amount of research available about how to best serve them depending on their actual needs, not the perceived needs stated by experts based on research from K-12 student populations, or the perceived needs of these students stated by their parents or other service providers or faculty. Semi-structured interviews were conducted with nine students from a Hispanicserving institution in the Southeast United States of America. The data gleaned from these interviews using holistic coding and the constant comparative method were used to create a case study of a resilient group of students that understand their needs in higher education, are interested in becoming more engaged with on-campus activities, and know what needs to be done to attend to these needs. They are a group of students who have goals of their own, despite what their loved ones and service providers may have to say, 
and they are utilizing the option available in higher education to live in student housing as a way of sharpening their life skills so they may be better prepared to live independently after graduation. The results of the study are followed by a discussion of how this information can be used in practice and what other research can be conducted to further these findings and better understand this student population.

Keywords: Autism Spectrum Disorder, Higher Education, Life Skills, Support Services 


\section{TABLE OF CONTENTS}

CHAPTER

PAGE

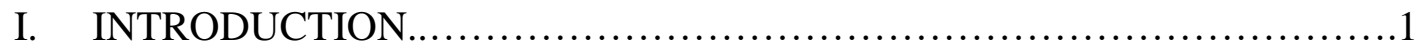

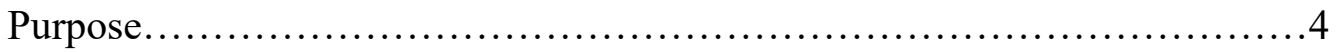

Theoretical Lens.........................................................

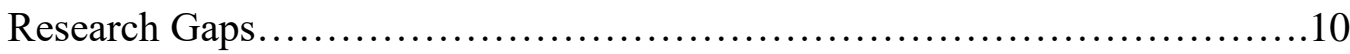

Research Questions.................................................. 16

Organization of the Study ................................................... 17

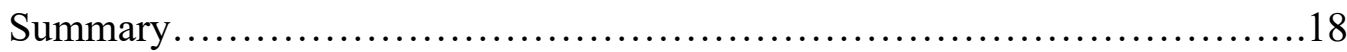

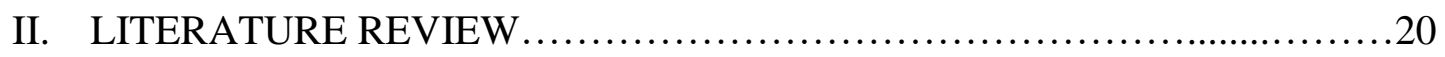

Journal Article Search and Screen Procedure................................21

History of Autism Spectrum Disorder........................................22

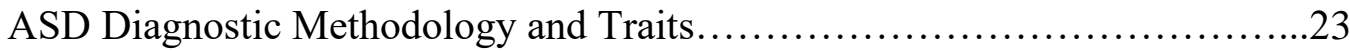

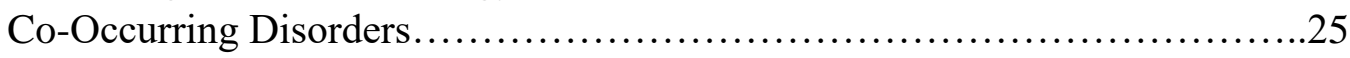

Support and Accommodation in Higher Education...........................26

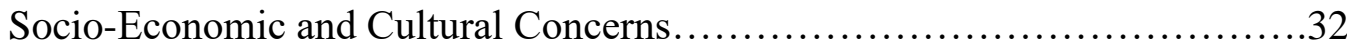

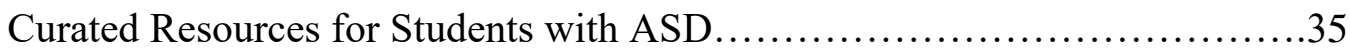

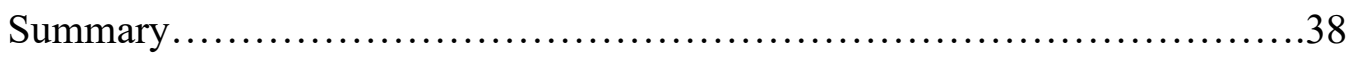

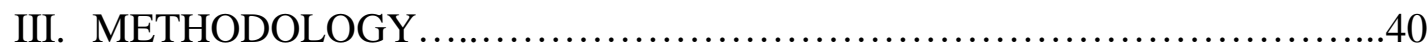

Research Design: The Case Study ........................................41

The Role of the Researcher.................................................43

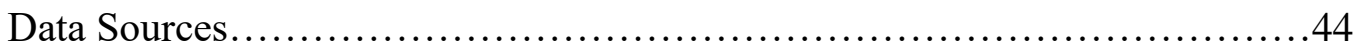

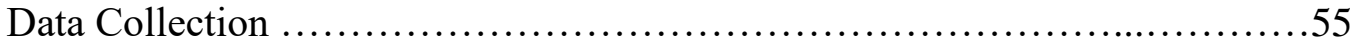

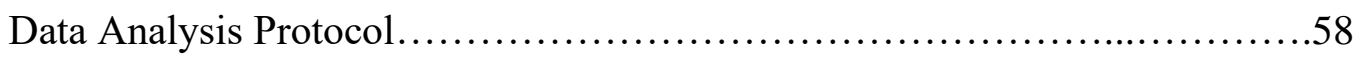

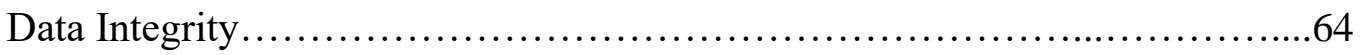

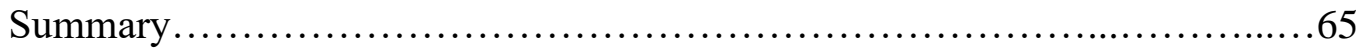

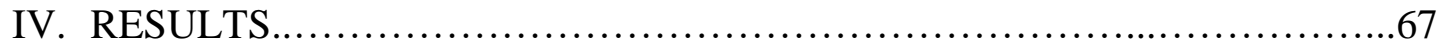

Participant Descriptions and Interview Summaries...........................67

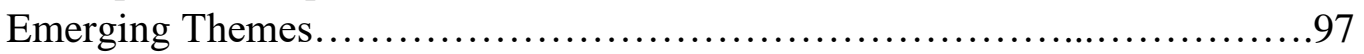

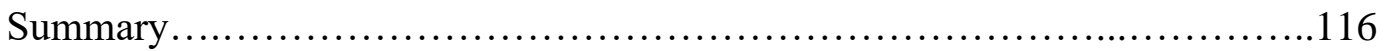

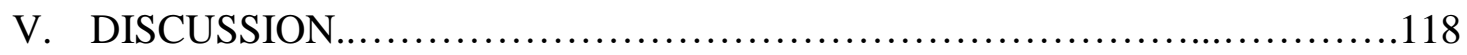

Research Questions Responses and Interpretations..........................119

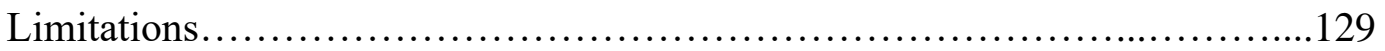

Implications for Practice................................................ 132

Recommendations for Future Research......................................138 
Concluding Remarks.

References............................................................ 144

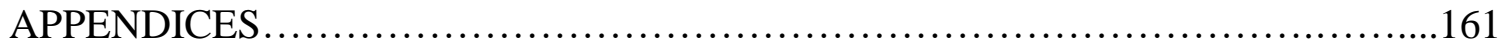

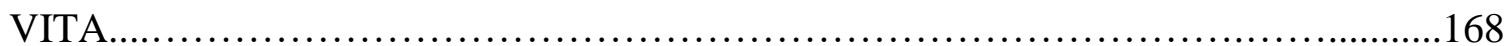




\section{CHAPTER I INTRODUCTION}

According to the Center for Disease Control and Prevention (CDC), 1 in 59 children is diagnosed with autism spectrum disorder (ASD) in the United States (U.S.) as of April 2018. This ratio represents an increase of ASD diagnoses from 1 in 150 in 2000 - a span of only 18 years. As of 2016, the U.S. Department of Education reported that in the 2013-2014 school year, up to $8 \%$ of the students served under the Individuals with Disabilities Act of 2004 (IDEA) were living with Autism. As mentioned in Lee and Carter (2012), the number of students served in special education type programs exceed 370,000. In the educational arena, according to the U.S. Department of Education (2011), most of the known population of students with ASD is currently in the $\mathrm{K}-12$ educational system. As ASD awareness has risen the pedagogy used in the $\mathrm{K}-12$ system has become more robust. Currently, more students with ASD are completing high school and are now looking forward to a collegiate experience (Vanbergeijk, Klion, \& Volkmar, 2008). In turn, students now have an expectation that various post-secondary options are available and accessible (Rocco \& Delgado, 2011). Individually, and holistically, these data only strengthen the necessity of research regarding the needs of students with ASD and the urgency for higher education professionals in the future who will be serving these students to know more about what these students need to be successful.

As reported in the literature, there is a notable increase in students with disabilities in higher education in the last four decades. In Gordon and Keiser's 1998 book titled, Accommodation in Higher Education under the Americans with Disabilities Act, increases were noted during 1988-1994 when first-time college freshmen with 
disabilities rose from 15.3 to $32.2 \%$. Furthering the idea that the disabled student population is growing and needs to be addressed is research from Dutta, Kundu, and Schiro-Geist (2009) confirming that the overall population of students in higher education with disabilities has grown more than three times its size in 1978. Also supporting this increase in the number of known students with disabilities is research done at the University of Massachusetts. During the period of 2003-2008, the number of students that closed out (completed) of state vocational rehabilitation programs went from 1,617 students in 2003 to 5,344 students in 2008 (Smith \& Lucas, 2010). In regard to students with ASD in higher education, Cocchi and Wilson (2011) confirmed that this was a growing population at the Columbus State Community College, which prompted them to implement a new transition program for students with ASD. There is a growing number of students with disabilities in our educational system, specifically, students with ASD who are not only in the system but entering higher education (Florida Department of Education, 2018).

The increase in the number of students with disabilities - and ASD, in particular-in higher education should not be surprising. The data are available for all persons working with students with ASD and other disabilities to manage their efforts accordingly (Test, 2008). According to Indicator 14 in the Florida Department of Education's 2018 Local Educational Agency Profile Performance Report, 36.2\% of the students who graduated in the 2014-2015 school year were enrolled in a higher education program the following year. Indicator 14 is a valid source of information to gauge the need for future research in higher education because its intention is to measure what activities, such as higher education, competitive employment, and vocational training, 
students with Individualized Education Plans (IEPs) are engaged in after high school (Prince, Hodge, Bridges, \& Katsiyannis, 2018). Notably, 61\% of these students are minorities, 31\% being of Hispanic descent (Florida Department of Education, 2018). According to the 2018 report, within the U.S. Hispanic population, ASD is diagnosed at a similar rate as the general population. The rate of diagnosing among U.S. Hispanics is concerning since the literature demonstrates that Hispanic and other ethnic minority families tend to have less awareness and access to resources to support their children with ASD caused by a variety of factors related to cultural norms and socio-economic status, an issue that affects every aspect of their educational endeavors (Magaña, Lopez, Aguinaga, \& Morton, 2013; Thomas, Ellis, McLaurin, Daniels, \& Morrissey, 2007; Thomas, Zahorodny, et al., 2012). Lastly, helping to expand the growing population of Hispanics and other minorities in higher education, which in turn marks this as a major concern to be attended to, is legislation like the Higher Education Opportunity Act of 2008 that helps promote opportunities and initiatives for students from cultural minority groups to attend and succeed in higher education (Boland, 2018; Sampson, 2008)

As the number of students with ASD in higher education rises, so does the importance of students with ASD having access to quality higher education experiences. Access to higher education for students with ASD is dependent on having adequate support from various professionals, the most critical support coming from those overseeing the transition from secondary to post-secondary education and those faculty and staff working with them throughout their collegiate careers (Dutta et al., 2009). Success in higher education is dependent on a set of skills many of these students have never had to depend on for themselves. When a student receiving support services 
graduates from the $\mathrm{K}-12$ system and transitions to higher education certain support systems and tools previously accessible to them are no longer available to them, such as the opportunity to have an IEP, parental access to educators and support services, and a team of educators and support staff specifically trained to work with their disabilityrelated needs (Shattuck, Wagner, Narendorf, Sterzing, \& Hensley, 2011). A lack of these support tools could be detrimental to the successful completion of their higher education goals.

All the support services and teaching strategies implemented to provide students with ASD a K-12 education are organized via an IEP, a mandate of the IDEA of 2004. In addition, IDEA also assures services for students up to age 22 are funded (Janiga \& Costenbader, 2002). Under the mandates set forth by IDEA, all students with disabilities in the $\mathrm{K}-12$ education system have an IEP that states the specific learning goals, accommodations, and support strategies a student needs (DeDeppo, 2009). According to IDEA, students with ASD and other disabilities need to collaborate with the appropriate personnel and have post-secondary transition planning discussions started as early as their sixteenth birthday depending on their general knowledge, skills, abilities, and interests (Daly-Cano, Vaccaro, \& Newman, 2015).

\section{Purpose}

Most of the current research about students with ASD has been centered on the K-12 population. The focus of young students with ASD has left a considerable gap in the research pertaining to college students with ASD, including the processes meant to support them with the transition to higher education and the completion of their college degrees (Brown \& Coomes, 2016). Piven and Rabin (2011) also confirm that the adult 
population with ASD has not been researched as much as the child and adolescent populations. The articles mentioned help us identify research opportunities by leaving the vast part of life known as adulthood open for discussion and further inquiry, which is also the time period in which individuals participate in higher education.

Given that higher education is seen as an opportunity for students to develop their academic and personal skill sets (Keeling, 2004), we must question how much more can higher education professionals do to help students with ASD prepare for life in college and after graduation. As evidenced by students with ASD continuing to need their relatives to provide essential living support with finances and self-care (Wehman et al., 2014), there seem to be gaps in how the law and current practices align regarding transitions from secondary education to a more independent post-secondary education world. Furthermore, some of the professionals charged with developing and preparing students with ASD simply are not able to get this task completed properly on a large scale, and many students are transitioning to higher education ill-equipped for success in higher education or work, or to live independently (Rowe, Mazzotti, Hirano, \& Alverson, 2015). Shogren and Plotner's (2012) analysis of the National Longitudinal Transition Study II revealed evidence that students with ASD have limited engagement with the transition process, which exacerbate problems in the future because plans and goals are not properly aligned with the needs and interests of the student they intend to support. Simply stated, students with ASD are not being prepared to transition properly by "not [being] given the opportunities to develop the self-advocacy skills" (Adams \& Proctor, 2010, p.167) needed to be successful in college. "Students with disabilities [are entering] college unprepared to disclose their disability or lack the understanding of how to access 
services on campus" (Getzel, 2008, p. 208). Given that these students are not coming into higher education prepared to succeed, and that institutions are very concerned about their ability to graduate and persist (Getzel, 2008), it is the duty of higher education professionals to lead research that will help narrow the current gap that exists between the law, mission statements, theory, and practice.

Further supporting the need to resolve the gap that exists in how prepared students with ASD are, and how prepared they should be, to enter college is the McCall (2014) study that discussed how students rely on organic support systems such as classmates, friends, and family. On the basis of our current knowledge, additional work needs to be done to prepare these students, their families, and education professionals to work together in a more productive manner. Because many college students do not activate some of the essential support services they need to be successful, such as disabilityrelated accommodations (Daly-Cano, Vaccaro, \& Newman, 2015), faculty and staff will sometimes discover a student that needs support accidentally rather than know about them and their needs through the formal disability services support process.

Students with ASD are a population with many needs that are not being properly served as they depart the $\mathrm{K}-12$ system and transition to higher education. In essence, the literature says that schools are in compliance with their obligations to these students, but many students with ASD have not received the necessary guidance and training to transition to, and be successful in, higher education (Shogren \& Plotner, 2012). As further evidence of the deviation of practice from the stated standards, students with ASD in higher education have confirmed they need more assistance with transitioning and being successful in higher education (Webster, 2004). 
In addition to the concerns presented thus far regarding how prepared students with ASD entering higher education are compared to how ready they should be, are the following concerns about their persistence in higher education. Typically, students with ASD do not complete their higher education goals as often as the neurotypical population, despite all the current knowledge and resources available (Luey, 2014). Higher education's lack of expertise on how to serve students with ASD has put these students at a dangerously high risk of attrition compared to their non-disabled peers for reasons ranging from not opting in to support services and fear of stigma, to faculty and staff personnel being ill-prepared to work with students with ASD (Sayman, 2015). Although some of these patterns can be seen with many students with disabilities, students with ASD have significantly lower rates of engagement with the transition process and preparation for the transition out of secondary education to post-secondary opportunities that will help support their success in higher education and future employment (Wehman et al., 2014).

In the following section, the theoretical lens being used to focus the research will be introduced. The theoretical lens of the research will be followed by the short- and long-term benefits the study will provide, as well as the questions that have been derived from the information presented. Afterwards, the strategies for how these questions have been studied will be discussed, followed by a summary of this chapter.

\section{Theoretical Lens}

Many perspectives have been used in the literature reviewed for the present dissertation to study the concept of disability (Gilon \& DePoy, 2002). In the evidence presented, a medical model of viewing disability was widely used. As cited in Connor et 
al. (2008), the medical model of viewing disability is characterized by the viewing of disability through the perspective of the medical community. The traditional medical model of viewing disability posits an oppressive ontology that those with disabilities are incapable of choosing for themselves and that those who know better should be the deciders of what can, or cannot, be done for people with disabilities. As a consequence of the conceptualization of what is normal in society, under disability theory, disability is defined more by the environment and the barriers created by society, than by the actual need of the person with a disability (Preston, 2010). In essence, the voice of people with disabilities is taken away in favor of what society has deemed correct, fair, and just. To resolve the inequity of perspectives of how someone with a disability should be supported, add the narrative of these students to the research, and have them become more active participants in their higher education transition and success, the ideas from Disability Theory aim to free those with disabilities from their oppressive situation and let them have a more commanding role in their own lives and within society.

When working with students with disabilities, it is important to treat them as collaborators to ensure their interests are kept at the forefront of all efforts (Freire, 2000). The concept of more students with ASD being included in research is supported by the research of Hendricks and Wehman (2009) that confirmed that very few students with ASD enagage the transition planning process in a meaningful way. Higher education seeks to support students and help them become independent contributing members of society, but students with ASD are not included in the conversation about what is best for their own well-being. The inclusive mindset used in this study imbues the current body of research with the thoughts and concerns of those most affected by it in an equitable 
manner (Watson, 2012). A goal of Disability Theory is that efforts to support people with disabilities will not ignore their medical needs, but rather narrow the gaps between their needs and the unnecessary and unintentional barriers created by society so these barriers can be eliminated (Lowen \& Pollard, 2010). The present dissertation does this by infusing the voice of college students with ASD into the research being done to support their success.

When reading the articles reviewed for this dissertation, a long list of issues being presented for solutions and prescribed actions to resolve them are showcased. As sound as the methodology and recommendations that are found in the studies reviewed for the present dissertation are, they seem to be missing the one component that Disability Theory requires us to include, and that is the point-of-view of the person with the disability. As voiced in Munger and Mertens (2011), research done to support people with disabilities must be less medicalized and needs to include more ideas and perspectives from people with disabilities.

The study I conducted is concerned with including the perspectives of students with ASD about how well they are being prepared for higher education, how supported they are to complete their degrees, and how well they are being prepared to live independently after they have completed their collegiate years. As creative and innovative as the recommendations promoted by all the research are, without the thoughts of the students included in them, there is a gap. To continue conducting research under the medical mindset prevents the goal of eliminating any and all potential bias against people with disabilities in its findings (Gilon \& DePoy, 2002). By diverging from the medical model of research, focusing on the student perspective, and conducting this 
research in a university with a high level of diversity, this study accomplishes the goal of bringing together the necessary components for a meaningful step towards strategies that will help students with ASD better transition to higher education, complete their degrees, and live independently once they have completed their post-secondary degrees.

\section{Research Gaps}

The study's goal is to help narrow the gap found in our current understanding of how to best serve college students with ASD. By using a Transformative Disability Theory-based research model, including more student narratives in the research is possible. Including the perspectives of students with ASD in higher education is accomplished by allowing the experiences of students with ASD interviewed at a research institution that is rich in diversity, Hispanic serving, in an urban setting, and has a population where the majority is a minority teach us what their perception of how well they have been prepared for success is and how well supported they are. Although there is some new research being produced in this mindset (Gobbo \& Shmulsky, 2011), the overall body of knowledge being used to serve students with ASD is still lacking breadth and depth (Zeedyk, Tipton, Blacher, 2016).

According to a database search that was done for the dissertation, 95 articles were published from 2006-2016 discussing support strategies for students with ASD in the post-secondary education setting. A more detailed explanation of this database search will be provided in the Literature Review section. Unfortunately, the research that has been reviewed for this study has not been done at a university with the percentage of diversity found in some modern institutions that espouse an ethos of inclusion and diversity (Shmulsky \& Gobbo, 2013), further supporting the evidence-based guidelines 
on how to serve people with ASD and other disabilities (Hewitt, 2015). The procedures and findings related to the literature review will be discussed further in the second chapter of this dissertation.

There are many benefits that can be derived from narrowing this gap in our current understanding of how to best serve college students with ASD. The short-term benefit of this kind of research is that higher education professionals working with students with ASD will be able to support and provide a high-quality educational experience for their students (White, Ollendick, \& Bray, 2011). Often, students with ASD do not get all the support they need and this can have a negative effect on their educational experience (Hendricks \& Wehman, 2009). Given the differences in the educational environments students with ASD are transitioning through, it is imperative that the faculty and staff supporting them know how to assist them in activating support services in higher education (Janiga \& Costenbader, 2002). For example, in higher education, disclosing your status as a person with a disability to the institution is optional. As mentioned in Gordon and Keiser (1998), there is a lack of awareness of how disconnected the $\mathrm{K}-12$ environment is from higher education regarding the continuity of support services and other student needs. Unless students are interested in receiving the support they need to be successful in the higher education environment (Smith, 2007), there is no obligation to disclose their needs to the institution in which they are enrolled. Similar to opting in to accommodations in higher education is the activation process for any support service in higher education; this can overwhelm a student that has been accustomed to receiving services in a specific manner for a very long time (Barber, 2012). 
Opting into accommodation support services can also be difficult because of the changes in vernacular and processes (Dutta et al., 2009). The change in how accommodations are accessed, processed, and implemented in higher education as compared to K-12 is because of the Americans with Disabilities Act as Amended of 2008 (ADAA) - the anti-discrimination law that governs these processes in higher education. In higher education, the ADAA governs the way post-secondary institutions must comply with regard to providing accommodations. According to Cragg and Schloss (2013), the ADAA prohibits students enrolled in a public institution from being discriminated against and to be reasonably accommodated. In research done on 680 students regarding their ability to transition to post-secondary education or employment setting, students with ASD were found to be ill-prepared to transition to many post-secondary settings (Shattuck et al., 2012). The concept that students with ASD are ill-prepared to transition to higher education is further supported by research confirming that schools are not complying with the minimum standards in regard to coordinating the transfer of support service plans with post-secondary institutions (Shogren \& Plotner, 2012). In addition, there are data confirming that many students with ASD are not working or attending postsecondary education within the first two years after high school; the need for effective support as these students transition to the post-secondary environment is critical (Test, Smith, \& Carter, 2014).

As they transition to post-secondary education, individuals with ASD are presented with options that are both compelling and unclear (Lee \& Carter, 2012). As evidenced in the British Journal of Learning Support, there are many options available for students finishing primary and secondary schooling, but not many options have been 
made for students with the unique needs presented by ASD (Elson, 2011). Like the U.S., Britain has laws that protect its citizens with disabilities from discrimination, such as the Disability Discrimination Act, the Mental Health Act, and the Education Act. These acts help students with disabilities access education much like IDEA and the ADAA in the U.S. Although these laws provide students with disabilities access to education, issues such as poor planning, inadequate personnel expertise on working with students with disabilities, and no individualized support in higher education have left students with ASD and other disabilities with little meaningful options once they transition out of the K-12 system (Elson, 2011).

The long-term benefit of the present research is for higher education faculty and staff to be prepared, much like their $\mathrm{K}-12$ counterparts, to work with students with disabilities as they persist towards the completion of their post-secondary educational goals such as obtaining a higher education degree, seeking employment, or living independently. Research from Grillo and Leist (2014) confirms that students with enhanced support will more likely be successful in attaining their degree and after graduation. Having higher quality support services helps students with ASD accomplish their goal of completing their degree, but it will also help institutions of higher education in other ways. Graduation and retention rates are also an important issue for institutions of higher education because these metrics directly influence the performance-funding programs that have been adopted by many states, which regulate the amount of funding and resources a higher education institution can receive (Sanford \& Hunter, 2011).

Unfortunately, funding and resources can have a direct effect on what options students with ASD have at their institutions of higher education. Sometimes these issues 
tend to go unnoticed at institutions that have a robust infrastructure and a variety of program offerings and degree paths that cater to a variety of students' interests and styles, but haphazard solutions should be left out of the equation (Elson, 2011). According to Elson's (2011) article, other contributors to the issues faced by a student with ASD of not finding the services they need include inadequate college planning opportunities, a lack of communication and transparency between secondary schools and higher educational institutions, and an overall one size fits all attitude from disability service representatives. Elson (2011) states that in Britain, there are very few adequate program options for students with ASD which leads to attrition and failure. The root cause of students with ASD not getting the appropriate support they need, as identified by Elson's respondents, is that higher education professionals are treating students with ASD the same way they treat students with other disabilities. Students with ASD have special needs in nonacademic areas that neurotypical peers do not, such as independent living skills (Knott \& Taylor, 2014).

Fortunately, the resources and ability to improve this situation exist, but they need to be directed towards a resolution of this situation rather than keep perpetuating the status quo, which is the intention of the present study. In support of acquiring and retaining funding and resources and promoting the success of students with ASD, institutions of higher education need to search within the various departments and experts found within their current faculties (Longtin, 2014). The concept of searching within your institution and building collaborative groups of departments with similar goals to unite resources is also supported by research such as the Learning Reconsidered document. In Learning Reconsidered, Keeling (2004) writes that viewing the entire institution as a 
whole in calculating resources helps open the possibilities to join personnel and departments with common goals as collaborators and contributors in resolving the myriad of issues that may at times quell efforts to serve students with ASD. Once the barriers encapsulating and separating each individual and campus entity in this endeavor are removed, many options can be created.

It is important to identify and prepare for some of the future needs of a student with ASD in order for faculty and staff in higher education to be able to provide immediate and adequate attention to any issues that arise (Brown \& Coomes, 2016). Understanding and recognizing these long-term needs helps the university professional charged with developing infrastructure, as well as meaningful programming and experiences for this population. To meet the needs of students with ASD, higher education institutions must serve students in non-traditional ways such as with independent living, communication, and socialization skills training rather than the typical academic support and professional development opportunities provided to all students (VanBergeijk, Klin, \& Volkmar, 2008). In addition to a quality education in a timely fashion, higher education is also expected to help develop a student's ethos of lifelong learning, which means a student should be able to identify a need and learn how to resolve it on their own, or with the appropriate resources (Beytekin \& Kadi, 2014). The collegiate environment has become one of the last opportunities many students have to learn the skills needed to handle transitions and other challenges they will face during and after college. As the higher education environment becomes the last opportunity for students to learn various life and academic skills, the importance of assuring these skills are being learned so that students with ASD are ready to live independently after college 
increases. This is where the higher education profession's obligation to better serve students with ASD lies since one of the measures used to judge the quality and need for higher education is how well students' quality of lives are after graduation (Ross, Marcell, \& Williams, 2013).

Within the work that has been reviewed thus far, the gaps mentioned are higher education faculty and staff being underprepared and lacking resources to work with students with ASD (Pillay \& Bhat, 2012), knowing what kind of help students with ASD need to be successful (Burgstahler \& Russo-Gleicher, 2015), and improving the transition experience for students with ASD to postsecondary education (Skaff, Kemp, Sternsky McGovern, \& Fantacone, 2016). With the data collected from college students with ASD answering the following research questions, my study will construct a narrative of what these students are experiencing and will illuminate a path that helps lead higher education professionals to better serve them.

\section{Research Questions}

Upon review of the concerns and benefits presented thus far, there are three questions that are evident; the questions my study explored are listed below. These questions serve as the foundation for exploring the perception of college students with ASD at a Hispanic-serving, research university in an urban setting with a large minority population have of how well prepared they are to succeed in that environment and of the support services they have at their disposal. In addition, their perception of how well they are being prepared to succeed after they graduate will be explored. Please note that in qualitative studies, there can be some changes to the questions asked during the study as 
new information and themes emerge during the collection of data (Creswell, 2007). The research questions for this study include:

1. What are the experiences of college students with ASD?

2. What are the experiences of college students with ASD with support services intended for them?

3. What are the perspectives of college students with ASD with regard to how well they feel prepared to live independently after graduating?

\section{Organization of the Study}

In the second chapter of this dissertation, a literature review is provided to explore the knowledge base of higher education faculty and professionals serving students with ASD. The goal of the literature review is to develop an understanding of what the limitations of the current body of knowledge are and in which direction the I need to take the study to properly answer the questions presented. In the third chapter, the appropriateness of the qualitative methodology chosen for this study is discussed. In order to understand the experiences of the students being interviewed, data were collected and analyzed via a case study methodology. This afforded the me an opportunity to answer the research questions using the thoughts and experiences of those who will be affected by the product of my study — college students with ASD in an urban, minorityserving institute of higher education. The case study proved to be an acceptable method to use for the data collection and analysis of this study because it allowed for the participants' experiences to be showcased (Merriam, 1998). The results of the data collection and analysis process are presented in the Results chapter of this dissertation. In 
the Results chapter, a description of each participant and a summary of their interviews are presented along with quotes from their interviews that support the themes that were developed from these interviews. The themes that will be mentioned in the results chapter are that students with ASD at the host institution are self-aware, interested in further developing various life and independent learning skills by living on campus, they are capable of addressing their needs, are interested in increased campus engagement, and are interested in further developing their life skills. How these themes can be used to improve support services in higher education and how this research can guide other studies will be discussed in the final chapter of this dissertation.

\section{Summary}

In this introduction, the purpose and need for this study were defined. In essence, higher education is ill-equipped to properly work with the growing number of students diagnosed with ASD who are attending colleges and universities now and in the near future. The purpose of this research is to learn more about the experiences of students with ASD at a diverse urban research university with a large Hispanic population and a minority-majority by interviewing students from a university that fits this description. These characteristics represent the growing number of modern institutions of higher education where student demographics, learning spaces, collaborations, and learning modalities are changing and becoming more diverse and inclusive (Boys, 2015).

The themes derived from this study could be used to inform the higher education field of what needs to be done to rectify the lack of appropriate support for college students with ASD. As students with ASD transition into the collegiate environment, persist towards the completion of their academic programs, and transition into the world 
as its future independent citizens and leaders, it is their right to receive the same standard of educational and developmental opportunities as their neuro-typical peers. It is the ultimate goal of this study to help develop a stronger platform for college students with ASD to live, learn, and develop into the individuals they aspire to become. 


\section{CHAPTER II LITERATURE REVIEW}

My study was executed to infuse the perspectives of college students with ASD from a large, primarily Hispanic, urban, research university on how well prepared and supported they are to be successful in a post-secondary education environment, and how prepared and supported they are to be successful as they transition out of that environment. In Chapter II, an analysis of the current literature related to the topic of the present study is discussed. The sources for the review vary but consist primarily of peerreviewed journal articles and other publications (Creswell, 2007). The literature review supports and questions the veracity of what is currently known in this field and guides my study towards serving its mission of defining and narrowing the gaps in our current body of knowledge on how to best support students with ASD in higher education towards the successful completion of their educational goals.

The structure of this chapter is as follows. First, an explanation of how the search for journal articles related to the focus of this study will be presented. Secondly, an explanation of what ASD is and how it is diagnosed will be presented. The proceeding sections will explore the knowledge base available to researchers and working professionals and how it has been composed. In essence, the literature review will provide a rationale for the questions being asked in this study and the methodology chosen to explore them (Galvan \& Galvan, 2017). The rationale for the questions and theoretical framework of the study will be developed by an evaluation of various authors' works in an effort to develop a compelling focus and structure for the study (Charmaz, 2014). 


\section{Journal Article Search and Screen Procedure}

To develop the focus and methodology for the study, multiple databases were accessed in order to establish and delineate the current body of knowledge for this topic area. The databases used for this research were ERIC, PsychArticles, and PsychINFO. These databases were chosen following a discussion with the faculty members of my committee. It was agreed that these databases are the leading databases for researchers in education, psychology, counseling, and student support in higher education fields of study. In an effort to maintain uniformity in the search, a list of key words was used. The uniform use of keywords allowed the search to be conducted across the three databases in a way that would assure, as much as possible, that all pertinent articles would be found. The key words used in this search were: "ASD," "Autism Spectrum Disorder," "Autism," "Asperger's Syndrome," "PDD-NOS," “College," "University,” and "Vocational School." In all searches, the following criteria were also specified: all articles had to be peer-reviewed, all articles needed to be published between 2006 and 2018, and they had to be published in English. In the searches done with PsychArticles and PsychINFO, the population criteria were set to "College Students." In the ERIC database search, all the searches required that the populations studied would be from "Higher Education," "PostSecondary Education," and "Two Year Colleges." The goal of the selection of these criteria was to exclude articles focusing on the K-12 population from the results as well as any studies done on adults who were not enrolled in a college or university.

In sum, over 1,300 articles were identified in this search. After reviewing the abstracts for these articles, 95 unique publications were highlighted for inclusion in the literature review. The inclusion criteria consisted of confirming that the article indeed 
met all the keyword parameters. In addition, the decision to exclude any studies that only examined "autistic traits" was made in order to maintain the scope of the research focused on students in a college or university setting actually diagnosed with ASD. Lastly, all duplicates were rejected in order to avoid inflating the number of articles found that met the search criteria among the different databases.

In addition to searching the leading databases, five leading peer-reviewed journals in the fields of education, psychology, counseling, and student support in higher education were also surveyed. The peer-reviewed journals selected for this search were "The Journal of Post-Secondary Education," "Focus on Autism and Other Developmental Disabilities," "Education and Training in Autism and Developmental Disorders," "The Journal of Career Development and Transition for Exceptional Individuals," and "The Journal of Research and Practice for Persons with Severe Disabilities." These peerreviewed journals were also identified via discussions with faculty members of my committee for the study. A manual search of each journal's previous year's publications was conducted, and articles matching inclusion criteria were selected. Of the 101 peerreviewed journal articles reviewed, five met the criteria to be included in the literature review. In addition to this systematic search, various articles that have been reviewed in previous academic endeavors or cited in articles reviewed for the study, but did not come up in the systematic search, were also used if their themes were congruous with the purpose of this study.

\section{History of Autism Spectrum Disorder}

Autism Spectrum Disorder (ASD) is a phenomenon that was first recognized in the 1940s (Pevin \& Rabin, 2011; Robinson, 2008). According to Pevin and Rabin (2011), 
little was known about the adult lives of the population that was studied at that time. Widespread awareness of ASD did not occur until late in the $20^{\text {th }}$ century; therefore, many individuals may not be correctly diagnosed or diagnosed at all (Pevin \& Rabin, 2011). Research from the United Kingdom suggests that the prevalence of ASD is up to $1 \%$ of the general adult population (Spencer et al., 2011). The number coincides with the same statistic Pevin and Rabin (2011) gave in their report that approximately $1 \%$ of the population was living with ASD. As more awareness is created, and more efforts are aimed towards properly identifying and developing methods to work with individuals with ASD, those diagnosed with the disorder will be able to access all the opportunities available to them to learn, live, and further engage with options like higher education (Anderson \& Butt, 2017; Brown, Pena, \& Rankin, 2017; Roberts \& Birmubgham, 2017). In the next section, how ASD is diagnosed will be discussed.

ASD Diagnostic Methodology and Traits

The primary tool used to reference the criteria for diagnosing an individual with ASD is the fifth edition of the Diagnostic and Statistical Manual of Mental Health (Robinson, 2008). According to the American Psychological Association, the latest version of this manual was published in 2013 and is known as the Diagnostic and Statistical Manual of Mental Health -5 (DSM-5). Since the vast majority of the students currently in the higher education setting were diagnosed as children (VanBergeijk, Klin, \& Volkmar, 2008), the criteria used to diagnose them was dictated by the DSM-IV-TR. For more information on the current criteria used to diagnose ASD in higher education, please refer to the latest version of the DSM, the DSM-5, (APA, 2013). As per the DSMIV-TR, some of the diagnoses included in the Autism Spectrum are Autistic Disorder, 
Pervasive Developmental Disorder-Not Otherwise Specified, Asperger Syndrome, Rett Disorder, and Childhood Disintegrative Disorder. The DSM-IV-TR listed the full criteria needed in order to meet each diagnosis.

In essence, these disorders are marked by a compromised ability to communicate, socialize, a lack of executive functioning, and repetitive behaviors (APA, 2000). Students with Asperger Syndrome will exhibit similar symptoms, but with higher language abilities and increased curiosity about the parts of a whole; they also have impairment in the area of showing and sharing enjoyment. Please note that throughout this document, the term ASD will be used as a blanket term for these diagnoses since it is the current term used in the DSM-5. Another change that was made for the DSM-5's diagnostic criteria was that varying levels of specificity are used to identify how much support the individual would need to participate in daily life activities, the degree of intensity of intellectual and language impairments, and any level of biological factors related to the individual's case. The level of these factors is assigned using a variety of data analyzed by a qualified healthcare service provider (APA, 2013). In the DSM-5 there is also a new recommendation for those individuals who do not exhibit the behavioral symptoms of ASD, it is now recommended that these individuals' cases be evaluated for a possible diagnosis of Social (Pragmatic) Commnication Disorder (APA, 2013).

It is important to be knowledgeable not only about the criteria to diagnose ASD, but also about the diversity within the ASD population since this can have an impact on how someone with ASD's symptomology manifests and what support services they may need (Macloud, Lewis, \& Robertson, 2013). According to the literature, creating accessible programming in higher education that informs students and other stakeholders 
on how to identify an issue and how to engage the resources available to a student to resolve an issue and is relevant to a student with ASD's needs is a critical component of a student with ASD's ability to have a successful and positive experience in higher education (Brown, Pena, \&Rankin, 2017).

Co-occurring Disorders

In order to ensure academic success, higher education professionals have an ethical obligation to understand the needs of their students to support their success (White, Ollendick, \& Bray, 2011). According to the DSM-5 (2013), “about 70\% of individuals with autism spectrum disorder may have one comorbid mental disorder, and $40 \%$ may have two or more comorbid mental disorders" (p.58). As mentioned in Spencer et al. (2011), although the literature on how to best serve students with ASD in higher education is limited, some useful strategies can be gleaned from it and the literature that focuses on the ASD population in the K-12 environment. The reason knowing about cooccuring disorders is important is that if only the needs of another diagnosis or of the ASD are being attended to, without attention to the co-occurring diagnosis(es), the efforts of the higher education professionals and faculty to help the student become moot (Pugliese \& White, 2014). Thus, informing higher education faculty and staff to be aware of an ASD diagnosis and the possibility of another diagnosis becomes a critical step in ensuring the student has the support needed to be successful in higher education (Pugliese \& White, 2014). In addition, not only is lack of awareness of one's diagnostic profile an issue, but also some students have not had the opportunity to equitably participate in transition planning while in high school and may have conflicting views on what they should be doing as a college student (Hatfield, Falkmer, Falkmer, \& Ciccarelli, 2017). 
Thus, it is up to the higher education faculty and professionals to be prepared to assist in developing and referring appropriate resources, using their observations and expertise, to students with ASD who are academically-able to succeed in higher education, but are not socially ready to engage the collegiate environment (Anderson \& Butt, 2017).

Furthermore, given the prevalence of co-occurring disorders within the population of students with ASD, awareness - along with appropriate and accessible mental health, executive functioning, socialization, and communication support-is critical for these students (Elias \& White, 2017; Hewitt, 2015; Sarrett, 2017). In essence, any effective research or service program developed for students with ASD must take into consideration possible co-morbid disorders that may present complications to students with ASD’s educational experience (White, Ollendick, \& Gray, 2011).

\section{Support and Accommodation in Higher Education}

The literature regarding higher education in the U.S., the rights of students with ASD, how students with ASD are supported throughout their educational career, and the theoretical framework used to conduct the current study will be reviewed. When the information is combined with what is already known about the medical aspect of ASD, the foundation for my study is clarified and the methodology chosen for the study is supported.

\section{Brief History of U.S. Higher Education}

The history of higher education in the United States generally starts with the chartering of Harvard University in 1636 (Thelin, 2011). Originally, universities were designed by academic elites to train a small group of upper-class members of society (Rege Colet, 2017). Throughout the history of U.S. higher education, it has continued to 
evolve and become an option for a broader segment of society and to serve the needs of the various communities and a variety of people wishing to seek better lives for themselves (Kupfer, 2012). Although not at its apex and in need of further development, higher education has experienced great strides and has become more accessible to more significant segments of our population such as, but not limited to, people with disabilities, racial and religious minorities, veterans, women, and international students since the end of World War II (Thelin, 2011). As called for in the literature documenting the evolution of higher education and its policies, more research and legislation is needed to not only make higher education accessible, but to also have it foster a climate that welcomes a variety of students and supports them in developing their unique identities and accomplishing their goals in an equitable fashion (Jones, 2016; Mullen \& Baker, 2015; Stebleton, Soria, Huesman, \&Torres, 2014).

Legal Mandates

The policies and practices of American higher education are typically regulated by the legal resolutions created in U.S. courts (Kaplin \& Lee, 2014). Herein, the general legal mandates for working with students with ASD will be described via a summary explanation and comparison of the legal mandates for $\mathrm{K}-12$ and higher education. It is important to understand these laws since the difference between them regarding what students are entitled to and what they must autonomously activate is a major factor behind why students in higher education with ASD experience challenges (Lee \& Carter, 2012; Morrison, Sansosti, \& Hadley, 2009). 


\section{$\underline{\mathrm{K}-12 \text { Legal Mandate Summary }}$}

In the K-12 environment, students with ASD are eligible for educational support services and academic accommodations under the Individuals with Disabilities Education Improvement Act (IDEA) and Section 504 of the Rehabilitation Act (Adreon \& Durocher, 2007). Under IDEA and Section 504, all primary and secondary education level students are entitled to receive necessary educational support to complete their Free and Appropriate Public Education (Brown \& Coomes, 2016; Longtin, 2014). Under these laws, students have been provided a pathway for successfully completing their entitled primary and secondary education goals, and are now ready, if they so desire, to pursue higher education (Barnhill, 2016). In sum, these laws represent a philosophy and practice that espouses a focus on the guarantee of a $\mathrm{K}-12$ education, but they do not extend past the twelfth grade (Adreon \& Durocher, 2007).

Students with ASD are provided with various accommodations to assist in the successful completion of their primary and secondary educational programs. These accommodations include extended testing time, note-taking assistance, and flexibility in scheduling. In addition to the accommodationsjust mentioned, students are also often provided with extended due dates, alternative assessments, and exemptions from group work (Adreon \& Durocher, 2007). In addition to these various accommodations, some students also have various goals listed in their IEPs such as developing communication, organization, and social skills, which are often implemented by their educational institution in order to develop their autonomy (Morrison, Sansoti, \& Hadley, 2009). In essence, the education plans and services in place to support students in the K-12 setting are focused on the completion of the secondary education level and a variety of options 
after graduation, such as employment, vocational training, and higher education (Adreon \& Durocher, 2007; Hewitt, 2011; Mazzotti, Rowe, Sinclair, Poppen, Woods, \& Shearer, 2016; Skaff, Kemp, Sternsky-McGovern, \& Fantacone, 2016).

\section{Higher Education Legal Mandates Summary}

In higher education, students with ASD are provided accommodations under a different set of laws, philosophies, and processes than the K-12 educational setting (Hewitt, 2011; Morrison, Sansoti, \& Hadley, 2009). In the collegiate setting, civil rights laws such as the Americans with Disabilities Act as amended in 2008 and Section 504 of the Rehabilitation Act of 1973 primarily regulate how accommodations are handled (Simon, 2011). The ADAA and Section 504 afford students in higher education reasonable accommodations that do not fundamentally alter any federally funded programs of study in which they are enrolled (Brown \& Coomes, 2016; Luey, 2014; Simon, 2011). According to these two sets of laws, once students identify themselves and their needs to the institution, the institution is obligated to serve them their reasonable accommodations within the parameters the student is entitled to, which are typically limited by the learning objectives and goals of their particular program (Luey, 2014). In addition to these acts, the Family Educational Rights and Privacy Act (FERPA) and the Higher Education Opportunity Act (HEOA) of 2008 also affect how a student with ASD is able to access higher education (Adreon \& Durocher, 2007; Hart, Grigal, \& Weir, 2010; Hewitt, 2011; McKeon, Alpern, \& Zager, 2013; Simon, 2011). Under HEOA, higher education institutions are able to build more pathways that will provide students with ASD, and other disabilities, more opportunities to enter higher education (Ross, Marcell, \& Williams, 2013). Although it does not regulate accommodations, it supports 
pathways being built for students who may be diagnosed with ASD and do not have access to a robust infrastructure of support to enter higher education (Magaña et al., 2013; Thomas et al., 2007; Thomas, et al., 2012). Acts such as the HEOA provide the foundation for support of any work that helps close gaps in transition planning and higher education engagement. In the United States, FERPA is an act that restricts how much information is able to be given to entities other than the student such as parents, success coaches, and other key stakeholders (Hewitt, 2011). Although FERPA restrictions can be mitigated with the appropriate authorizations, and some students enjoy the opportunity to be in control of their education, this can pose a threat to the educational success of a student with ASD since support systems that include parents, success coaches, and tutors have been a critical part of their educational success plan their entire lives (Dallas, Ramish, \& McGowan, 2012; Simon, 2011).

The acts previously mentioned highlight the change in philosophy from an entitlement of education to an optional, more self-driven type of educational opportunity (Lee \& Carter, 2012). The shift in laws supporting students between the K-12 environment and higher education represent not only a transformation in legal protection and philosophy, but also a change in the process of requesting, acquiring, and implementing reasonable accommodations (Brown \& Coomes, 2016; Hewitt, 2011; Morrison, Sansosti, \& Hadley, 2009). In higher education, students with ASD are required to advocate for their accommodations by disclosing their needs to the institution's disability resource center, opting into their accommodations for every class they need them, and participating at a much higher degree than in the $\mathrm{K}-12$ setting in the 
implementation of their reasonable accommodations (Morrison, Sasosti, \& Hadley, 2009).

\section{$\underline{\text { Legal Mandates Comparison }}$}

In sum, the laws that regulate the accommodations process in the $\mathrm{K}-12$ setting and in higher education share the same goals, which is to provide students with disabilities access to educational opportunities, but that is where these similarities end. Their differences are showcased by variations in the educational goals of each setting. The differences in educational goals in each setting causes a change of the accommodation obligation of higher education institutions to be set differently, which is where many of the challenges students with ASD are facing originate (VanBergeijk, Klin, \& Volkmar, 2008; Wolf, Brown, \& Bork, 2009). In reference to the goals of each educational setting being different, one of the differentiating factors is that a $\mathrm{K}-12$ education is an entitlement that must be provided to every citizen, whereas higher education is not (Brown \& Coomes, 2016). The change in the legal mandates between the K-12 education setting and higher education and their educational goals puts the onus of opting into and implementing reasonable accommodations on the student, rather than on the institution (Gordon \& Keiser, 1998). In essence, regardless of the differences and similarities of these laws, what they hold in common is that they have helped eliminate barriers students with ASD have experienced completing their K-12 education and have created pathways for them to higher education (Pillay \& Bhat, 2012).

Higher education not being an entitlement and requiring students to opt into it and its support services have made the process of implementing accommodations to be especially difficult for a student with ASD (Anderson, Carter, \& Stephenson, 2017). The 
following literature reviewed for the present study provides evidence that some alternatives to this method that helps facilitate the disclosure and accommodation request process are needed (Anderson, Carter, \& Stephenson, 2017; Cai \& Richdale, 2015). In the following section, some recommendations from the literature will be discussed, which will help support the questions that have been presented to the participants of the current study.

\section{Socio-Economic and Cultural Concerns}

According to McDonough (1997), the cultural capital and habitus a student brings with them to college can lead to positive and negative experiences in college. Cultural Capital is a term referring to the familial resources and supports a student has access to for their venture in higher education (McDonough, 1997). Habitus is the overall perspective a person has on various matters, which is based on his/her life's experiences (McDonough, 1997). These concepts help support the connection between a student with ASD's socio-economic status and his/her ability to succeed in higher education because people with disabilities and lower socio-economic status tend to have less access to resources and fewer quality experiences to develop the adequate cultural capital and habitus needed to succeed in higher education (McDonough, 1997; Munger \& Mertens, 2011). These concerns, combined with some of the disability-based challenges faced by students with ASD, which include identifying and activating the support services they need to succeed in an institution of higher education (Barnhill, 2014), highlight the importance of better understanding how to support students with ASD at a Hispanic serving university. 
A contributor to the problem of inadequate habitus or cultural capital can be that families from different cultures and lower socio-economic classes either prioritize different conversations that do not focus on higher education, or they lack the overall awareness to properly attend to their children's needs (Zhang et al., 2010). The difference in how the topic of higher education is attended to by some Hispanic and minority students's families may explain why developing an awareness of their disability-related needs and how to find the appropriate support for these needs because of late intervention, misdiagnosing, cultural norms, urban-based homes in resource-poor areas, and an overall lack of family resources may be delayed (Thomas, et al., 2017; Magaña, 2013). In turn, not adequately addressing their higher education needs as students with ASD may have the effect of forcing them to constantly have to work themselves out of a deficit, just to stay on par with their non-disabled and non-cultural minority peers (Chaidez, et al., 2013). Moreover, such an effect might contribute to the continued need to be more dependent on their institutions for support (Thomas, et al., 2012).

Supporting the population growth of Hispanic and other minority students with ASD in higher education is legislation such as the HEOA that has opened various pathways for cultural minority students who, coincidentally, are often from a lower socioeconomic status and are dependent on the institution for support (Boland, 2018; Sampson, 2008; Thomas et al., 2012; Arana \& Blanchard, 2018). The large number of students attending higher education institutions that are dependent on institutional support exacerbates the issue that many higher education institutions may not be well-equipped to handle the increasing demand on them since many students from cultural minorities often 
enroll in underfunded and resource-poor Minority/Hispanic Serving Institutions (Flores \& Park, 2013; Gasman, Nguyen, Samayoa, \& Corral, 2017). Institutions catering to cultural minorities tend to experience a variety of issues related to funding and are not always able to fully support their students' needs (Hubbard \& Stage, 2009). As mentioned in other studies in addition to funding, some of the most critical issues faced by Hispanic and minority-serving institutions include generally illprepared students, a lack of quality faculty, low affordability, and a lack of technology, which are all things viewed as essential to student success (de los Santos \& Cuamea, 2010). The lack of institutional resources available at minority-serving institutions combined with minority students with ASD being ill-prepared to enter higher education because of a lack of awareness, resources, early interventions, and other developmental life experiences - that many non-minority students with ASD have access to-leads to a need for research on how these students can be supported with their goals of obtaining a college degree (Hubbard \& Stage, 2009; Chaidez, Hansen, \& Hertz-Picciotto, 2012, Magaña et al., 2013). It is important to continue contributing to the scant amount of literature available on how minority-serving institutions can best serve minority students with ASD since these students will depend on institutional resources to supplement their familial resources to accomplish their educational goals and make their families proud (Kouyoumdijian et al., 2017; Arana and Blanchard, 2018).

In essence, because of lack of cultural capital and habitus in Hispanic and minority students with ASD, and a variety of institutional factors related to many institutions of higher education's inadequate approach to serving them, the probability of them having a negative experience in higher education is higher than that of non-minority 
students' (McDonough, 1997; de los Santos \& Cuamea, 2010). The current study showcases some of the experiences that minority students with ASD have had at a leading well-regarded research university and hopefully will inspire solutions for the issues faced by them. These experiences will be expanded on in the Results Chapter.

\section{Curated Resources for Students with ASD}

According to Kuder and Accardo (2017), support for creating and providing “specialized non-academic support services" (p.729) was provided in their research. Providing non-academic support services is a growing trend buttressed by research supporting a more holistic approach to accommodating students with ASD that considers academics as well as the social aspect of their education (Zeedyk, Tipton, \& Blacher, 2016). Historically, students with ASD have been well-prepared and supported by learning how to cope with the academic rigors of higher education, but this is only a part of the requisite skills needed to be successful in higher education (Cai \& Richdale, 2015). The challenge throughout this time, though, has been developing support services for the critical social, communication, and organizational skills needed to succeed in higher education that students with ASD tend to lack, but are concerning for both the student and the institution since the cost and benefit of the solutions tend to outweigh the dismissal of their importance (Shmulsky, Gobbo, \& Donahue, 2015). Simply stated, "[based on current research], it is evident that not all diploma-capable high school students with ASD are ready for college" (Anderson \& Butt, 2017, p.3037). Academic, Life, and Professional Skills Coaching

According to the literature, many students with ASD going to college are often at the expected level of academic readiness for their age (Gelbar, Smith, \& Reichow, 2014; 
Lee \& Carter, 2012). Academically well-prepared students often raise concerns with many of the faculty and support staff that work with students with ASD since they also expect these students to communicate at the standard of the academic field throughout the learning process (Robinson, 2008). In the $\mathrm{K}-12$ system, social and communication accommodation needs are handled via the yearly meeting of all the stakeholders in the student's education and the drafting of an IEP. However, in higher education, the same support and process are not available — it is often a partially unfunded mandate, or an add-on responsibility of a disability services counselor or faculty member open to using more universally-designed pedagogies (Burgstahler \& Russo-Gleicher, 2015; Dipeolu, Storlie, \& Johnson, 2015; Pillay \& Bhat, 2012; Sarrett, 2017; White, Ollendick, \& Bray, 2011). Through the IEP planning process, not only is student academic support discussed, the social and behavioral aspects of their needs are also addressed (VanBergeijk, Klin \& Volkmar, 2008). Unfortunately, many transition professionals are not doing an adequate job of preparing students and their families for this transition (Cote, Jones, Sparks, \& Aldridge, 2012). In the collegiate setting, students with disabilities work with accommodations focused primarily on the work needed for their courses, which places many of the needs of a student with ASD outside the typical scope of services provided in that environment by disability support service providers (Longtin, 2014). It is crucial to advocate for the support of a student with ASD's needs regarding the social aspects of higher education with options like coaching and mentoring since these types of supports are not typically considered accommodations and these students are not being prepared to do it on their own (Cote et al., 2012; White, Ollendick, \& Bray, 2011). Unfortunately, with funding being a significant issue higher education institutions face, it is difficult to 
add any non-academically linked support service offering to what is typically available for students in higher education (de los Santos \& Cuamea, 2010).

Lastly, a critical aspect of a student with ASD's support team, the student's family, is removed from the formal educational support process in higher education, unless the student actively requests to have them included (Fleischer, 2012; Wolf, Brown, \& Bork, 2009). Despite how knowledgeable they are about higher education, not allowing a student with ASD's family support system to be a default aspect of the accommodation process can prevent a student's needs from being adequately addressed in a timely fashion since family members may often know how to communicate a student's needs more effectively and provide supplemental support at home (Brown \& Coomes, 2016; LeGary, 2017). These discrepancies become the factors in creating a gap in support services for students with ASD towards successful completion of their postsecondary degrees and are negative influencers of an institution's retention and graduation rates (Dillon, 2007; Hansen, 2011).

\section{The Service Gap}

Service gaps exist for students with ASD for a myriad of reasons; one reason that is cited in the literature is the misunderstanding or confusion of faculty and staff of the accommodation needs of a student with ASD, even though they are very academically talented (Anderson \& Butt, 2017; Pillay \& Bhat, 2012). Another reason that appears is that the transition process from the $\mathrm{K}-12$ environment to higher education often leaves students ill-equipped to succeed because of the break in continuity of support systems, services, and procedures (Anderson \& Butt, 2017; Elias \& White, 2017; Elson, 2011; Getzal, 2008; Van Hees, Moyson, Roeyers, 2015). Third, there is some support in the 
literature for the campus culture being a reason for a student's success (Jackson et al., 2017). A campus community with a culture that is inclusive and diverse, that supports the use of accommodations and support services, as well as the involvement of various student communities in campus activities, is a campus that leads to the success of students with ASD (Cullen, 2015). Lastly, the overwhelming sample of "discussion papers" (Carter \& Lee, 2012, p.997) and the scant number of empirical articles currently informing higher education regarding its students with ASD are not enough to adequately support the needs of the professionals providing student support services and campus activities in the post-secondary environment for students with ASD (Bennett \& Dukes, 2013). More research showcasing and discussing empirically supported strategies for helping students with ASD succeed after high school is needed to truly support professionals with this effort (Carter \& Lee, 2012).

\section{Summary}

To date, we have a process of diagnosing someone with ASD and other co-morbid disorders, as well as information on how the symptoms may manifest in most environments (APA, 2013). We also have a set of laws that guide institutions on how to accommodate a student with ASD in various educational settings (Lee \& Carter, 2012). As was mentioned in the introduction and this chapter, a significant amount of research has been conducted on how to best serve students with ASD in the $\mathrm{K}-12$ setting in accordance with the law and the concepts of Disability Theory, which call for the removal of as many unnecessary barriers as possible in the educational setting (Pillay \& Bhat, 2012). 
The problem identified in this literature review, which serves as the foundation of my study, is that students with ASD are not adequately prepared to be successful in higher education due to various factors such as a lack of appropriate cultural capital and habitus (McDonough, 1997; Munger \& Mertens, 2011), and a variety of challenges faced by institutions attempting to support their needs (de los Santos \& Cuamea, 2010). These two variables are exacerbated by changes in how a student with ASD engages higher education compared to how they engaged their K-12 education (Longtin, 2014). This leads to a gap being formed in how students with ASD are supported in higher education and the call for more research to help narrow it (Carter \& Lee, 2012).

In essence, the available body of literature is an adequate primer and call to action for more research. My study helps answer this call to action by adding more experiential data to this body of literature and will hopefully be used to inform higher education professionals and design studies that will develop and test various interventions to prepare the professionals working in post-secondary environments with students with ASD to better attend their student's needs. In the following chapter, the methodology used to conduct this study is discussed. 


\section{CHAPTER III METHODOLOGY}

The purpose of the present case study is to understand the support service needs of students with ASD in higher education. An understanding of these issues may help narrow the gap of knowledge higher education professionals, faculty, and other student support personnel are currently working with. By narrowing the gap, higher education professionals, faculty, and student support personnel may be equipped to work with the growing number of students with ASD entering higher education with information from one of the most critical sources in this field — the student (Seidman, 2013). In this chapter, the methodology used for the current case study will be described.

The methodology of my research was guided by the research questions asked and the needs of the field as presented in the literature review, which calls for qualitative research that helps higher education professionals better understand a student with ASD's needs and helps develop students with ASD's ability to thrive (Farley, et. al., 2017). As is the case with qualitative research, this research is aimed at gaining an accurate, in-depth understanding of the lived experiences of a group of students with ASD at a research university that is rich in diversity; another goal of this research is that it will influence future research, and the planning of appropriate high-quality support services for this population via interviews (Merriam, 1998; Rubin \& Rubin, 2012). When the goal of a study is to gain understanding or to document a case that represents a group's experience to create stronger policies and support services, a qualitative case study design is appropriate (Bogdan \& Biklen, 2007; Creswell, 2007; Merriam, 1998; Seidman, 2013). 
In the following sections, how the support service experiences of a group of students with ASD at the host institution of higher education were studied using the case study methodology will be discussed. First, the purpose of the study will be confirmed, along with the questions that were used to study it. In the following sections, the participants' recruitment and characteristics will be discussed. Afterward, the setting for the data collection will be discussed. Lastly, the methods that were used to collect, manage, and analyze the data will be discussed, followed by what strategies were used to maintain the integrity of the research. The last section of this chapter will summarize its contents and help transition the document to the Results Chapter.

To adequately explore the overarching question being asked in this study, "What are the experiences of college students with ASD in higher education regarding the quality of support services they are receiving as they enter post-secondary education, persist through their academic programs, and enter their post-graduate lives," the following research questions were used:

1. What are the experiences of college students with ASD at a public research university?

2. What are the perceptions of college students with ASD of the support services available to them at a public research university?

3. What are the perceptions of college students with ASD of how well-prepared they feel for life after graduating from a public research university?

\section{Research Design: The Case Study}

In the first two chapters of this dissertation, I presented the reason, need, and support for the current study. On the basis of the literature reviewed, the current practices 
in place to support the rising number of students with ASD in higher education are inadequate and need to be improved. As mentioned previously, under the lens of Disability Theory, the best way to understand the students with ASD we hope to serve and quell the barriers imposed on them in the higher education environment is to allow their voices to lead the efforts that will support them (Freire, 2000; Preston, 2010). To accomplish the goal of creating an improved understanding of this particular group of students, the case study methodology stands out as an appropriate selection because of the goal of the study and my experience and skillset (Yin, 2006). I have over a decade of experience working with students with disabilities in the higher education setting. Additionally, his academic training is in the area of Psychology (Bachelor's Degree) and Mental Health Counseling (Master's Degree).

According to Yazan (2015) and Yin (2006), it is essential to understand some of my skills and motivations since I am the primary tool in gathering and analyzing data and then presenting the findings. More details regarding my skillset and my effect on this study will be discussed in the following section. The purpose of my study was to create a detailed record of the experiences a group of students with ASD have had while attending a minority-serving university to better inform higher education faculty and staff (Merriam, 1998; Yin, 2018). Ultimately, this research aims to better understand the experiences these students are having so the services provided to them can be created or modified in accordance with what is understood about students with ASD in higher education (Yin, 2006). The data were collected using individual interviews and were analyzed using the constant comparison method and holistic coding (Creswell, 2007; Glaser \& Strauss, 1967; LeGary, 2017; Merriam, 1998; Seidman, 2013; Yin, 2018). The 
case study methodology was ideal in this type of research because it allowed the me an opportunity to reconsider my approach to the research and continue accordingly until I was able to provide a thick and rich record of the participants' experiences that was relevant to the purpose of the present study and would enable me to answer the research questions (Merriam, 1998; Yin, 2006A). In the following section, details regarding my role as the researcher and how the case study design was implemented will be further discussed.

\section{The Role of the Researcher}

As the researcher in the present study, I have been working in the field of disability support services in higher education for over ten years and have been working in higher education in general for over thirteen years. During this time, I worked in the academic and student affairs aspect of higher education, as well as in both public and private-parochial institutions. Additionally, I currently hold a Bachelor's Degree in Psychology and a Master's Degree in Mental Health Counseling. Lastly, I have an entrepreneurial spirit that enables me to identify issues that need to be resolved in my environment and confidently develop a comprehensive response utilizing a variety of resources (Birds, 2014). As documented in my Vita, I won a leadership award in 2015, run workshops for students with ASD, and am a person with a disability. Combined, my professional and academic experiences provide a strong foundation for having the skills and awareness of the needs of this population of students to conduct the study presented in this dissertation. Additionally, my motivation is supported by me identifying as a person with a disability and endeavoring to have my research help others, just as the medical world's research has benefited me. 
According to the literature reviewed to design this study, a researcher utilizing the case study approach to be able to learn about the population they are studying has to be able to present an authentic interest in the topics being discussed since this will allow a stronger rapport to be developed and better data to be provided (Rubin \& Rubin, 2012). I meet this standard. Although not diagnosed with ASD, I identify as a person with a disability. I am a cancer survivor and understand how a variable outside of my control can take over one's life and change the way we engage our environment. I am able to appreciate the need for support in a time when a person is not able to carry on with their daily obligations in an independent fashion. I have benefited from the research that has been done in my area of need and am aware of how my research will, in turn, benefit other people with their needs. Although the characteristics described in this section may be seen as strengths by me that help reduce interviewer bias, there is no way of knowing how participants may have interpreted them (Bogden \& Biklen, 2007). I have and continue to reflect on this and have carried out this study while assuring the best possible outcome for it and those I hope to serve through it in an ethical manner that is conducive to this study's goals.

\section{Data Sources}

This section will focus on where and whom the data for this study came from and how it was collected. The first portion of this section focuses on the characteristics of the host institution and the setting where the interviews were done to collect data. The following sections will focus on the participants interviewed. and how this institution's student population helps narrow the gaps found in the literature, which show many studies have been done in male-dominated, predominantly white institutions found in the 
western, northern, and northeastern areas of the United States or from other countries, with the students' parents or support staff being a primary source of data (Brown \& Coomes, 2015; LeGary, 2017; Morrison, Sansosti, \& Hadley, 2009; Reid, 2015; Ross, Marcell, \& Williams, 2013; Van Hees, Moyson, \& Roeyers, 2015; White, Ollendick, \& Bray, 2011). Lastly, the protocol for the recruitment of participants, interviews, and how the data were analyzed and processed will be discussed.

Setting

The study was carried out at a public research university located in the southeastern region of the United States. As per this university's rankings and facts website (2018), it is home to approximately 57,000 students and is considered one of the largest universities of its kind in the United States. The university offers 201 degrees, ranging from the bachelor's level to graduate and professional level degrees via inperson, hybrid, and online modalities. In addition to a strong academic profile as an "R1 Carnegie Classification Doctoral University - highest Research Activity," the institution is focused on working with the community at large by providing various educational and professional development opportunities (Host University's Website, 2018). According to the university's website (2018), the university student body is $60 \%$ female and $40 \%$ male; its student enrollment is 58.13\% Part-Time and $41.87 \%$ Full-Time. As for its diversity and distinction as a top-ranking Hispanic Serving Institution with a minority-majority, its student body's racial composition is $61 \%$ Hispanic, $15 \%$ White-Non-Hispanic, $13 \%$ Black, 4\% Asian or Pacific Islander, and 7\% other (Host University’s Website, 2018). Overall, using the facts presented on its website, the university represents an ideal location for the needs and purpose of the study. 
As mentioned previously, the data for this study were obtained via interviews of students with ASD recruited from the population of students with disabilities at the host institution (Merriam, 1998). The campus was ideal since it allowed me to engage the participants within the environment where they are using their accommodations and is accessible and convenient to them (Seidman, 2013). Additionally, the literature supports having some flexibility with how a participant that is a member of a minority group is engaged due to the increased possibility of them having limited access to resources to transport themselves to specific places at specific times (Thomas et. al, 2012). Once a participant had responded with an interest to participate in the study, an appointment for the interview was scheduled by me for a time and day that was convenient for the interviewee. Upon the interview's day and time being confirmed by me and the participant, the host university's disability services office allowed me to use a private office to conduct the interviews.

A review of the host university's disability services office's population of students with disabilities further supports this institution as an optimal setting to conduct this study. Based on the 2017 Annual Report of the host university's disability services office, approximately 2,223 students are served by this department every year. In addition, the host university's disability services center has a workgroup dedicated to helping students with Autism Spectrum Disorders, with the number of attendees ranging from 14-21 students within the last two years, respectively. Overall, this university and its population of students with disabilities represent an ideal location and population for the study. 
The office that was provided to me was a private administrative office that was not scheduled for use during the times stated by me needed to conduct the interviews. All the interviews were able to be conducted quietly, with the door closed, and no interruptions. The office used for all interviews had a desk, chairs, writing utensils, and power outlets for the digital recorder. Lastly, there was access to both electric lighting fixtures and natural light via a spacious window that could be dimmed via vertical blinds, if needed.

In essence, all the facets of this institution's general population support it as an ideal site for research that will help narrow the gaps found in the literature regarding students with ASD that tend to have less awareness, fewer resources, less access to support, and are entering higher education with a possible deficit in their development as a minority student with ASD (Magaña, Lopez, Aguinaga, \& Morton, 2013; Thomas, et. al., 2007; Thomas, et. al., 2012). As demonstrated by the demographic information in Table 1, the group of participants interviewed met one of the goals of the study, which was to diversify the body of literature available about students with ASD with more voices from a minority population.

The Participants

The purpose of the study was to create an accurate description of students with ASD's experience in the higher education environment of a Hispanic serving, research university located in an urban setting with a large minority population. Nine current degree-seeking students at the host university were interviewed to help narrow the gaps identified in the literature review (Causten-Theoharis et. al., 2009; Creswell, 2007). Nine students was accepted as adequate since the amount of data collected allowed me to 
answer the research questions and that it was more than the number described in the literature as being adequate for a case study (Creswell, 2007; Merriam, 1998). Also, since case studies tend to be focused on a particular kind of participant that has experienced the phenomenon being studied, in some situations, the total number of participants could be as low as one (Yin, 2006). Lastly, the number was seen as adequate since the total population at the host institution represents only a fraction of the $37 \%$ of students with ASD that transition to higher education of the local K-12's total population of students with ASD, despite its overall growth to about $1 \%$ of the total general K-12 population throughout the years (Florida Department of Education, 2018; Wilkinson, 2017). Because of a variety of reasons such as the use of social and medical support services and stigma, some students may still identify with the older terminology for ASD (Kite, Gullifer, \& Tyson, 2013). No student with an earlier diagnosis that would have been included under the umbrella of ASD such as High Functioning Autism, Autism, Asperger Syndrome/Disorder, or Pervasive Developmental Disorder-Not Otherwise Specified (APA, 2000) was denied an interview. The goal was to obtain the most diverse set of positive and negative experiences within this population of students in a diverse Hispanic-serving research university in an urban setting, which would help eliminate the limitations found in previous studies (LeGary, 2017). The student body of this institution's demographics helped produce research from a pool of participants from a population of students that tend not to be represented in the literature and deserve to voice their experiences and make their needs heard (Magaña, et al., 2013). In total, nine participants were interviewed for the study. 
The findings presented in the following chapter are from a total of nine interviews. These participants were recruited via a series of six e-mails sent out to the population with the specified demographics of the host university's disability services office over a period of two semesters. It is important to note that there were five other students that inquired about the study. Other than the nine students interviewed, one male and one female student canceled and rescheduled, but eventually canceled their interviews again and did not reschedule. An additional pair of male and female students demonstrated interest in the study, but declined to participate when they were told that there was no compensation being provided for participating in the study. One male student opted out of the interview because he was no longer comfortable with the idea of having to potentially be interviewed up to 90 -minutes. These difficulties experienced in recruiting students will be elaborated on in the last chapter of this dissertation within the recommendations for the future research section. Overall, the age range for the participants was 18-24 years of age, the mean age being 21. Except for one student, all the participants were from minority populations. Lastly, the identified gender of seven of the participants was male, while one identified as female, and one identified as nonbinary. For a more detailed self-reported bio-demographic descriptions of the participants in this study, please refer to Table 1. 
Table 1

Participant Self-Identified Bio-Demographic Data

\begin{tabular}{|c|c|c|c|c|}
\hline Pseudonym & Age & Ethnicity & Race & Gender \\
\hline Charles & 18 & Eastern European & White & Male \\
\hline Raven & 19 & Afro-Caribbean & Indigenous Caribbean & Non-Binary \\
\hline Scott & 19 & Hispanic & White & Male \\
\hline Logan & 19 & Bi-Racial White/Black & Black & Male \\
\hline Jean & 21 & Hispanic & White & Female \\
\hline Erik & 22 & Hispanic & White-Hispanic & Male \\
\hline Remy & 23 & $\begin{array}{l}\text { Hispanic/White- } \\
\text { Caucasian }\end{array}$ & White & Male \\
\hline Pietro & 24 & $\begin{array}{c}\text { African American } \\
\text { Haitian }\end{array}$ & Black & Male \\
\hline Henry & 24 & Hispanic & Latino & Male \\
\hline
\end{tabular}

Sampling Method

Participant selections for interviews in the study were made via purposeful and snowball sampling (Merriam, 1998; Seidman, 2013). These two methods allow a researcher to have access to a broader array of possible participants. When purposefully selecting participants from a particular environment, the researcher selects participants that fit the demographic needs of their study (Causten-Theoharis, Ashby, \& DeClouette, 2009; Jackson, Hart, Theirfeld Brown, \& Volkmar, 2018; Seidman, 2013). For the purpose of the present study, participants were current adult university students with a diagnosis of ASD. Once contact had been made with a participant, that participant was asked to refer potential participants to me after they completed the interview; the referral process is known as snowball sampling (Cullen, 2015). The snowball sampling method is a good tool to use in the current study since registration with the host university's disability services center is not mandatory for students with ASD, or any disability (Gordon \& Keiser, 1998; Smith, 2007). The sampling strategy had the potential to inform 
students not registered with the host university's disability services center to become aware of the study. Once the person referred to me had made contact with me, I would have then had the opportunity to repeat the process until the study's participant pool had produced data with maximum variation and saturation (Anderson \& Butt, 2017; Merriam, 1998; Seidman, 2013). The goal is in line with the critical lens of Disability Theory, which calls for diversity to be present in the sample to properly help identify and address the societal problem being studied (Rubin \& Rubin, 2012). Unfortunately, despite all participants being asked at the end of their interview if they would be able to refer to me anyone sharing an ASD diagnosis attending the host university that would be interested in participating in the study, no additional potential participants contacted me by way of the referral process from a former participant. The next section will discuss the recruitment process of study participants.

\section{$\underline{\text { Participant Recruitment }}$}

All interviewees were found through the host university's disability services center and flyers placed on public bulletin boards around the host institution's campuses (Mertens, 2007; Thomas, et. al., 2007). A copy of the flyer placed in the public bulletin boards and e-mailed to the students by the host institution's disability services office can be found in Appendix B. The host university is also my home institution and the disability services is my place of employment. Because of my professional relationship with the host institution and, possibly, some of the students who would have seen the marketing materials for the study, strict adherence to the host university's disability services center's research protocols was practiced. As per the host university's disability services center's website (2018), there is a protocol in place that must be followed if any 
researcher wishes to access the department's student population to conduct research. The first step in the process involves requesting permission to conduct research with the host university's disability services center students. The request is typically handled exclusively by the host university's disability services center's leadership team. Since the I am an employee of the host university's disability services center and a member of the leadership team, I abstained from reviewing any research requests during the semester this study was proposed and executed. In order for the request to be reviewed and approved, the host university's disability services center was informed of the desired characteristics of the students needed for the study, protocol of the study, marketing materials for the study, the Institutional Review Board's approval, and materials that would be used for the study. After the complete request was submitted and approved, the host university's disability services center advertised the study to the appropriate student population via e-mail and printed copies of the flyer in the office and public areas of the campus. At no time did I have access to the list of students the disability services center used to support the recruitment efforts. A total of six emails were sent to the customized host university's disability services center student mailing list over the two semesters the study was conducted. Additionally, the host university's disability services center facilitated an introduction of me to any students that were interested in participating in the study. A careful review of the host university's disability services center's research protocol supports the protection of students' identities and contact information to any researcher. Only students wishing to participate in the study contacted me. I never had access to any student's contact information for the purpose of the study. It was important to use the institution's disability services office as an intermediary because of my 
employee role within the university as well as to gain confidence with potential participants that the study is sensitive to the needs of the students by being approved by the disability services office (Mertens, 2007).

As per the host university's disability services center's website (2018), the disability services office could provide an explanation to potential participants of what the research was for, how it would be beneficial, and how it would not pose any threat to the students' services. It was very important to keep the student identities and I separate until the moment when a student opted to get in contact with me. A part of the required documents for the host university's disability services center to recruit participants was an informed consent form (Appendix C) that provided explanations as to how, when, and where the interviews would be conducted and recorded and how the data would be managed in the current study (Creswell, 2007; Merriam, 1998). Providing the informed consent form to the study's participants also helped empower the them as collaborators in the research since their participation could help enrich the knowledge base used to support their own, and others' needs within their communities (Lincoln \& Guba, 1986). Additionally, working with the host university's disability services center helped the authenticity and credibility of the study since they were able to target the participant recruitment efforts to individuals who have a confirmed ASD diagnosis and attend classes at the host institution (Rubin \& Rubin, 2012). When conjoined, the process of recruiting via the disability services office and the snowball sampling technique were supported by the literature since its dualistic approach helps recruit the most participants possible, which typically yields a more representative sample of the case being studied (Thomas et. al., 2007). None of the interviews conducted came from a referral of an 
interviewee or a poster placed on a public bulletin board. All interviews conducted were based on the recruitment efforts of the host university's disability services center.

\section{$\underline{\text { Risks, Benefits, and Alternatives }}$}

Participants' concern about their vulnerabilities when engaging in research, especially when a researcher is a person who helps provide support services, is something that must be addressed as soon as possible to build trust in the researcher and their purpose (Mertens, 2007). Concerns about the power differential between a researcher and a research participant have been found in the literature and were attended to during the study. According to Bogdan and Biklen (2007) a power differential concern may be difficult to attend to, but can be controlled with thoughtful planning and communication. According to Seidman (2013), some of the concerns regarding reciprocity, retaliation, and in-equitable treatment was resolved by me via open communication about the rights of the participants and the purpose of the research via the written informed consent form. In addition to a written consent form, the use of the host university's disability services center to manage all recruitment efforts was a strategy that made them act as a gatekeeper and possibly instill confidence in the participants in the current study that I had met all the requirements set forth by the university and the host university's disability services center that the study was conducted safely (Lincoln \& Guba, 1986; Seidman, 2013).

After carefully reviewing the questions being asked and the protocol for collecting data, the risks in the study were minimal. Furthermore, depending on the information disclosed, the students may have been able to get referrals for complex situations, which include dropping out of college, substance abuse, and academic failure (Wolf, 2006). There was some risk of discomfort because a participant having to 
remember and discuss a challenging experience or the lack of support during a difficult time. Additionally, participants discussed and anticipated future success, challenges, and the ability to live, work, and recreate independently. These situations were responded to with appropriate university-based referrals in order to help the student with any unmet need that was presented such as the counseling center, the residential life coordinators, or the general campus life office. This provided an opportunity for a benefit that students had for participating in this study, which was to discuss their experiences with a higher education professional and possibly be made aware of support services and referrals they may not have known about previously.

\section{Data Collection}

The data collection for the present study was started upon approval from the host university's Institutional Review Board. As is commonly seen in qualitative research, a semi-structured interview was the primary source for in-depth data in this study (Bogdan \& Biklen, 2007; Menzies \& Baron, 2014; Merriam, 1998; Rubin \& Rubin, 2012; Zhang, Landmark, Grenwelge, \& Montoya, 2010).

Since a review of the study's procedures and participants' rights-oriented materials was done at the beginning of each interview, a timeframe of 60-90 minutes was allotted for each interview in order to give participants adequate time to engage and respond to each aspect of the interview appropriately (Anderson \& Butt, 2017; Knott \& Taylor, 2014). Once the interviews were completed, the average time for all the interviews was approximately 55 minutes. Upon arrival at the disability services office, all participants were greeted by the front desk staff and asked to wait in the lobby while I was alerted of their arrival. After being alerted of the participant's arrival, I personally 
went to greet the participant and walk them to the office where the interview would take place. Upon entering the office and closing the door, the participants were welcomed to take a seat. At this point of the interview, a second review of the informed consent form was done, the first opportunity having been over e-mail when the participant was informed of the study; the second review was done to assure each participant was aware of his/her rights and that any concern he/she may have was attended to (Ness, 2013). A pseudonym was created to protect the identities of the participants in the study immediately after the informed consent documentation was completed. Pseudonyms were created at the beginning of each interview to remove identifying information that may be stated during the interview (Anderson \& Butt, 2017; LeGary, 2017). To create a record that could be transcribed and used to verify details in the future, all interviews were audio-recorded (LeGary, 2017; Merriam, 1998; Zhang et. al, 2010). All the interview audio recordings were started after the informed consent forms were reviewed and signed by the participants and the pseudonym was created.

The questioning format for the interviews was semi-structured to afford the participants and myself the chance to fully explore the interviewee's experience at the host institution using a predetermined set of questions (please refer to Appendix A for a list of the preset questions), but still providing some opportunity to explore emerging topics (Merriam, 1998; Zhang et. al., 2010). To support a more accurate record of the participants' experiences, a modified template of questions used by LeGary (2017), in a similar study of students' with ASD perception of support services in higher education, was used. These questions are derived from Flanagan's (1954) Critical Incident Technique, which helps identify critical aspects of a person's experience in line with 
Social Support Theory (LeGary, 2017). Social Support Theory is a concept that outlines the support systems people use to succeed in various settings (House, 1983), which is in line with the goal of the present study. It was LeGary's use of this theory that allowed his questions to be used as a benchmark for the questions in my interviews. In the LeGary (2017) study, Social Support Theory was used to evaluate the perception of the quality of support services students had at their institution. Given the social competencies needed to succeed in higher education regarding transitioning into the environment, then activating and engaging the various support services available at most colleges-including the host institution-LeGary's (2017) questions represent an adequate means of exploring the research questions presented for the present study (Astin, 1993; Harper \& Quaye, 2009; LeGrary, 2017; Menzies \& Baron, 2014).

As per the questions used in LeGary's 2017 study, interviewees were asked to respond to each question by "[describing an exemplary experience for each question]; then the respondents [were] asked to answer the [modified version of the] following questions: (a) what led up to [that event], (b) what they did that was especially effective or ineffective, (c) the outcomes of their actions, and (d) why they felt the actions were particularly effective" (p.256).

Once each interview was completed, all the notes, thoughts, and reflections of the interviewer were recorded as a field memo and added to the body of data collected to be analyzed and coded along with the transcripts of the interview (Merriam, 1998). Since the type of person attending a higher education institution is becoming more diverse, this line of questioning allowed the participants' experiences to set a benchmark that can hopefully influence the service options being developed in other institutions so that 
students with ASD support service experiences can be better developed (Boys, 2015;

Flanagan, 1954). Additionally, as the data collection and analysis processes were carried out, the questions asked in the interviews were modified to "reflect an increased understanding of the [experience]" (Creswell, 2007, p.43). It is important to note that while data collection was taking place, all memos, recordings, and transcripts were kept in a secure locker within the research team's locked offices, as per the host institution's standards (Brown, Valleja-Peña, Rankin, 2017).

\section{Data Analysis Protocol}

The primary method that was used to analyze data in this study was the constant comparative method. The constant comparative method is a technique used in qualitative research that requires data to be analyzed as it is being gathered so categories and themes can be refined as they begin to emerge (Anderson \& Butt, 2017; Creswell, 2007; Glaser \& Strauss, 1967; LeGary, 2017; Merriam, 1998; Seidman, 2013). The constant comparison method used to analyze the data allowed me to focus on the themes that were developing and were repeatedly found among the interview data. Focusing on these themes presented the first steps of the process for generating the overarching themes that provided a holistic description of the experience of the group being studied (Bogdan \& Biklen, 2007; Merriam, 1998). Although the data analysis starts immediately after the first pieces of data are collected in the study, the final analysis and formation of the themes of the study were not done until all data had been collected (Bogdan \& Biklen, 2007; Creswell, 2007; Merriam, 1998). Once the minimum number of interviews mentioned in the proposal — and what has been referred to in the literature as ideal — had been reached in order to report commonly occurring themes, I felt it appropriate to 
continue on to the next phase of data analysis, which was the coding and generation of categories and themes (Creswell, 2007, Merriam, 1998). The following section will discuss how the data collected were transcribed and coded for further analysis. Coding and transcription

To organize and analyze the data collected, interviews were transcribed so they could be coded (LeGary, 2017). A transcription of all interviews was made by using a professional transcription service to dedicate more time to data analysis and preparation for upcoming interviews (Merriam, 1998). Once the transcriptions had been proofread and edited by me against the audio recording for accuracy, the participants were given an opportunity to review them for accuracy (Anderson \& Butt, 2017; LeGary, 2017;

Stodden, Yamamoto, Folk, Kong, \& Otsuji, 2013). This follow-up meeting was to be done via an in-person meeting. In total, only two participants of the nine interviewed agreed to meet a second time to review their transcripts. Once the transcription of an interview was completed and fully proofread, and the participants had proofread their transcript, formal coding began (Merriam, 1998). In regard to the transcripts of the seven participants that declined to meet a second time to review the transcripts, coding began upon confirmation that they were not interested in meeting a second time.

The data analysis was completed manually by me since the number of participants was within his ability to do so (Creswell, 2007). The data were coded using a holistic coding scheme, which is when I attempted to "grasp a basic theme or issue in the data by absorbing them as a whole rather than analyzing them line by line" (Saldana, 2013, p. 142). The coding scheme was kept simple with only one type of coding used to better manage the amount of data that was produced during the interviews (Merriam, 1998). 
The process was repeated two times in addition to the initial review done after every interview to assure that the coding was done in a uniformed manner with same results attained in both coding attempts (Glaser \& Strauss, 1967; Knott \& Taylor, 2014). In all, a total of twenty-one codes were identified during this process. For a list of all the codes, how many times they were identified among all the interviews, and how many participant interviews they were identified in, please refer to Table 2.

Table 2

Frequency Distribution of Codes among Participants

\begin{tabular}{lcc}
\hline \multicolumn{1}{c}{ Code } & Number Participants Mentioning Code & Frequency \\
\hline Social Experience & 9 & 39 \\
Support Service Staff Experience & 9 & 39 \\
Campus Engagement & 9 & 33 \\
Faculty/Academic Experiences & 9 & 28 \\
Housing & 9 & 19 \\
Self-Awareness & 8 & 18 \\
Transfer Student/Previous Institution & 9 & 17 \\
Experience & & \\
Family Support & 7 & 13 \\
Time Management & 5 & 10 \\
Discipline & 8 & 9 \\
Life Skills & 7 & 9 \\
Ownership of Personal Development & 5 & 6 \\
Public Resources & 3 & 6 \\
LGBTQA & 2 & 6 \\
Self-Reflection & 3 & 5 \\
Mental Health Issue & 3 & 4 \\
Sensory Experience & 2 & 4 \\
Substance Abuse & 1 & 4 \\
Confidentiality & 2 & 3 \\
Work & 2 & 2 \\
Law Enforcement Experiences & 1 & 1 \\
\hline
\end{tabular}


Once all the data in the interviews had been coded, it was used to create categories and themes that could help me answer the study's research questions and inform the literature supporting the future practices of higher education professionals with students with ASD (Knott \& Taylor, 2014; Merriam, 1998; Seidman, 2013). Since the data analysis was done manually, an electronic version of Merriam's (1998) organization strategy was used where all coded data were transferred to an index card and placed in a stack that represented the tentative themes that explained the holistic understanding of the participants' experiences. The electronic version of this method was created by using a database via spreadsheet software, such as Microsoft Excel, to produce a flat-file database that could be filtered and manipulated in a variety of ways to analyze the data for categorical and thematic creation purposes (Meyers \& Bagnall, 2015). Category and Theme Generation

The final phase of the data analysis process was the generation of themes that could be used to inspire future studies and practices and their refinement to representing the different facets of the experiences reported that answer the research questions (Glaser \& Strauss, 1967; Merriam, 1998). The 21 codes used to analyze the data were reduced to five categories that elucidated how higher education professionals can better serve their students with ASD (Seidman, 2013). The grouping of the codes into categories was made using the commonalities among them (Seidman, 2013). For example, the category of Life Skills was developed by combining the codes used to analyze the data: Life Skills (e.g., learning to cook or clean), Time Management (e.g., scheduling time for work, study, recreation, transportation, etc.), Work (e.g., any reference attending to the need for funds), Public Resources (e.g., the use of public transportation and other resources), and 
Housing (e.g., any reference to and reason for living on campus). Although each code was unique, they all supported a skill needed to live an independent life or way of developing that skill. For an outline of what codes were grouped into the categories generated for this study, please refer to Table 3 . The categories generated by this process will be reviewed in the Results chapter.

Table 3

Code Consolidation to Categories

\begin{tabular}{lc}
\hline \multicolumn{1}{c}{ Category } & Code \\
\hline Family Support & Family Support \\
Self-Awareness & Self-Awareness \\
& Ownership of Personal Development \\
& Sensory Experience \\
& Self-Reflection \\
Confidentiality & Discipline \\
Mental Health Issue & Social Experiences \\
Social Experiences & Substance Abuse \\
& LGBTQ \\
Campus & Law Enforcement Experience \\
Engagement & Campus Engagement \\
& Faculty/Academic Experiences \\
& Transfer Student/Previous Institution \\
Experience \\
Life Skills & Support Service Staff Experience \\
& Life Skills \\
& Time Management \\
& Work \\
& Public Resources \\
& Housing \\
\hline
\end{tabular}

The themes were created on the basis their ability to allow me to answer this study's questions, provide a unique classification for all the relevant data collected, easily 
describe the data, provide equal conceptual status for all the data collected, and provide an understanding of the participant's experiences that will help inform professionals working in the field of higher education how to best serve students with ASD (LeGary, 2017; Merriam, 1998; Seidman, 2013). For example, the theme of Students with ASD are capable of addressing their needs was populated with the categories Self-Awareness, Social Experiences, and Family Support. Although individually unique, these categories share the characteristic of referring to the general experience of a student with ASD at the university being studied and how the student handled or interpreted the situations they were in. Please refer to Table 4 for a listing of which categories generated in this process were used to create the themes I used to answer this study's research questions. Once data analysis was completed, all consent forms, notes, recordings, transcripts, and memos used in the study were consolidated and will be kept securely as per my home institution's protocols. The themes generated by the data analysis process, and how they answer the research questions, will be discussed in the last two chapters of this dissertation, respectively.

Table 4

Theme Generation from Categories

\begin{tabular}{lc}
\hline \multicolumn{1}{c}{ Theme } & Category \\
\hline $\begin{array}{l}\text { I. Students with ASD are capable } \\
\text { of addressing their needs }\end{array}$ & $\begin{array}{c}\text { Self-Awareness } \\
\text { Social Experiences } \\
\text { Family Support }\end{array}$ \\
II. Increased campus engagement & Campus Engagement \\
III. Life Skills Development & \\
& Life Skills \\
\hline
\end{tabular}




\section{Data Integrity}

The quality of the methodology used to complete this study was of utmost importance since it dictates the quality of the data and results obtained from it (Rubin \& Rubin, 2012). Historically, the quality of study has always been based on various measures of reliability and validity, but in the world of qualitative research, these are not measures that can be applied (Lincoln \& Guba, 1986). Although there are some authors that attempt to bridge qualitative and quantitative research by creating ways to prove the concepts of reliability and validity in qualitative research (Merriam, 1998), it is "[impossible to fulfill] such methodological requirements" (Lincoln \& Guba, 1986, p.75). Notwithstanding the type of methodology being used in research, "every researcher wants to contribute results that are believable and trustworthy" (Merriam, 1998, p.218). This section will review the strategies I used in this study to assure it was carried out in an ethical manner and that its results are trustworthy.

Given the information that was collected from the participants in the present study, it was important to assure they benefited from participating in it and were not being "exploited, disempowered, or disenfranchised" (Lincoln \& Guba, 1986, p. 53). To control these concerns, each participant was provided an opportunity to review the informed consent form that was given to them over the original recruitment e-mail so they could ask questions and clarify anything they did not understand before signing it. Being given an opportunity to review the informed consent form gave the participants an opportunity to confirm their pseudonym, understand how the recordings and data files would be kept, further understand the objectives of the current study, and what benefits they and society at large will have via their participation in the study (Merriam, 1998). 
In essence, the trustworthiness and authenticity of the current study and the data collected were maintained via the recruitment controls in place by the host university's disability services office protocol that would only allow students meeting the diagnostic and enrollment criteria requested at the host institution to be contacted for the purpose of recruiting them as participants for this study and the overall design of the study used by me based on the available literature (Merriam, 1998; Creswell, 2007; Rubin \& Rubin, 2012; LeGary, 2017). According to Reid (2015), trustworthiness is also dependent on having opportunities to review the data and build rapport with the participants, and developing this trust leads to collecting quality data and creating a meaningful interpretation of it. The opportunity to establish this rapport and to review data was created via the stated process of offering a member checking meeting after the completion of the transcript for each interview, which was done for the two participants that agreed to participate in it. Lastly, using the host university's disability services office to recruit participants via their e-mail list server and flyer postings may have allowed the participants to feel that their rights were being attended to throughout this study's execution (Mertens, 2007; Thomas et. al., 2007).

\section{Summary}

In summary, the case study and data analysis methodology that was used for this study has been presented in this chapter. By using a variety of research methodology reference materials and peer-reviewed journal articles, a set of procedures to recruit participants, collect data, analyze data, and draw information from it has been used in an ethical manner that abides by the standards set forth by the literature and the host institution (Van Hees, Moyson, \& Roeyers, 2014). Going forward, a review of the data 
obtained and how it can be implemented in the daily efforts of the faculty and staff working with students with ASD in the higher education setting will be presented in the following two chapters. 


\section{CHAPTER IV \\ RESULTS}

The purpose of this chapter is to share the information that has been gleaned from the interviews completed in this study (Seidman, 2013). As mentioned in the previous chapter, upon completion of each interview, the transcript was created and proofread. Once the transcripts were finalized, my thoughts and notes were joined to them to provide a document that could be reviewed in preparation for the next interview and to start identifying emerging themes. Upon completion of the ninth interview, all the interviews were coded and reviewed an additional two times in order to proceed with the data analysis that has informed this chapter (Saldaña, 2013).

In the following sections, a description of each participant and a summary of each of their interviews will be provided. This will allow the reader to understand each participant in more detail and better understand the origins of the themes generated (Seidman, 2013). Afterward, the common themes generated from these interviews will be presented along with quotes that will support their origins, contexts, and interpretations (Bogdan \& Biklen, 2007; Merriam, 1998; Rubin \& Rubin, 2012; Seidman, 2013). Following the presentation of the themes generated in this study, a summary of the chapter will be provided.

\section{Participant Descriptions and Interview Summaries}

In this section, a description of each participant and a summary of each of their interviews will be provided for readers to understand the participants' experiences and learn more about what can be done to better serve students with ASD in higher education (Seidman, 2013). Each section will contain some information about the participant's 
presentation for the interview and a summary of what was spoken about during the interview. Before starting the Interview Summaries and Theme Generation sections, it is important to note that some responses may not have been very robust. This is something that was expected since some of the hallmark symptoms of ASD include noticeable deficits in the ability to communicate and socialization complications arising from issues related to the Theory of Mind concept (Kimhi, 2014). The concept of Theory of Mind states that people with ASD may have deficits in being able to respond appropriately to various situations, like an interview, because they may not be able to fully interpret what is expected of them and what the other speaker is asking them, leading to lower conversational skills, despite the efforts of all the participants in a conversation (Kimhi, 2014). Concerns regarding the Theory of Mind concept will be further discussed in the limitations and implications sections of Chapter 5. Each of the following participant sections will be labeled with the pseudonym created for them. The data presented in this section is the foundation for the themes discussed later in the chapter (Creswell, 2007; Merriam, 1998; Seidman, 2013).

Raven

Raven was the first interview conducted. Please note that I was told by this participant the preferred pronouns to use when referring to them were they, them, and theirs due to their non-binary gender orientation. Raven presented themselves on-time as a non-binary, 19-year-old Indigenous Caribbean student of Afro-Caribbean descent majoring in Women's Studies who lives in housing. The student was casually, but appropriately, dressed for being at a university campus. Raven was familiar with the informed consent document since it had been sent to them in the recruitment e-mail by 
the host university's disability services center. The participant seemed very intelligent, independent, and was highly aware of their thoughts, values, and general needs to be successful and how to find the appropriate resources to meet their needs. This description is supported by the rare accomplishment that they were able to complete their Associate of Arts degree while in high school and some of the highlighted statements in the following paragraphs.

The interview was started as intended and quickly began to focus on the participant's LGBTQ experiences. Many of the positive and negative experiences mentioned throughout the interview had an LGBTQ theme integrated into them. A variety of statements such as "[I] experienced anti-gay preachers on campus, but I don't think I learned anything from that" were said. Raven also mentioned that housing options are not very gender-inclusive since they "always default to your [legal] gender on your record." Lastly, the interviewee had what they considered and described as a transphobic experience with a psychiatrist at the university's counseling center. When asked to elaborate in this negative experience, Raven said:

When I was called into my appointment, the doctor referred to me as Ms. I let him know what my preferred pronouns were and he was like you should carry a sign. I told him he could just ask for my preferences... he carried on and asked so do you need to know about my sex life, you need to learn to relate with other people's experiences not just impose yours on others that's when I just left since he wasn't being understanding of my needs.

The statements made by the participant may highlight the need for the campus community to be more gender-inclusive. But these statements were accompanied with others that demonstrated an overall positive experience that taught the student essential life skills while living on their own in housing such as how to "cook for myself, clean up 
after myself, go to the grocery store, and manage my money... so that's going to be helpful after college." In addition, the interviewee remarked that they had "made friends that care about me" and had faculty members that were "very understanding" of their disability and LGBTQ-related needs and that they had been able to develop some relationships around campus that made them feel "recognized, and like, some familiarity, and were willing to talk to me and such." When asked how they experienced support service, typically found resources, and how confident they were in their skills to do so, the participant confirmed that using Google to find resources was their primary method for doing so, and that they were "pretty confident" that they could find what they needed that way. Lastly, they mentioned that the overall experience on campus with the support staff and faculty was an "overall good experience... college has been much better [than high school]." When Raven was asked to elaborate on some of the positive experiences, she mentioned:

I'm involved in groups like the Black Student Union and Stonewall and it has helped socially with making friends. In terms of faculty... many have been understanding. I'd say that even our cafeteria actually stands out cause they remember how much I love fries... that kind of brightens up my experience.

In essence, Raven provided a perspective that, despite a demonstrated sense of competency and savviness to identify and resolve their needs, highlighted a need for the host institution's culture to not only continue working on supporting students with ASD, but also be more accessible to members of the LGBTQ community. Raven described hopes of a campus that was genuinely inclusive for people with disabilities and varying sexual orientations. Raven also described a willingness to continue working towards the accomplishment of their goals with all the resources available at the university. How the 
data provided by Raven contributes to the themes developed in this study will be discussed in the Emergent Categories and Themes section of this chapter. Some of the ideas that can be explored by higher education institutions and personnel based on Raven's narrative will be discussed in the closing chapter of this dissertation.

Charles

Charles was the second interview conducted. Charles presented himself on-time, as a male 18-year-old white student of Eastern European descent majoring in Accounting who lives in housing. The student was very casually dressed in shorts and a t-shirt, but still appropriate for a university campus/classroom. Before starting the interview, he asked some questions confirming his understanding of the informed consent form. He seemed to fully understand the terms of the research and his rights throughout this process. He also commented before the interview began that he was very excited about the opportunity to participate in research that could potentially help other students with ASD in Higher Education.

Since this was Charles' first year at the host university and in the university environment, his experience had a sense of naivete compared to Raven's experience. In his interview, Charles focused on his lack of non-academic social campus experiences and overall positive experiences with faculty and staff members at the university. An example he offered supporting this was:

The disability services office helped me along with their welcome appointment and that helped me with the transition phase... since then I've been getting along with my teachers accommodating my needs like when I need extra time to complete an assignment and stuff like that. 
In regard to the more social aspect of his experience in higher education, he commented that better marketing of events "would help [him] get involved with other people that share similar interests as him." He also mentioned the rigor of the curriculum in "college is so much harder than high school," but the faculty have been accommodating and helpful, and departments like the host university's disability services center made the transition to the university much easier; he was still having some challenges with this since "it's harder for [him] than other people because he is not used to change." One thing he had mentioned was very helpful was having gone through an intensive independent living training seminar the summer before starting at the host university. In this training that his parents paid for, he learned a lot of the skills needed to be a successful college student living in on-campus housing, but he felt he was still behind on socializing and finding opportunities to meet other students because he was not able to easily find opportunities to do so due to poor marketing. One thing he did appreciate was the opportunity to have some roommates since "we don't always get to pick who you have to deal with in life." When elaborating on how his on-campus housing experience was helping him prepare for living independently, Charles mentioned:

Well, I feel like it will help me, because people say they have coworkers they disagree with and other people they disagree with, so I feel like this living on my own is preparing me to deal with other people I disagree with. Not ignoring them, but learning how to just be cordial with other people that you don't like, but you have like. You know?

In essence, the experience Charles has had at the host university was within his expectations since his family had provided him opportunities to visit various universities and he had chosen the host university based on available services, affordability for his family, and it was "close to home, but not too close." He described a hope that included 
more opportunities to develop relationships with others, a variety of academic and collegiate experiences, and a continuance of opportunities to develop the skills and abilities he will need to be independent and successful after graduation. How the data provided by Charles contributes to the themes developed in this study will be discussed in the Emergent Categories and Themes section of this chapter. Some of the ideas that can be explored by higher education institutions and personnel based on Charles' narrative will be discussed in the closing chapter of this dissertation.

Scott

Scott presented himself on time to the interview as a 19-year-old White-Hispanic male of Colombian and Czechoslovakian descent majoring in Statistics. This was the third interview being conducted for the study. For this meeting, the participant was formally dressed in a shirt and tie. When asked why he was formally dressed, he mentioned that a family member of his was graduating from the host university, and he was going to celebrate the occasion after the interview. He too expressed an understanding of the informed consent document since it had been e-mailed to him in the initial notification of the study. Since he had no questions or concerns regarding the informed consent forms, the interview was started without further delay.

Similar to Charles, Scott was within his first year at the host university. Much of his interview had a sense of novelty that could be expected from a first-year level student. This was expressed by him crediting the orientation department on several occasions with having helped him "know about many of the services [at the university]." During his interview, Scott commented on how his mother and brother were both alumni of the university and were also helping him with many of the processes and procedures he was 
engaging such as settling into the dorms, picking a good class schedule, and setting up the appropriate support services. When asked about his current ability to live on his own, he commented that he was "getting advice from his brother," but he was still learning about what was needed to live independently on campus since he assumed pillows and bedsheets were included in the dorms. He described the experience as "I wasn't prepared... fortunately, it was only one night without pillow and sheets... I just got through it." When asked about how else he was learning about the different resources on campus, he mentioned, "from my mom" and that "[the disability services] office was a good start." Additionally, Scott credited living on campus with opening the desire to learn more about himself by saying:

Finally, I'm realizing for myself that I will become a better person through the college experience... I've already learned that I can be, um, really funny and smart. I have like really good memory, and um, I just been to afraid and I should stop being afraid to just be more of myself.

This was an important lesson he learned because it helped him socialize more with others. He connected getting better at socializing with others to being able to eventually do things in the future "without your parents, like go out and be on your own without them and interact with other people." Overall, he described his experiences with faculty and staff as "it is good, really nice" and that he has not "encountered any unhelpful stuff."

In summary, it was apparent that Scott was still very new to the university environment. Many of his responses were broad and he didn't have many examples to support them. Notwithstanding, he was still able to contribute data to the study by way of showcasing how an opportunity to live in a different environment can allow a person with 
ASD to recognize different aspects of themselves and identify areas of improvement or strength within their skillsets for being a good student or independent person. How the data provided by Scott contributes to the themes developed in this study will be discussed in the Emergent Categories and Themes section of this chapter. Some of the ideas that can be explored by higher education institutions and personnel based on Scott's narrative will be discussed in the closing chapter of this dissertation.

Logan

Logan was the fourth person interviewed for the study. Logan presented himself on-time as a 19-year-old Black male of Bi-Racial descent composed of White and Black cultures majoring in English. The student was casually dressed in jeans and a t-shirt, but still appropriate for a university campus and classroom. Although he confirmed he had read the informed consent form that was sent to him in the original recruitment e-mail, he took his time to read over the informed consent form again in its entirety before starting the interview to make sure he understood it and did not have any questions for me about its contents before signing it.

Logan offered an interesting perspective since he had initially, and accidentally, started taking classes at the host institution as a fully online student. The change in how he attended classes occurred because he did not realize the scheduled day for the beginning of classes conflicted with the time he was going to be spending at his father's home in another state. To not forfeit his admission, he opted for taking classes fully online for the semester. Taking online classes gave him the opportunity to take classes without the support he tends to "use a bit more." He was able to "[do the work] through disciplining [himself]." As the interview continued, Logan spoke about feeling better 
about being a student at the host institution once he was able to find a group of people he could identify with and "where he could be comfortable, like club meetings with Stonewall Alliance." Being able to find this group and make friends helped him "feel more laid back and be able to socialize with them." Being able to socialize and build skills that would help him in the future were important goals to Logan since he felt academically proficient having completed several college courses in high school and having done well without consistently using the typical support services he used in high school, like the school's disability services office. In addition to feeling academically proficient, he also valued the confidentiality that came with not using support services. In reference to appreciating confidentiality, Logan mentioned that:

For the most part, [professors] don't know that I'm on the spectrum. I don't feel like I want to, you know, go up to every single teacher and tell them [about my disability], and the same goes for like everywhere else I go [in the university].

Unless it was necessary, Logan preferred to maintain his confidentiality and only disclose when he had to. This strategy proved to have some good and bad results. He mentioned that "most of the teachers themselves were not bad," but he did have a problem with one professor. In that situation, he learned that he needed to "not be bothered by the class itself" and "try to communicate with the teacher earlier." $\mathrm{He}$ admitted that in some cases, teachers knowing he needed more time for homework or some extra office hours would be helpful. Fortunately, the professors he has had have been willing to work with him, even without the disability services office being involved.

Other important lessons he was learning were how to live on his own as an oncampus resident. Through this experience, he learned he valued having personal space 
and how to get along with people who do not understand the needs of a person with ASD or that identified as a member of the LGBTQ community. "[He] wasn't able to warm up to them like the students from Stonewall." He was also able to work on skills his mother typically supported him with such as maintaining his room and feeding himself, "[my mom] noticed that I didn't need as much supplies as she packed when I came.” He agreed that he had learned to be more resourceful than his mother anticipated. Despite being resourceful and doing well on his own, he did find comfort in having his family close by. For Logan, family was "a very good support system to have."

In conclusion, Logan highlighted many issues discussed in the literature that students with ASD face when entering higher education, with a significant differencehe was coping very well with them. Despite not having some resources and support systems readily available, he had been able to cope well with the situations he found himself in and had just enough support to learn from these experiences without compromising his academic career or personal development. This finding will be discussed in greater detail in the Categories and Themes section of this chapter. Additionally, some of the ideas that can be explored by higher education institutions and personnel based on Logan's narrative will be discussed in the closing chapter of this dissertation.

Erik

Erik presented himself on-time to the interview. He identified himself as a 22year-old White-Hispanic male with Hispanic ethnicity majoring in Psychology. Erik was casually dressed, but appropriate for the university campus environment. When he was presented the informed consent form he quickly signed it since he had already read it 
when it was sent to him in the recruitment e-mail and he confirmed he had no questions about the study. Furthermore, he mentioned that he was excited to talk about his experiences in a study like this since it may help other students with ASD in the future, a goal that he has as a Psychology major. Upon being assigned the pseudonym, the interview was promptly started.

Erik was one of the students interviewed who transferred to the host institution after having completed coursework at another institution of higher education. This gave him some references to compare his current experiences against. During the interview, he mentioned that the faculty at the host institution was "nice and neutral, and always willing to help." He felt he could be forthcoming with the faculty about his needs and that they were able to better serve him, "you tell them a little bit more about yourself, and that helps them, you know, work better with you." Similarly, Erik commented on how flexible and more available support services were at the host university compared to his previous institution, "there's more customer service, more note-takers, and [support services] are more connected [with the students] than in [my old school]." Overall, Erik described a better experience than what he had encountered in his previous institution. Unfortunately, he was not able to say the same about his student body experiences. When describing some of the experiences he had with other students, he described them as being very focused on their own interests and some of the superfluities of life such as "money, music, hanging around" or "using [me] for help." He also commented on how some students have befriended him because of his work ethic in order to get access to his homework and class notes. When asked to elaborate on this, Erik mentioned the following story: 
There was this girl that needed my help with some notes for a class and I said yes. Eventually, she started to take [his] books for herself to use and she tried to copy a paper [he] wrote. [He] had to go to the teacher for help and she got in trouble.

Erik mentioned that this experience angered him and made him sad. Throughout the interview, Erik seemed to also take some responsibility for sometimes not being better at engaging others and perhaps not knowing them very well since he keeps to himself a lot and has a speech impairment. With this in mind, Erik mentioned that "[he] does [his] best to practice [his] public speaking, even if it feels negative, he tries to keep talking to people." He also relies a lot on his father to learn more about how to better interact with people and learn more about "the reasons they do the things they do."

Additionally, he also described using various software options to learn the basics of public speaking and other languages in order to be better prepared to complete the requirements of his degree. Erik felt that this effort will allow him to succeed in his major. He hopes to help others the same way he and his family were helped when he was younger and supported him to get to where he is today. Erik had a strong focus on personal development. He focused on his efforts to help his family by working in his father's upholstery shop and how he has spoken with them about living on campus again to learn how to live on his own. He had tried it when he first came to the university, but his anxiety was too high and he opted to go back to living with his parents, but he feels he might be ready to try that again during graduate school since "many students live on their own during graduate school... but I want to be ready because I won't have anyone else [to help me]." Erik commented on knowing "the basics like cleaning the house, maintaining laundry, and cooking, but I need to know a higher level like paying bills and 
rent... but I will follow what my mother can teach me since she likes doing accounting." Erik did mention the possibility of having roommates to help with the financial aspect of living independently, but he was not very focused on this strategy. He is determined to learn how to be self-sufficient. Continuing with the theme of preparing to live independently and be a competent helping professional, Erik also spoke about having to learn to manage unexpected events and his time. Erik elaborated on maintaining his focus on his goals and not letting himself be distracted like other students since a person "in [his] position, a person with disabilities" is not expected to succeed in college. He is happy he has accomplished so much and knows he still has more to experience. He spoke about how he has learned to work with professors' expectations to complete assignments, catch up on work, and study during vacation times like spring break, despite what he had originally planned to do with this free time. He summarized this by saying "sometimes we feel younger and want freedom, but that has to be on the weekends." He described his weekly schedule as focusing heavily on school, working with his family, and going to the gym before engaging in more entertaining pursuits such as playing video games.

Overall, Erik presented himself as a hard-working and goal-oriented person who hopes to continue finding options to complete his degree that will prepare him for the future as a professional and independent person. He described the hope that his institution will grow to be more flexible and offer more options for him to have a quality collegiate experience. Erik's interview was full of examples of experiences that highlighted his work ethic, determination to be successful and his dream to become the best psychologist in order to help others like him. His interview concluded with the following response to the last two questions of the interview which I feel embodies Erik's positive attitude and 
mindset. For the last two questions, Erik was asked how he typically finds out about the different support services at his school and how confident he was he knew who to ask and where to look for these support services. Erik's response was:

I get information from online and asking people around school for help... sometimes I feel like an explorer, I try things at least once, maybe it's for me, maybe it's not; then I try again. You can't just sit there, maybe a different one will work out better than this one.

How the data provided by Erik contributes to the themes developed in this study will be discussed in the Emergent Categories and Themes section of this chapter. Some of the ideas that can be explored by higher education institutions and personnel based on Erik's narrative will be discussed in the closing chapter of this dissertation.

Remy

Remy was the sixth person interviewed for this study. He presented himself for the interview on time as a 23-year-old White-Hispanic male of Hispanic descent majoring in Environmental Science. He was casually dressed, but appropriate for a university campus. Upon being greeted, he was exceptionally cordial and well-spoken. When provided the opportunity to read over the consent form he quickly skimmed it and confirmed it was the same as the one he had read in the recruitment e-mail sent to him. Before starting the interview, he asked if I was a mandated reporter. He was assured that unless there was some imminent harm reported to himself or another person, there was no duty to report any of his statements to local police. He was agreeable to this response, at which point a pseudonym was assigned to him and the interview was started.

Remy provided a very dynamic narrative of his experiences at the host institution. He brought a perspective to the study that included other institutions as well as other state 
and local township experiences that contribute to his development as a person throughout his collegiate years. Although Remy had just finished his first year at the host institution, he had already attended six other institutions of higher education in four different states. When asked how he had been to so many schools, he responded that he had been in “college-level classes since he was 13 years old through dual enrollment programs." His teachers had noticed a lot of academic potential in him and supported him in engaging in more rigorous academic coursework. Although Remy had a very strong academic narrative, much of his interview focused on some of the negative experiences he has had socially and how he has grown from them. Early in his interview, he mentioned that it was difficult to adjust to the new environment since he didn't know anyone. Because of this, he started to use cannabis. This form of self-medication caused him to develop an addiction to cannabis and not "get along with [his] fellow staff, students, professors, and whatnot." He attributes breaking his leg at the end of his first semester and not being able to go meet with his supplier of cannabis and other friends at the time with gaining a new perspective on life and changing his focus to be "more on [his] studies, [his] own interests, and things that attract [his] curiosity." Remy was very proud of being able to stop his addiction and his progress such as "making new friends and... being on the dean's list." He was very excited for the future given that he was leaving his past behind him. This point was elucidated with a story he told about a former female friend of his that was trying to drive home drunk and then tried to shoplift when they were at a store. During this encounter, Remy offered to drive her back home and stop at a store to get something for her. Remy chose to separate himself from this situation by "leaving her at the store and going back home." This caused a future encounter with police when the 
female friend came to his dormitory and started banging on his door and screaming for him to return some of her belongings later in the day. When the police came to his dormitory to resolve the situation, they obliged to the request of Remy to speak with his father who was also a police officer. Remy's father informed the officers that his son had autism and may not be able to communicate with them very effectively about the situation that had occurred due to the anxiety it had caused him. Remy admitted to being very sensitive to the loud screaming and banging on his door, in addition to not being able to interpret the intentions of his female friend, or the officers. Because of this experience, he has learned to be more selective about whom he becomes friends with, despite always wanting to make more friends and engage more people. Unfortunately, these lessons caused him to do poorly in school that semester and stay traumatized with the experience he had with law enforcement. Remy described the end of that semester as:

Initially, I was scared of approaching anyone else for a period of about four months. I didn't want to talk to anyone. I didn't want to associate with anyone. I just wanted to be left alone, smoke my weed at the time and focus on my schoolwork. Obviously, those things did not combine very well and I couldn't do my school work. I was a mixture of traumatized, addicted and sad. So my grades struggles. Everything, a lot of things slipped.

After his first semester, Remy was able to use different resources on campus to help himself be a better student such as group therapy at the counseling center and support from the disability services office on his campus. Through these two offices, he was able to work out some of the situations he was experiencing, get academic support, and meet new people that he could relate to on campus. Additionally, he was learning about new socialization skills through a workgroup hosted by the disability services office. Additionally, he was also able to start using the tutoring center. This has helped 
him a lot, although he is still trying to get regularly scheduled tutoring sessions with the same tutor rather than the randomized process they currently have. This has caused him to spend more time building trust and rapport with that staff, something that "takes [him] a bit longer to do than others." Lastly, Remy was able to start using the gym as a resource to help build his confidence and physical well-being after he broke his leg. "I realized it was more important to do stuff, to be active and to appreciate my body." By engaging the on-campus gym, Remy mentioned he was able to experience the physical benefits of exercise and some of the mental health benefits such as support with stopping his use of cannabis, increased confidence as he started feeling and looking better physically, and he especially enjoyed the opportunities to socialize at the gym when using exercise equipment with others.

The remainder of the interview focused much on social experiences, campus engagement opportunities to increase socialization opportunities, and semi-independent living. Remy made it clear he needed to have people around him to talk to. This was supported by his admission that he felt many symptoms of depression on the single occasion that he was living by himself at his previous institution. Unfortunately, having roommates has some negative aspects to it, such as having to become accustomed to others' habits, "but I'm not doing bad." Remy describes having to learn to live with people with different life experiences, socio-economic status norms, promiscuity, and general living habits. As an example of this, Remy mentioned, "I've had some awkward moments, but I'm very close with my roommates now." Remy expressed at all times an eagerness to engage others socially despite the stereotype of people with ASD "that suggests they prefer to be alone and solitary... it's quite dynamic." In closing with 
Remy's social experiences, he views his school, in part, as a source of socialization opportunities, but he feels he has managed his development on his own, "I did that by myself."

Lastly, Remy spoke highly about his living skills. Although he is still financially dependent on his family. "[He] has never had to work a day in his life, " instead he has been able to use that time for "personal development and education, which are a more productive use of [his] time." He felt confident that he had developed a good set of living skills, that he could "live in a tent in the Bahamas." "Once I have that short period of adjustment, I am content wherever I am." Over time, he has grown dependent on public resources for transportation and entertainment, as well as coping with stress. Remy described himself as "very cosmopolitan." He felt as if his environment was critical to his success. He was not happy in more rural areas, such as those in South Carolina and Georgia, but had more satisfying experiences in Miami and Washington, D.C., cites he described as having more public resources and activities. In his current living situation, he described having easy access to his campus by living in private student-only housing, access to public transportation, and a variety of options to be entertained and socialize. In essence, Remy attributed having an environment that offered positive options that were conducive to his needs as a key to him successfully changing the behaviors that negatively affected him in his first semester...

I think the most important thing is at first finding and connecting people to better methods of communicating and meeting people and better [social activity] alternatives than going to a bar on a Friday night or smoking some pot on the weekend. I think the core of it, if you will, would be a stage... that is someone's setting; change the stage and resources on that stage and people will have what they need to be successful. 
In summary, Remy presents a compelling narrative that opens itself to exploration from more lines of inquiry that are beyond the scope of this study. Remy's interview is the only interview that had to be guided to a close since the 90 -minute time limit was fast approaching. Remy showcases a collection of life experiences that highlight many developmental milestones that have been reached. How Remy's contribution supports the mission of this study will be discussed in the Categories and Themes section of this chapter. Some of the ideas that can be explored in other studies presented in Remy's narrative will be discussed in the closing chapter of this dissertation.

Pietro

Pietro was the seventh person interviewed for this study. Pietro presented himself on time to the interview as a 24-year-old Black male of African-American/Haitian descent majoring in Computer Science. He was dressed casually, but appropriate for attending the university campus or classroom. He had learned about the study via the recruitment e-mail sent by the host institution's disability services office but admitted he had not thoroughly read the informed consent document included in it. He was provided the opportunity to review the informed consent form in its entirety and ask any questions he may have about the study. Upon him understanding the study to his satisfaction and being assigned a pseudonym, the interview promptly started. Similar to other participants interviewed up to this point of the study, he was very short with his answers, only elaborating on the topics being discussed when prompted by me. Nonetheless, his narrative was able to inform the study with his perspectives and allow me to gain a better understanding of the experiences students with ASD have had in higher education. 
After taking six years to complete his associate's degree at a local community college, Pietro transferred to the host institution during the previous semester. In comparison to his experience with his previous institution, he said the communication between his faculty, him, and his support services had "been pretty well; it could be a little difficult, but [he] enjoyed it." When asked if any experiences could be given as an example of this description, he was not able to provide one. However, he was happy with the quality and amount of service and support he has received given the university has so many other students that also need support. He did not have any negative experiences to talk about. The only thing that made it difficult to interact with others was his speech impairment. "I stutter a lot, so I know it's on me to be more clear and transparent to say what I want to say... that's my biggest weakness in life so far... but I'm able to get tasks done." Overall, Pietro noticed an improvement in support services when he transferred to the host institution, but he commented that things could always be better. Something that could be improved would be that people could be more patient with him and others with disabilities. For example, if he talks to fast or too slow, people should either give him time to express himself or ask clarifying questions rather than guess about what he wants.

As the interview continued, topics such as independent living and personal development were discussed. In regard to Pietro's ability to live on his own, he specified that he would prefer to live with people he is familiar with. He needs to be able to easily say "hey, I know you." He currently lives with his family, but plans to live on campus the following semester. When asked how he hopes to benefit from living on campus, he smiled noticeably and said: "to be fair, tutoring, getting to know my friends more, and honestly, go to more university events." Pietro commented on his resilience and 
determination to continue to better himself in anything he is performing well in. Some of the things he does to develop himself are practice speaking at home, studying, trying to make friends, and "build upon the skills that got [him] here in the first place." He found it important to be accountable, address problems immediately, and talk to his professors about his needs. This way of addressing situations has proven to be useful for him. By developing this mindset, professors have helped him complete assignments, and he has been able to develop relationships. Additionally, his family has been an important resource for him. Despite lacking many resources as a child, his mother was finally able to get him diagnosed and connected with support when he was 8-years-old. Throughout his $\mathrm{K}-12$ years, he did not have much support in school. Thanks to his sister, who is a college graduate, he was able to get the support he felt he needed to be successful when he got to college and have some guidance navigating the complicated processes that need to be completed in order to activate some support services, especially financially-based ones. But, he did not seem to see himself as a victim of his circumstances; he described his experiences as having contributed to his resilience and being accountable for his own success. Pietro sees these negative experiences as a positive thing, "people like to see a man who is effective, works out, tries to improve themselves." He feels a sense of being respected because of his efforts and successes. He also feels this kind of work ethic will help with his confidence and love life. It was clear that Pietro's mindset is to be assertive and take the lead with his personal development and developing his ability to engage others as highlighted by his statement:

You can't just settle with what others want, you can't just ignore a problem and be done with it. If you ignore a problem it will grow like a cancer tumor until it explodes. I want to avoid those experiences. I want to 
talk to people and be truthful... I'm open and ajar with my mother and father... I talk to my professors... I exercise my right to solve my problems. It's worked pretty good for me.

In essence, Pietro described himself as a resilient and hard-working student that has had many challenges in his life, but he has chosen to view them as motivation. He can also be described as responsible for his own development and focused on finding solutions for any issue he experiences. In his responses, I was able to interpret that Pietro hopes to see more opportunities to engage other students at his institution, see support for students like him be easier to access, and an overall more inclusive culture for students with disabilities.

Henry

Henry was the eighth interview conducted for this study. Henry presented himself for the interview on-time as a 24-year-old Hispanic Latino male majoring in economics. He was dressed casually, but appropriate for the environment. He learned about the study via the recruitment e-mail sent and by asking the disability services front desk staff some questions about it. He was recommended to speak with me, and upon confirming that the study was still active and what its purpose was, he agreed to participate in it. When Henry arrived for his interview, he was greeted by me and brought to the interview office. Having read the informed consent form when he received the e-mail and discussed it briefly with me, he skimmed the document one last time before signing it. At this point, he was assigned his pseudonym, and the interview immediately started.

Henry's interview was impactful to this study because, although he was more reserved than some of the other participants and did not elaborate much on his responses, his statements buttressed some of the themes that had already been developing 
throughout the other interviews and some concerns that were highlighted in the literature review that this study was designed to attend to. Before coming to the host institution for his education, Henry had spent some time taking classes at a local college. Upon starting his coursework at the host institution, he was exposed to a variety of services that, according to his recollection, had not been available to him in the past; he was able to use academic accommodations for the first time. When asked about what kind of support he had received, he only referred to speech therapy. According to Henry, "[he] never received any emails or anything about resource centers at his other schools, most of my support services were just there to help with my speech." It was not until he recently started receiving services from an agency called Vocational Rehabilitation that he was informed of academic accommodations that would not only be helpful to him, but that he was entitled to. It was clear from this information that this young man had not been adequately served in his previous educational institutions.

When I asked: What would have been better if you had support services in your other schools? Henry's response was that he: Would have been able to plan better how to schedule his classes, finish his homework, and ask his professors for help.

Other than the disability services office at the host institution, Henry also admitted to using the tutoring center. It was important for him to do well in his classes because he was motivated to prove he could complete this kind of rigorous coursework. Given his statements, Henry expressed a history of being underestimated throughout his academic career. When getting advised about future course work, as well as work options, by his counselors in high school and some of his family, Henry remembers being told: 
"[college classes] are too hard, that [he] should not take them. [He] needs to focus on something that does not require talking to people." To which he has responded: "I am still taking them, the classes are getting harder, but I am still here... so I can graduate and be an [Economics teacher]."

Henry's interview highlights the resiliency and the determination to accomplish their goals found in all the students interviewed thus far.

For most of the interview, Henry had a common theme in his experiences that his abilities to learn and become a professional in the field of economics have always been under-estimated. According to his responses, this has happened with several people in his life including not just his family and counselors, but also professors. When discussing some of his experiences at the university, he described an experience he had when meeting with a professor for help with a particular topic. Rather than the professor helping him with his question with an explanation, Henry was forced to read a passage from the book used for the class very slowly. Additionally, many e-mails sent to this professor by Henry went unanswered. He confessed that "[he] felt embarrassed" and was not comfortable communicating with this professor, and consequently other professors without the assistance of the disability services office, although "most professors seemed to be nice." Continuing to work with the disability services office provided Henry not just support for speaking with professors and implementing his accommodations, but they also helped him gain the confidence to engage his faculty better and have a better relationship with them. Throughout the interview, Henry seemed to focus mostly on academic issues, although he seeks to find opportunities to engage others in different ways and develop more independent living skills. 
In regard to his social experiences, he mentioned he does not have many to speak about because he does not go to many non-academic activities. He would like to change this since he "has done some community service, and he likes how it has helped him with his communication." He would like to be more involved with school-sponsored activities, such as a football game or club meeting. He confirmed, "[he has] never been to any football game, like a homecoming game... I have never had the chance to join a club." Additionally, he feels it would make his days more fulfilling since he does not have many activities to attend to after he has completed his studies and class sessions for the day. From his statements, it seems he has always been directed to more solitary pursuits, even though "[he] actually does like to communicate with people." When asked about some of the factors preventing him from doing this, he referred to his homework obligations and lack of transportation since he often uses the bus. Other than intending to improve his socialization abilities and his communication skills, Henry was also interested in further enhancing his ability to live on his own. When asked how being at his institution has helped him develop skills to live on his own, he confirmed that despite still living with his parents, he feels he has learned many budgeting and decision-making skills that will aid him in living on his own, something he hopes to do after he graduates. In order to better prepare for living on his own after graduation, he plans to live on campus before graduating. He mentioned that his brother did this and credited the on-campus living experience as being the best learning opportunity of independent living skills that will be helpful after graduation.

In summary, Henry provided an account of his experiences that support the reason this study was done, to learn how higher education institutions could better serve students 
with ASD in minority-serving institutions. Henry presented the story of a young man working diligently on his goals, despite being underestimated by those that he would typically count on for support. Henry's story is of a person that recognizes his deficits in communication and socialization skills and how critical they are to his success in life, but has not had the resources to work on developing these skills. Lastly, he gave a narrative that echos characteristics of a sheltered life due to a lack of information and incorrect assumptions searching for opportunities to engage things that are of interest to him and he knows will allow him to lead a fuller and more satisfying life. How the data provided by Henry contributes to the themes developed in this study will be discussed in the Emergent Categories and Themes section of this chapter. Some of the ideas that can be explored by higher education institutions and personnel based on Henry's narrative will be discussed in the closing chapter of this dissertation.

Jean

Jean was the ninth and final interview conducted for this study. Jean presented herself on-time for her interview as a 21-year-old White Hispanic female majoring in Environmental Studies. She was dressed casually for the interview, but appropriate for on-campus activities like going to class and participating in this interview. She learned about the study via the recruitment e-mail sent by the host institution's disability services center. Having reviewed the informed consent form when she initially received it, she quickly reviewed it a second time before signing it and then being assigned her pseudonym so the interview could start.

Jean's interview carried throughout it a generally positive tone. In many of the experiences she has had in the last few years in the institution, she seemed to be 
competent in resolving any issues that developed, resourceful, and astute. In regard to her academic experience, she spoke highly of the school's faculty in that they "gave me a vibe and gave me the feeling that they really wanted to help all their students... they reached out to [her] and were like available after class for talking to." In one of the few instances she felt she had a negative experience, she cited her inability to view the faculty member as helpful as the main reason she perceived her professor to not wanting to help her. "In my mind, I made them out to be more intimidating than I should have, and like after I talked to them, it wasn't that bad." She credited the lack of support she was used to in high school with the preconceived notion that the professors would not want to work with her. Jean described her high school as "kinda small" and providing only a few options for accessing disability-related resources, even though it was a college preparatory school. Upon resuming her studies at the host institution, she was immediately impressed with the relationship she was able to establish with her disability services counselor, her faculty, and academic advisors. She and her mother no longer had to advocate for support as strongly as she was used to. The concern that was most pressing for Jean when she started at the university was in her "first semester, not knowing anyone." Jean describes her experience with the disability services office and starting the new school as:

I built a good relationship with [my counselor]. The ability to talk to her was like really important and she always made herself available. As I learned more about how to speak up about what I needed so I wouldn't feel anxious, I knew I could copy her on my e-mails and she would be there to help me... this was very important for me and my mom. Because of how good [my counselor was] I refused to change counselors as I progressed and requested to stay with her. Having a person I can consistently rely on has been the most helpful support option in college. 
When Jean first arrived at the host institution, she was concerned about not knowing anyone personally or from a student resource perspective. Fortunately, she was able to meet "plenty of friends" by living in housing for two years, going to the gym and taking different fitness classes, and through courses since her major consists of a small cohort of students and it is easy to get to know all of them. From a student support service perspective, up to this point, she and her mother were only accustomed to the process in her high school to get support, which was not very good. Fortunately, Jean and her mother were able to get referrals from the disability services office for on-campus departments providing tutoring, psychiatric services, and workshops on topics such as time management and communication skills. In essence, it was comforting to know that she "could advocate for herself and at the same time have that backup [support from the disability services office]." Lastly, another resource she found for her academic needs, such as working in groups with unfamiliar people by way of the opportunity she had to socialize within her major's student cohort, were the students themselves. Having a small cohort of students in the major that she could regularly see in different classes helped "have a familiarity with them and [she] could talk to them and it's easier to socialize with them... rather than like complete strangers." Overall, Jean described a generally positive experience with her faculty, support staff, and fellow students. Additionally, having the disability services office and her mother for guidance, she described herself as in an excellent position to continue her success at the university and be able to ask for more help from the right people when it is needed. In regard to her campus engagement, some issues came up that forced her to reconsider some of the decisions she had made such as living on campus and using on-campus healthcare services. Lastly, she expressed 
concerns about her ability to be made aware of opportunities to become more engaged with on-campus student activities.

Jean described some of the issues she has encountered that led her to move back home with her family and reduce her use of on-campus healthcare services. Although she had an overall good experience living on-campus, which included making long-term friendships, learning to resolve conflicts with others in an amicable manner, learning how to maintain her living space and her class schedule, self-care, and social/familial obligations, she quickly became overwhelmed with having to manage all these duties on her own. Suddenly, "all the things that like [she] did not have to worry about before living at home, now [she] has to worry about them." Although it meant having to factor in more driving time into her schedule, the best decision for her in that situation was to move back home with her family. This also had the added benefit of saving her a considerable amount of money by not having to pay for housing. As for her reduced use of on-campus healthcare options, although she felt they were good options, she preferred not to disclose too much of her medical issues to campus community members such as university employees or students in group sessions. Furthermore, she was not comfortable with other students to see her use these same services. Additionally, on the occasion that she tried using the pharmacy, her medication was not available and she had to wait several days to refill her prescription, which caused her some stress and lower performances in the academic deliverables she was working on during that time. Fortunately, she was able to resolve these matters via her efforts with off-campus resources and now prefers to continue using off-campus resources. In essence, the few negative experiences Jean described in her interview allowed her to learn better problem- 
solving skills and be able to recognize what options are better for her overall well-being.

Despite these being negative experiences, they provided Jean positive growth in her personal development.

In summary, Jean provided a narrative that was generally positive regarding her experiences in higher education. They help provide examples of how negative experiences can be handled in order to ultimately gain some benefit from them. Furthermore, her positive experiences help showcase some of the strategies that may help other students with ASD such as smaller student cohorts, engaging faculty, and wellprepared service providers. In this regard, Jean mentioned:

Being a part of a small department meant I could have more intimate oneon-one meetings with the advisors, and I wasn't competing for attention with as many students so it was easier to get a mentor... I was also able to get to know more students and that made it easier to work on in-class group projects...

In closing her interview, Jean acknowledged she has had a generally good experience at the university, but hoped to see faculty members continue being more proactive and higher education institutions continue to develop more effective strategies to promote on-campus events to students. How the data provided by Jean contributes to the themes developed in this study will be discussed in the next section of this chapter. Some of the ideas that can be explored by higher education institutions and personnel based on Jean's narrative will be discussed in the closing chapter of this dissertation.

\section{Emerging Themes}

In this section, I discus the themes derived from the data collected. In total, three themes were generated after analyzing the data collected. Although it is being presented at the end of this dissertation, it is important to remember that these themes came to 
fruition throughout the entire process of this study, from identifying the topic of this study through the last interview, every piece of information reviewed by me has brought me to this point of the research process where what has been learned from the participants can be showcased (Seidman, 2013). The themes presented below are the collective understanding and expression of common experiences throughout the interviews, and they will be compared to what is already mentioned in the literature to demonstrate what has been learned from this study (Creswell, 2007; Glaser \& Strauss, 1967; LeGary, 2017; Merriam, 1998; Seidman, 2013; Yin, 2018). The three themes generated have been identified as a) students with ASD are capable of addressing their needs, b) increased campus engagement, and c) life skills development. The themes will be presented in the order mentioned. How they answer the research questions and what implications they may have on future practice and research will be discussed in the following chapter.

Theme 1: Students with ASD are capable of addressing their needs

The first theme that is going to be discussed is that students with ASD are capable of addressing their needs. The core of this theme is that students with ASD in higher education may be aware of their needs and have goals and support systems in place related to these needs than is suggested in the literature. As mentioned throughout the first and second chapters of this dissertation, students with ASD are often not given an active role in the transition planning and execution process of their educational plans throughout high school and often have deficits in being competent advocates for support of their needs during the transition period to higher education (Adams \& Proctor, 2010; Rowe et al., 2015; Shogren \& Plotner, 2012; Wehman et al., 2014). According to the 
literature, it is not properly engaging these processes that is causing students with ASD to not receive the necessary guidance and training to transition to, and be successful in, the post-secondary environment (Shogren \& Plotner, 2012). Upon reviewing the data collected within the nine interviews conducted at the host university, several instances demonstrated that students with ASD at the host institution for this study are demonstrating the opposite of what is said in the literature. The students interviewed in this study reported many of the same concerns as other students in general transitioning into higher education institutions, which include developing the personal skills to cope with the new environment, learning about what support is available in the new institution and how things are done at the new institution, assimilating to the new social environment, and adjusting to the new academic demands of the new institution (Trautwein \& Bosse, 2016). The students interviewed were keenly aware of their strengths and weaknesses. The participants in the study talked about having goals for their academic and social collegiate experiences, and in many cases, they knew what had to be done to accomplish these goals. Furthermore, many of them demonstrated a resilience in their character that was unexpected and counterintuitive to how people with ASD are sometimes portrayed in the literature and in the media, and this is a similar finding reported in Sosnowy, Silverman, and Shattuck (2018). In the following paragraphs, how this "nuanced understanding of [how young adults] conceive of, value, and strive to achieve desired outcomes" (Sosnowy, Silverman, \& Shattuck, 2018, p.37), supports this theme will be discussed.

In his interview, Erik acknowledges that "[he] has a speech impairment" and that "he is not very social." He is also aware that living on his own will be challenging and is 
something he needs to work on because when the time comes to live on his own, he "wants to be prepared because [he] won't have someone else there to help him." Of all the participants, Erik demonstrated one of the strongest work ethics and level of dedication to develop his skills in order to become a counselor someday for kids with ASD and give back the support he received to get to where he is now. Erik mentioned:

I have to do this work to be successful in life... I want to get my Masters Degree in Psychology and help kids like me. So far this is only the tip of the iceberg, because I want to help people... this makes me feel good. I want to thank everyone that helped me by doing the same for others with my problems, or different problems.

Charles recognizes he has deficits in managing his time and has a strict protocol in place for scheduling himself. He describes it as:

I have to manage my own schedule. I usually set a time limit for everything, like I usually time out what I'm going to do exactly when it starts and finishes, when is each assignment going to be done, and I time everything including breaks and free time. I have to do this because it is hard for [him to cope] when something unexpected happens, it's harder for [him] than other people because [he] is not used to change.

Logan confirmed that he needs to develop familiarity with others and know that they understand his needs. When comparing his roommates to friends he had made in a student group called Stonewall, he mentioned "I'm pretty sure they weren't on the spectrum and they were more social; they would sometimes do things that distracted and kinda irritated me, so I didn't really want to know or talk to them. It was hard, even though I lived with them, it wasn't very easy to warm up to them, not like with those students from Stonewall.”

Additionally, at least two of the participants were aware that the common perception of students with ASD is counterintuitive to some of their needs. In Remy's 
interview, he confirms that he needs to be able to live with someone else in order to be able to have interactions with others. As an example, he mentioned:

At my previous university I had an apartment all to myself, and I was miserable the entire time. The one thing I begged for was a roommate to at least say, "hi" to. I have to live with other people, which is perhaps different from the traditional view of autistic people that suggests they prefer to be alone and solitary - into their own thing. That's just a stereotype, we're quite dynamic.

Similarly, when speaking with Henry, he confirmed he would like to develop his public speaking and communication skills so he could someday teach Economics rather than follow the advice of his family and high school counselors and "do something that requires very little having to talk to other people."

Furthermore, the participants interviewed have goals related to supporting, or further developing, their ability to resolve the needs they present, such as improving their public speaking skills, being able to effectively socialize with others, and making sure their medical needs are being met. This is evidenced with excerpts from the interviews conducted, and these are provided in the paragraph below.

In his interview, Pietro acknowledged that he has a speech impairment and to develop his skills, "he practices at home... tries to make friends by being amicable and not ignoring his problems." In Raven's interview, it was confirmed that "learning to speak up for [themselves], will not only help them, but other students." Raven's interview was very focused on needing to advocate for more gender inclusive environments and options on campus, such as:

We need to actually have gender neutral bathrooms, not label one in the building and let it stay broken the whole semester. Things like updating forms to include non-binary options in housing and other places. Not having this sends a message to people of different genders that we can't 
cohabitate. That things have to be sexual, or something perverted, or whatever. We can share a room, we can live in the same place, it will be fine.

Additionally, the participants have support systems in place in the form of their families, support services at their home institution, and peer groups. Sometimes, the participants are forced to be their own support service. This portion of the theme helps support that despite the documented lackluster support mentioned in the first two chapters some students are receiving as they transition to higher education; they are finding ways to move forward with accomplishing their goals whether it be on their own, or with their family, peers, and school-based support services. This aspect of the theme may be explained by the motivation to be successful in higher education, have their families be proud of them, and respect them (Arana \& Blanchard, 2018; Kouyoumdijian et al., 2017). This is evidenced with the quotes provided below from the interviews conducted.

In Jean's interview, she referred to having a "reliable person like Joanna from the disability services office" as key in her success in college. She added that she was able to make friends in class in order to get support when she needed notes by "texting each other a picture of our notes instead of having to go to the disability services office." In Raven's interview, “[academic] advising wasn't really too helpful, but they were nice people." Raven felt she had to help herself when transitioning to and navigating the collegiate environment. Raven was happy and proud to have been able to accomplish these tasks without depending on the traditional support services and mentioned, "I knew what career I wanted, what degree I wanted, what classes to take... I prepared myself since the advisors didn't know how to help me." Raven also confirmed trying to use the host institution's counseling center to see "a counselor and a psychiatrist." Unfortunately, 
Raven was quickly disillusioned about the idea of using this resource since some of the staff had strong opinions regarding Raven's gender orientation and preferences.

Unfortunately, a support service department not being able to adequately respond to a student's need was not an isolated incident. To highlight that some support service providers are not always reliable and force students to feel the need to learn to be selfsufficient, Jean provided a story of how she had to take it upon herself to resolve her prescription needs, despite the campus pharmacy being only a few steps away from her dormitory. When having to attend to her medical needs, Jean was:

Forced to find an off-campus pharmacy to fill her prescription for [a commonly used psychopharmaceutical drug (drug name removed to help maintain medical confidentiality). I was living on campus at the time and had to go to another city to get my medicine because we didn't have it on campus and the nearby pharmacies didn't stock it because its highly abused by college students, but I really need it. This made me waste a lot of time and gas for something I should have been able to get in the building across from my dorm!

Jean also disclosed that she has grown to prefer using off-campus

resources since she is able to afford it through her family's resources to maintain more confidentiality for herself as well as get what she believes are higher quality services. In reference to the on-campus health services, she mentioned "I've also like heard not great things about them, which kind of deterred me... They may put you in group counseling, and I don't like doing things in a group." Some participants also provided stories of relying on their families, but actively learning to be more independent. To illustrate this, Logan mentioned:

[According to my mom] I have learned to be a bit more independent. She like the fact that I am living on my own, she thinks it will help me in the future. She already noticed that I don't need all the supplies and food she 
thought I would. I am a lot more resourceful than she thought and have figured out ways to get what I need done better and faster.

In essence, despite some of the known literature's assumptions mentioned earlier in this section and in the literature review, students with ASD at the host institution are aware of their needs and are working diligently to not only obtain their degrees but also develop the skills and implement the strategies necessary to learn how to communicate better, socialize, and advocate for themselves. In addition, this is being done with a combination of institutional and family resources, as evidenced by the following quotes from participants' interviews.

Remy confirmed he has "never had to work a day in [his] life thanks to the generosity of [his] family." Meanwhile, Erik has to work in his "father's upholstery shop" in order to have the resources necessary to go to school. Charles mentioned a variety of resources he uses such as his family and the host institution. He chose to come to this school because "my parents couldn't afford anything outside of [my home state], this school seemed to have the best services available, and it wasn't too far from [my home town]." Lastly, Logan confirmed he was using a combination of financial aid via the host institution and his father's veteran's benefits as a dependent. But this was not meeting all his needs. According to him, he feels he is not getting everything he should because of all the "VA's red tape." Due to his inability to garner more financial support from his current resources, Logan was actively searching for scholarships and grants that could support his academic and housing needs. In line with the proposal of this study, information about scholarship and other state funded resources were given to Logan after his interview. The fact that most of the participants mentioned that they are still 
dependent on a combination of their families' resources, federal and school-based financial aid, military benefits, or other forms of funding was not surprising. This coincides with the Host Institution's (2018) fact sheet confirming that approximately $70 \%$ of the students attending it use some form of financial aid. Furthermore, de los Santos and Cuamea (2010) confirmed that students in minority-serving institutions, like the host institution, often cite financially-based concerns as a critical issue preventing them from progressing in higher education at the rate they would like due to a lack of resources and options.

In closing, the students with ASD interviewed at the host institution can collectively be described as being aware of their strengths and weaknesses and putting forth the effort to develop them. The participants interviewed can also be described as determined to satisfactorily attend to their needs by opting into a variety of options offered both on- and off-campus. They are working diligently on completing their degrees and developing the necessary skills that will aid them with their personal and professional success after graduation. As mentioned earlier, the findings presented in this study based on the interviews of this particular group of students help quell several concerns found in the literature that not all students with ASD may not be adequately prepared to engage higher education. In conclusion, Pietro and Erik provided great descriptions of the work ethic communicated to me while interviewing this group of students. Pietro said:

[His] resilience as a student is key, every time [he] feels [himself] about to collapse, [he] just picks [himself] up and go[es] home to start studying, go read a book, get better at things like making friends and continue building upon the skills that got [him] here in the first place. 
Meanwhile, Erik compared himself to an explorer in that:

[He] likes to try things at least once, maybe it is for [him], or maybe its not for [him], then you try again; you have to try different options until you see a better result than [what you have now].

How this theme will help answer the research questions and how the information presented can affect the profession and future research will be discussed in the following chapter. In the next section, the second theme generated in this study is discussed. Its focus is on how and why the students interviewed are attempting to engage their campus and what are some of the challenges they identified that are preventing them from doing so more often.

Theme 2: Increased Campus Engagement

In this section, the second theme identified in this study is discussed, which is that the students with ASD interviewed for this study are interested in opportunities for increased campus engagement. This is a critical finding because there is an overwhelming collection of data in the literature available on this topic, supporting the important role campus engagement plays in a college student's successful completion of their degree (Arana \& Blanchard, 2018). Additionally, increasing campus engagement opportunities may also help an institution in general since this variable is also known to improve the retention and graduation rates of an institution, such as the host institution, which in turn helps support their funding and other performance-based resource eligibility (Tinto, 2012). Lastly, this is an important finding since there is budding research supporting the concept that institutions creating more socialization and engagement opportunities for their students with ASD have seen an increase in these students' overall collegiate experience satisfaction and, possibly, an avoidance to co- 
occurring mental health complications related to Anxiety and Depression (Koegel, Ashbaugh, Koegel, Detar, \& Regester, 2013).

In every interview conducted for this study, the desire to be more engaged with on-campus activities was expressed. The reasons that were cited in the interviews for students not being more engaged varied between simply not being aware of what events are happening to not feeling welcomed. In some cases, the participant had such a negative experience with the campus entity, they felt hesitant in engaging that entity again, despite the benefits they may have experienced if another member of that team had served them. In the following paragraphs, this theme is explored along with the quotes supporting it from the participants. How these quotes relate to well-established literature available on the topic of campus engagement and the long-held understanding of students with ASD's tendency to be socially isolated will also be discussed.

The first aspect of this theme reviewed is what the students have said they have experienced. This will be followed by why they think they have experienced this kind of campus engagement. During his interview, Erik mentioned that he is often surprised by “changes in schedules and expectations" and not being aware of special events: "I don't feel connected to the campus." Additionally, Raven described not feeling welcomed in various areas of the campus, and thus, not engaging these facilities more. During the interview, Raven described her experiences as:

I remember walking towards the student union and having to listen to antigay preachers on my first day of class. This riled me up because I told them about my situation and we ended up arguing. When I complained to the Dean of Students about this, they told me the preachers were protected under the first amendment and there was nothing that could be done about what they were saying. I was so disappointed. 
In addition to this, Raven was also disappointed about the lack of gender-neutral options on campus for things like bathrooms and housing options. The concern of engagement being expressed in these statements is how much do these students feel that they belong in the institution. Research by DaPeppo (2012) supports the notion that institutions should make more of an effort to make students feel like they belong there in order to promote their success. Although other factors may be involved when a student is not successful in higher education, it is known that having a disability can make it more difficult to graduate and this can be ameliorated by an institution cultivating a culture in its community that makes students with ASD and other disabilities feel welcomed and supported (Wessel, Jones, Markle, \& Westfall, 2009).

Another aspect of this theme that needs mentioning is that some of the students do not know how to find out more information about what engagement options are available on campus. Supporting this statement was Charles' statement that he is concerned that there is no easy way to find out about events. He mentioned that:

It would help me get involved with other people and meet other people with similar interests with me if there was better advertising of things happening on campus. For example, I only found out about a volunteering group on campus called GoGreen because I happened to walk through a nature trail. They only had one sign on one post, no other signs, nothing in the dorms. If I hadn't gone through that particular trail I would have never heard of this opportunity to clean up parks, something I like doing.

Logan was focused more on engaging opportunities on-campus for funding. $\mathrm{He}$ seemed comfortable with how he was engaging the social aspect of the collegiate experience, but he wanted to make sure he was getting all the benefits he could to pay for 
school by engaging different departments like the on-campus veteran's center, the scholarship office, more effectively utilizing the disability services office's scholarship options and getting more information about some third-party partners that offer a variety of funding support for students with disabilities without having to disclose so much about his condition. Logan described some of his experiences as:

I like not having to tell all my professors and people I talk to at school about my disability. The classes have been pretty easy so I have not had many problems that needed to get accommodations. I just wish there was a way for me to get help with the VA and scholarship stuff without having to go through the disability office.

Although Logan was the only participant in the study to present concerns of this nature regarding confidentiality, this is something that has been seen in the literature regarding people with disabilities' preference to maintain confidentiality. According to O'Shae and Meyer (2016), the fear of having a negative stigma be associated with a person can force them to not disclose any information about their condition unless it absolutely needed. Other than Logan, one other participant in the study mentioned being interested in more opportunities to engage the campus and earn money, not just socialize. Pietro mentioned he had a desire to be more active in clubs and competitions related to his major led by student groups such as "Hack-a-Thon," which are "competitions that focus on building the best app or the best program; the winners get funds and [a chance] to build out their idea."

Scott did not bring up any concerns about confidentiality but was also very interested in more institutionally-based opportunities to engage the campus such as events sponsored by the disability services office, the counseling center, housing, and the orientation office. He felt that through these departments he can acquire a variety of 
"advice and pieces of information about things here at the campus." Remy was hopeful to see more advertising of general campus events in his housing area other than only what pertains to housing. Although he is aware of private student events, his past experiences have left him preferring to go to more school-sponsored events. In his interview, Remy mentions:

I need better options for communicating with people and meeting with people than just going to a bar on Friday night or smoking pot on the weekends... I tried going to the campus life office and they just told me to look online. All I found was a list of information that wasn't very organized or easy to browse. I was able to get some responses to the messages I sent the groups about when and where the meetings were, but this required a lot of effort from me. I wasn't given a lot of direction.

The concept of institutionally organized opportunities to engage other members of the campus community is something that is supported in the general higher education literature. Based on some of the findings from Chukwuorji, Ifeagwazi, Nwonyi, and Ujoatuonu (2018), institutions that work towards creating a stronger sense of community on campus can help students thrive in both the academic and personal areas of their collegiate experiences. Further supporting the concept of building a strong sense of community, but for a different reason than to only have socialization opportunities, was Jean's commentary. In her interview, Jean commented that she would like to learn more about events that build school pride and make people want to be on campus since she feels:

The school is not connecting [with us]... in a way, [the school] is just going through the motions. I don't know how to explain it, but it's like they are trying really hard to do all the things the bigger schools do, but it's not clicking with a lot of the students. 
Lastly, although some participants were not aware of what engagement options were available on campus, others were facing the issue of not being able to reliably transport themselves to and from the events that interested them. Henry referred to his inability to drive well so he would like to learn more about events that are easy to get to and are conveniently scheduled early in the day "because sometimes it takes more time to get out of campus and on campus." This is a topic that has received some attention in the literature of higher education, disability studies, and minority studies. Not having reliable access to resources, such as transportation, is something that can negatively affect a student's choice of how to engage with higher education, or if they even opt into going to college at all (Mgaña et al., 2013; Mcdonough, 1997).

In essence, this theme is in line with what is known to be a strong influence on the success or failure of any student in higher education. According to Astin (1993), the more engagement a student has with the campus environment, the higher the probability that that student will be successful in obtaining their degree. In his research, Tinto (2012) also supported this notion in that it inspires institutions to invest more in programming and support services that lower the rate of student departure and increase student retention and graduation rates. Some ideas that were mentioned in the interviews to help increase the likelihood that students with ASD at the host campus will be made more aware of campus engagement opportunities and opt into them more often will be discussed in the following chapter.

Theme 3: Life Skills Development

The third theme that was developed from the interviews was that students with ASD were interested in further developing life skills. Life skills are a collection of skills 
that are considered essential in being able to live independently and be successful in the workplace and other endeavors one may undertake in life, and it is especially important for people with disabilities, such as those with ASD, to learn these skills (Chiang, Ni, \& Lee, 2017). All the interviews conducted for this study mentioned the need and desire to develop stronger life skills. Some of the skills that were noted in the interviews as needing to be developed, that are also mentioned in the literature as being important life skills, are the ability to handle social interactions, interpret nonverbal communication, adequately organize and maintain living spaces, and successfully transition to the collegiate environment (Ackles, Fields, \& Skinner, 2013). This finding was not very surprising given the current understanding of how ASD manifests. What was interesting about this finding was that the method all of the participants independently agreed would be ideal to develop life skills would be to live in on-campus housing. In all cases, the participants either currently lived in student housing, had lived in student housing, or were planning to live in student housing in the near future for the purpose of developing or strengthening their life skills. Some of the statements supporting this theme are provided in the following paragraphs along with how this theme relates to what is currently found in the literature.

During their interviews, Erik and Henry both confirmed that, despite not currently living in on-campus student housing, they would like to live in it to, according to Erik, "learn about living on [their] own, and with roommates so [they] could interact with them... and [learn to delegate] responsibilities." According to Henry, "It would be better than some of the DVD's, YouTube videos, and short seminars [they've] seen." Additionally, Henry spoke about how this experience would add to what they are learning 
via their course work related to budgeting and decision making. Lastly, the students explained that they feel this experience will provide training for various tasks and responsibilities that their parents currently handle for them such as grocery shopping, meal preparation, and some time management and transportation tasks.

As a current resident on campus, Raven confirmed:

By living on campus, [Raven] learned how to cook for [themselves], clean up after [themselves]... It was especially helpful after my meal plan expired cause then I have to go to the grocery store, and manage money; so that's going to be helpful after college.

Echoing this sentiment, Charles and Scott provided similar responses about learning how to resolve conflict and resolving unexpected situations like not having the appropriate bedding supplies. On his first day moving into his new dormitory, Scott describes:

I wasn't prepared. I thought my dorm would come with some of the basic essentials like a pillow and some sheets so I never packed it. I ended up roughing through it since it was only for one night until my mother was able to get me a bed set from home.

Living on campus has allowed these students to practice socialization skills, such as conflict resolution and how to be amicable with others. According to Charles:

I feel like it will help me because people say that they have coworkers that they disagree with, so I feel like this living on my own is preparing me to deal with other people I disagree with. Not ignoring them, but learning how to be cordial with other people that you don't like, but you have to like. You know? Because when you're at work you can't always pick who your coworkers are.

Additionally, Charles and Scott mentioned they were practicing skills they had learned in different seminars they participated in before coming to the university that, according to Charles, covered tasks such as "maintaining their living space, their cleanliness, nutrition, budgeting, preparing for work, and other life skills, which is good." 
When referring to his experiences living on campus, Logan attributed living in housing with "becoming a bit more independent and more resourceful." He also mentioned having a better understanding of what an ideal living space looks like for him. He confirmed he needed to have some private space.

I like living on campus... but after my first year here, I don't like having roommates. I'm pretty sure they were not on the spectrum. They were very social and did things that were distracting to me, kind of irritating... I need to be able to have my own space.

There were some positive prospects for living independently reported by some of the participants, such as Remy and Pietro. Remy confirmed he had a robust set of independent living skills, but living in student housing provided him the opportunity to practice the life skills of communication and socialization. In his words, Remy described his independent living skills set and the longterm benefit of living on his own as:

I can live in a tent in the Bahamas if I had to. Once I can get past the initial adjustment period, I can be content wherever I am... It has prepared me well for living with people that are different from me...I have realized I don't want to live by myself, I get lonely.

In his interview, Pietro confirmed he had already made plans to live on campus starting next semester. In his perspective, living on campus was going to allow him to get to know his friends better and be more active with on-campus events. Given his lively reaction and focused answer, he was questioned as to why he was so excited about living on campus. For this question, Pietro responded that the life skills he seemed most interested in were socialization and communication. When asked about his general ability to live on his own, he confidently responded: "I think I'm capable of living on my own." He was asked why he felt he was capable of living on his own since he had confirmed he 
lived with his family and had not lived on his own before. Pietro was not able to answer this follow-up question.

Lastly, Jean remembered many good experiences from living on campus such as making long-term friendships, learning how to manage her daily living needs, and making hard decisions. She described the overall experience as:

[She] had to get used to getting ready for class, feed [herself], do homework, and everything, but it was extra stressful... eventually, [she] had to realize [she] needed to do what was best for [her] and not be ashamed it may not be what everyone else would do.

After two years of living on campus, she felt overwhelmed with the responsibilities of living on her own and doing well in school, but she acknowledges it was an overall good learning experience for the future. Additionally, Jean mentioned that the decision was also financially beneficial. She described herself as being more appreciative of the support she currently has from her family and feels ready to live on her own when the time is right.

In essence, those participants that currently live, or have lived, in student housing were able to reflect on situations where they had to be resourceful, amicably resolve some interpersonal conflicts, or get used to living and working with someone else to cohabitate successfully in the on-campus housing setting. These participants agreed that despite some of the negative experiences they had, they were able to learn skills that would help them in the future when they were living as fully independent members of society. For the few participants that have not lived in student housing, they connected this living arrangement with being able to better manage, or learn how to perform, some of the daily living obligations their families tend to do for them such as maintaining the 
living spaces and maintaining a budget. Lastly, being able to have more opportunities to socialize with new people and learn to build relationships were common, and the most cited reasons for living on campus. This rationale is supported by the literature in that "young adults [with ASD] who [live] independently [are] more likely to [have] more socialization opportunities compared to those who [live] with their parents" (Orsmond, Shattuck, Cooper, Sterzing, \& Anderson, p. 2717, 2013).

In closing, on-campus housing was identified as an ideal option to learn and practice the skills they need to live independently after graduation while still having their families and other campus support service providers as auxiliary support, if needed. This concept was supported in some of the literature reviewed. A cautious approach to living independently for the first time was recommended in Longtin's 2014 findings because, despite the confidence to live independently displayed by some of the students interviewed in this study, it is recommended that some continuous or regularly scheduled assessment process is in place involving school administrators and the student's family due to the variability found in independent living situations versus living at the family home. Lastly, the literature also supports institutions providing structured socialization opportunities in order to provide a more satisfying college experience and reduce mental health concerns related to anxiety-based disorders (Koegel et al., 2013).

\section{Summary}

In summary, this chapter presented the profiles of nine students with ASD that were interviewed at the host institution for this study. Although many of the narratives heard throughout the study support some of the negative experiences that a student with ASD entering higher education are expected to have, it was also found that this group of 
students exhibited a level of resilience, resourcefulness, determination, and grit that, at least in regard to this particular group of students interviewed, shows they have the knowledge, skills, and abilities to overcome many difficult situations, or at the very least know what kind of help to seek to do so. This is evidenced by the stories presented in this section related to interactions between the students interviewed and their roommates, law enforcement, substance abuse, mental health concerns, their faculty, various support staff, their families, making decisions that directly affect how successful they can be in various situations related to their academics, independent living, and engaging others, to name a few. All the narratives presented have contributed to three themes that both support what issues these students were expected to encounter, but challenge how well they would be able to respond to these situations. How the three themes discussed in this chapter help me answer the research questions, how they can affect higher education, and how they can be further studied will be discussed in the following chapter of this dissertation. 


\section{CHAPTER V \\ DISCUSSION}

This study was conducted to explore the experiences of students with ASD at a minority-serving institution. The goal of this study was to learn more about the students with ASD at the host institution and have their experiences help guide the direction of future best practices. It was important to do this study because, despite the growth of this population in higher education and all the research that has been carried out in the $\mathrm{K}-12$ environment, there is not a lot of research available about students with ASD in higher education. Upon its execution, the data collection for the study took place over a period of two academic semesters. To recruit students for the study, various recruitment e-mails were sent to the host institution's known population of students with ASD. Upon completion, nine students were interviewed from the host institution. After the students were interviewed, audio recordings of the interviews were transcribed and the data were analyzed. From the data collected, three themes were created to assist me in answering the study's research questions. It is hoped that the primary points of data that these themes encompass from the interviews will help shed light on the current experiences of students with ASD in higher education and lead the path for future research and best practices that will continue propelling these students toward accomplishing their goals.

The study's research questions will be answered in the following section. Following the responses to the research questions, the limitations of the study, the implications of this study's findings to current practice, and recommendations for future research will be discussed. The final section of this chapter will include my concluding remarks. 


\section{Research Questions Responses and Interpretations}

To explore the overarching question being asked in this study, "What are the experiences of college students with ASD in higher education regarding the quality of support services they are receiving as they enter post-secondary education, persist through their academic programs, and enter their post-graduate lives," the following research questions were presented:

1. What are the experiences of college students with ASD at a public research university?

2. What are the perceptions of college students with ASD of the support services available to them at a public research university?

3. What are the perceptions of college students with ASD of how well-prepared they feel for life after graduating from a public research university?

These questions are answered in the order presented in the following three sub-sections. Research Question 1 Response

The first question of this study inquired about what were the experiences of college students with ASD at a public research university. The college students with ASD interviewed at the host institution had a robust collection of experiences to talk about during their interviews. During these interviews, they offered me a glimpse into their lives concerning their activities in and out of the classroom, in housing, with their friends, their faculty, and with support services personnel. There were both negative and positive experiences, and in the end, the participants talked about how they persisted through the harder times and were able to continue working toward their goals. 
As mentioned in the literature review, there was a litany of concerns related to students with ASD transitioning to the collegiate environment from their $\mathrm{K}-12$ institutions. Some of the concerns mentioned throughout the literature included would they be able to identify and activate the appropriate support services, would they be able to navigate the new and diverse social environments they were entering, and would they be able to acclimate to the new culture of the higher education institution they were becoming a part of (Adams \& Proctor, 2010; Rowe et al., 2015; Shogren \& Plotner, 2012; Trautwein \& Bosse, 2016; Wehman et al., 2014). Additionally, would they be able to manage the barrage of new responsibilities they would have to manage such as scheduling classes, tutoring, more intense homework assignments, work and family obligations, working with student groups outside of class, finding their calling and eventually graduating and living on their own? Lastly, would they be able to do this on their own without the external support they have always had? To an extent, concerns in the literature also included helpful and well-intentioned parents being excluded from educational processes due to FERPA and changes in the laws governing the different educational environments entitling the students to different supports and benefits. When these concerns are considered in their totality, an uncertain picture is drawn as to what chance these students would have to successfully navigate this new world they were stepping into with only their previous experiences to guide them and the primary support systems they have always been accustomed to using relegated to a supplemental status. Fortunately, throughout the interviews, there was a high level of resiliency that was undeniably identified by me and was unexpected, given what is currently supported in the literature (Sosnowy, Silverman, \& Shattuck, 2018). 
Resiliency is defined in the dictionary as the ability of something or someone to recover from or adjust to adversity or change. That is one of the characteristics that best defines this group of students' experiences. An example of this is Pietro's statement regarding his own resiliency:

[His] resilience as a student is key, every time [he] feels [himself] about to collapse, [he] just picks [himself] up and go[es] home to start studying, go read a book, get better at things like making friends and continue building upon the skills that got you here in the first place.

Of course, there have been some mistakes made along the way—-for example, whom to become friends with, how to best prepare to live on campus, how to engage classmates, how to make the most of a situation where you are lacking the resources necessary to succeed, how to react to professors or professional staff members disrespecting you, going against what your loved ones and trusted advisors assume will be best for you, or potentially dangerous situations, such as arguing with a demonstrator. But despite these less than stellar circumstances, these students have overcome them with hard work, grace, and poise. These students have chosen to define their time at the university as a time where they are experiencing growth in who they are, a keen understanding of what they want for themselves and how to obtain it, and a time for them to learn the essential skills needed to live independently and invest the time and effort to develop them. The experiences described throughout this study show a group of students working towards many of the same goals other students are working towards. They want to earn their degrees. They want to make friends and develop the ability to take advantage of any opportunity that presents itself to assure themselves a future where they are able to sustain themselves. They want to enjoy life. They want to learn new things and 
experience the same things others do. During the interviews, Erik described the process of learning new things best when he mentioned:

[He] likes to try things at least once, maybe it is for [him], or maybe its not for [him], then you try again; you have to try different options until you see a better result than [what you have now].

In essence, the students with ASD interviewed for this study have expressed a desire not to be circumscribed by the assumptions, hopes, and dreams of others. Under the lens of Disability Theory, the statements made by these students represent a call to action for them to be provided opportunities to enjoy all the educational and personal development options available at a college campus, despite what society has deemed appropriate for them (Rocco \& Delgado, 2011). They demonstrated actions that showcased their capabilities to encounter a problematic situation and overcome it in a manner that is consistent with how many individuals may have chosen to resolve them. It can be argued that perhaps some of the negative situations described in this study could have been avoided; but to this, I would say that many students in higher education tend to make a variety of mistakes that they should learn from and experience positive transformational changes in their moral and ethical behaviors (Neumeister, 2017). Research Question 2 Response

The second question of this study inquired about what are the perceptions of college students with ASD of the support services available to them at a public research university. With the exception of a handful of stories shared throughout the interviews regarding negative experiences with faculty and staff members, the number of positive accounts provided by the study participants was higher than the negative accounts of their experiences. It may be possible to consider the overall higher education experience 
described in the interviews based on this information as positive. What is most concerning about these stories is the type of negative encounters discussed and with whom they were with.

In general, the positive stories included interactions one would expect with the general student body, faculty, and staff at the institution. These included accounts of resolving living arrangement concerns with roommates and building a working relationship with support staff. They were experienced in a variety of settings that students frequent such as a dormitory and a support service department office. Raven described the staff at the cafeteria as "brightening up the [college] experience" by remembering frequently requested condiments and side dishes. Also sharing a positive experience, Jean shared a story of building a strong relationship with her disability services counselor that she described as:

She is great! [She gave me] the ability to talk to her, which was really important to me, by always making herself available... She was able to help me with some problems I was having in class and I learned from that I need to keep the disability services office in the loop so they can help.

Additionally, Charles described some of the positive experiences he has had with the tutoring and writing center as:

If [he] didn't have the tutoring and writing center [his] papers would be terrible. They have helped a lot because [his] papers have bad grammar and they also helped [him] learn study and testing skills. It's a really nice service.

Lastly, Remy described his positive experiences with his roommates as:

With the help of an RA, [he's] been lucky to reach an understanding with his roommates about his needs. [They've] learned [they] have similar interests, don't hit on each other's friends, [they] share [their] food, [they] have meals together, and [they] play video games together, so [they're] 
almost friends. Actually, [he] would call them [his] friends. [He] trust these people and it's certainly been a major help.

Unfortunately, some negative experiences were shared and they were also experienced with many of the people students tend to interact with on-campus such as other students, faculty, and support staff. Similar to the positive experiences, these negative experiences were had at some of the typically visited areas on a college campus such as the counseling center, the classroom, a dormitory, and a campus common area. When describing some of the negative situations experienced on campus, Raven mentioned:

There were anti-gay preachers outside and [Raven] got riled up and went back and forth with them. When [Raven] went to complain about this at the Dean of Students office, [Raven] was told they were not doing anything wrong and were protected by the first amendment.

On another occasion, Raven had a negative experience with a psychiatrist in the counseling center. This experience was described as:

When [Raven] was called into the appointment, the doctor referred to [Raven] as Ms., which was not Raven's preferred way of being referred to. [Raven] let him know what the preferred pronouns were to be used and the psychiatrist said you should carry a sign. [Raven] told him he could just ask for my preferences... he carried on and asked so do you need to know about my sex life, you need to learn to relate with other people's experiences not just impose yours on others that's when [Raven] just left since he wasn't being understanding of [Raven's] needs.

Based on this experience, it was difficult for Raven to go back to the counseling center to receive services. It was only after being assured another psychiatrist would be available that Raven did go back to using the counseling center. Additionally, Erik described a negative experience with a fellow student. What he thought was an authentic friendship was not and he described it as:

There was this girl that needed my help with some notes for a class and I said yes. Eventually, she started to take [his] books for herself to use and 
she tried to copy a paper [he] wrote. [He] had to go to the teacher for help and she got in trouble.

Lastly, during Henry's interview, he described going to meet with his professor during office hours for help with a topic he had trouble understanding. Erik talked about feeling embarrassed by the professor because:

[He] went to meet with [his] professor in their office about some questions [he] had from the homework. Instead of just talking to [him] and helping [him], all [the professor] did was take out the textbook and forced [the student] to read with him the section the questions were about very slowly, like [the student] could not understand what [the professor] was saying. [The student] felt embarrassed.

The experiences shared in these interviews regarding support services on campus showcase how, despite various good experiences, there can be some negative experiences with harsh consequences, such as not feeling welcomed at a health care facility you depend on. Fortunately, the positive experiences outnumber the negative experiences, but it is concerning that these actions were done by professionally-trained and licensed staff or by highly educated and experienced faculty. Faculty and staff not having the appropriate level of awareness and training to work with students with disabilities is a known issue, but more effort needs to be put into providing this type of training, especially since it will help students with ASD succeed in obtaining their degrees and positively contribute to the graduation and retention rates that are critical measures of funding eligibility for many institutions (Pillay \& Baht, 2012; Sanford \& Hunter, 2011; White, Ollendick, \& Bray, 2011).

Lastly, it is essential to continue working on providing students with ASD, as well as others, with more positive experiences, safe and inclusive environments, and support services since this contributes to them successfully overcoming academic challenges and 
earning their college degree (Gobbo \& Shmulsky, 2012; Jones, 2016; LeGary, 2017;

Pillay \& Baht, 2012; White, Ollendick, \& Bray, 2011). In line with the goals of Disabiltiy Theory, higher education communities must strive to change the focus of support services for students with ASD and other disabilities from supporting individual student accommodation requests to how can an environment be created where all students can be empowered with experiencing the joy and benefits of the collegiate experience with dignity and without having to constantly request modifications to be made (Loewen \& Pollard, 2010). In closing, "the intent is not the creation of a new discrete program for special people but rather the creation of a flexible support service to assist some people with special needs to participate successfully in a typical college experience" (Dillion, 2007, p.503).

Research Question 3 Response

The third question of this study asked what are the perceptions of college students with ASD on how well-prepared they feel for life after graduating from a public research university. In response to this question, the participants shared thoughts that presented them as being at varying levels of readiness to live on their own. Some felt confident that they currently had the ability to live on their own or would be able to with little difficulty, some admitted to needing to work on various essential skills to live on their own before attempting to do so, while some talked about what they are doing now to sharpen these skills with confidence so they would be ready when the time came to do so. The variety of responses received to this line of questioning is concerning since these students are getting closer to needing these skills and are historically known to be deficient in them (Taylor \& Henninger, 2014). 
Although they expressed different levels of current proficiency and overall skill development expectations, the responses to the questions in this study related to living independently after graduation had a common theme, that it could be done. This ethos was expressed strongly in Remy's statement that:

[He] can live in a tent in the Bahamas if [he] had to. Once [he] can get past the initial adjustment period, [he] can be content wherever [he is]... It has prepared [him] well for living with people that are different from [him]...

However, Logan presented a much more reserved perspective by saying that:

I like living on campus... but after my first year here, I don't like having roommates. I'm pretty sure they were not on the spectrum. They were very social and did things that were distracting to me, kind of irritating... I need to be able to have my own space.

Lastly, Charles expressed a more centered perspective regarding his on-campus student housing experience:

I feel like it will help me because people say that they have coworkers that they disagree with, so I feel like this living on my own is preparing me to deal with other people I disagree with. Not ignoring them, but learning how to be cordial with other people that you don't like, but you have to like. You know? Because when you're at work you can't always pick who your coworkers are.

There is research supporting independent living as a major concern since many adults with ASD tend to have challenges living on their own related to their ASD diagnosis, more so if they have a co-occurring disorder (Gotham et al., 2015). Additionally, not only was the theme that learning independent living skills could be done noticed, it was how it would be done that was interesting. The aspect of this theme that made it interesting is that all the participants labeled living in on-campus student housing as their primary strategy for learning these skills. This trend was highlighted by Erik when he stated that: 
Living on [his] own will help [him] get used to dealing with people, especially room mates since [his] father says [he] should have some to help with expenses. [He] knows [he] can learn some skills from [his] family, but [he] wants more options than that or watching videos and reading books.

Raven also had the opportunity to mention what was learned thus far from living in housing such as:

By living on campus, [Raven] learned how to cook for [themselves], clean up after [themselves]... It was especially helpful after the meal plan expired cause then [Raven] would have to go to the grocery store, and manage money; so that's going to be helpful after college.

Upon noticing this trend, it was confirmed that the literature supported the concept that students with ASD were also a growing population in the housing area of higher education, not just the general classroom and campus, which was the initial scope of this study (Ackels, Fields, \& Skinner, 2013). This concept of living in on-campus student housing to develop stronger life skills was additionally supported by the general goal mentioned in various articles confirming that higher education aims at strengthening the student academically and socially, which includes learning to be an independent adult (Vanbergeijk, Klin, \& Volkmar, 2008). This was exemplified by Jean when she recounted having to drive far away to secure her medication. In her story, she was:

Forced to find an off-campus pharmacy to fill her prescription for [a commonly used psychopharmaceutical drug (drug name removed to help maintain medical confidentiality). I was living on campus at the time and had to go to another city to get my medicine because we didn't have it on campus and the nearby pharmacies didn't stock it because its highly abused by college students, but I really need it. This made me waste a lot of time and gas for something I should have been able to get in the building across from my dorm!

Eventually, Jean found herself feeling overwhelmed with all the added responsibilities of living on her own and decided to move back home with her family. 
Despite the negative experience and having to transition back home under these circumstances, Jean admitted to viewing this as a life skills lesson, being confident that when the time was right, she would be able to live on her own given the new understanding she has gained from living on on-campus. The knowledge Jean has gained from her stated experiences and the confidence she exhibited that she will be ready to live on her own when the time to do so presents itself, along with the similar voiced expectation from the other participants, allows this finding to be connected with other findings in the literature that support students with ASD in higher education learning life skills that will help them live more independent lives (Hume, Loftin, \& Lantz, 2009).

In closing, the data provided by the participants in conjunction with what has been found in the literature provides a foundation for higher education professionals to start focusing their efforts on how to build meaningful learning experiences and to design a dynamic model of support services in housing. This kind of programming and support must be able to support the student with their current goals and needs and foster a sense of competent independent living skills based on opportunities where the students have been able to prove to themselves that they can do it.

\section{Limitations}

This study was conducted with the methodology described in chapter three. As with any research endeavor, there are bound to be some limitations observed during their implementation. In this section, these limitations will be discussed.

My study was started as soon as it was approved by my Institutional Review Board. It took two semesters to secure nine interviews, and it is believed that this was due to a lack of funding. There was no compensation approved for the participant's 
engagement in the study. Because of this, there were two participants that confirmed they would not participate in the study unless they were compensated. It is believed that these two participants, and perhaps more, may have opted into participating in the study if there had been some form of compensation. Another limitation that was noted was that this study started in the summer semester, which was a noticeably less populated semester at the institution. It would be wise to start this kind of study, if possible, in a more active semester, such as the fall or spring semesters. Because of these two factors, finding participants for the study proved to be very challenging and extended the data collection process timeframe much more than had been anticipated.

The second limitation that was noted was the number of students that were interviewed. Despite being justified and supported by the literature as being sufficient for the purposes of the study, I yearned for more students to interview in order to assure a higher level of maximum variation. One of the reasons for not having more students was that the summer semester tends to be very inactive in regard to student enrollment. Students tend to go home or vacation during this semester. Furthermore, during the beginning of the fall semester, historically the most active semester at the host institution, students at this institution were seen by me as being focused on starting school again and trying to establish healthy routines that will provide a better chance at successfully completing the semester and set the tone for the remainder of the academic year. Perhaps in a similarly active semester, but not as critical as the fall semester, for example the spring semester, the number of students recruited to participate in the study may be higher. Lastly, the total active and currently enrolled population of students with ASD at the host institution was reported by the disability services office as being in the low 
hundreds, this may also help explain why not many students may have opted in to the study.

A third limitation that was noted was that only one option was used to collect data. Despite being supported by the literature, all the participants were only interviewed one time, with the option to meet a second time to review the transcripts and elaborate as needed to assure their thoughts were accurately recorded. This limitation will be futher discussed in the Recommendations for Future Research section.

A fourth limitation that was noted was the level of self awareness of the participants. Given the historical understanding that people with ASD have lower levels of emotional intelligence than the general population or people that would have been diagnosed with Asperger's Syndrome or the current diagnosis Social Pragmatic Comnication Disorder, engaging a group of students in this study with such a high level of self-awareness was not expected (Boiley, Kingston, Montgomery, 2017). However, there is some recent research supporting that people with the ASD diagnosis have higher levels of self awareness and are actively working on their needs (Macloed, Allan, Lewis, $\&$ Robertson, 2017). How this limitation can be acted upon will be further discussed in the following sections.

Lastly, a fifth limitation that was noted during the study was the brevity of some of the responses by the participants. There were some participants that consistently gave short answers and did not elabortate unless prompted to do so by me. There are two possible explanations for this. One explanation is the Theory of Mind concept and the other is one of the hallmark characteristics of ASD, which is a deficit in communication abilities. One of the diagnostic criteria for ASD is a noticible deficit in socializationa and 
communication abilities (APA, 2013). This diagnostic feature would helps support some of the brevity in the responses received. Additionally, the Theory of Mind concept also helps explains the brevity of some of the interviews. The Theory of Mind concept states that people with ASD may have varying levels of difficulty discussing their emotions or perceptions about their experiences in depth (Tager-Flusberg, 2007). Additionally, the Theory of Mind concept includes that people with ASD may not be able to fully understand what is expected of them in the interview scenario, there (Brown \& Klein, 2011).

The limitations discussed in this section were noticed throughout the execution of the study. Since it is important to identify and understand these limitations in order to move forward with thinking of ways for using the findings in practice and brainstorming ideas for future research, they have been purposefuly placed in this part of the dissertation. In the following sections, how the findings of this study can be used in practice will be discussed. Lastly, some recommendations for future research will be discussed before closing this chapter.

\section{Implications for Practice}

In this section, how the data collected can affect the way higher education faculty and staff carry out their work with students with ASD will be discussed. The goal of the present study was to learn as much as possible about the experiences of students with ASD in higher education. The purpose of learing more about this population is to better understand their needs in and outside of the collegiate classroom. In line with what has been found in the literature is that institutions of higher education already have much of the infrastructure in place to serve students with ASD, what is needed is a paradigm shift 
in how faculty and staff view their work and exert their efforts in the interest of serving these students (Brown \& Coomes, 2016). Three recommendations will be provided in the following paragraphs of this section. The first recommendation will focus on how the concept of universal design can help create meaningful changes to an institution's policies and procedures in ways that upholds their integrity and original intent, but helps the institution wield administrative and pedagogical learning instruments more effectively to tend to the needs of a broader spectrum of students. The second recommendation will focus on a more deliberate and purposeful effort - creating an academic and general life skills group for students with ASD. The last recommendation will focus on a smaller scale idea that disability service offices may be able to implement more effectively and with less dependency on other people. It is importan to note that given some of the limitations mentioned, these recommendations should be thouroughly vetted for appropriateness within the environment they are to be implemented in since not all student populations may have the same needs as those interviewed in this study.

The first recommendation that will be discussed is how the concept of universal design can help create meaningful changes to an institution's policies and procedures in a way that upholds their integrity and original intent, but helps the institution wield these administrative and pedagogical learinng instruments more effectively to tend to the needs of a broader spectrum of students. Universally designing a classroom or curriculum means that some thought has been put into creating a learning experience that a large variety of people can engage in without any adaption or modification being done to it (Burgstajler \& Russo-Gleicher, 2015). Drawing on my various professional experiences, and what has been mentioned in the literature, institutions of higher education have a 
variety of policies and procedures in place, that although may be well-intentioned in serving many students persist in a timely fashion towards their degrees and acquire a high-quality education, do not serve the needs of students with ASD. This recommendation does not seek to abolish these policies and procedures but make some modifications to them that avails their users of some maneuverability in specific circumstances that call for some understanding and accommodation (Taylor \& Colvin, 2013). Some of the reasonable modifications recommended that can be made to various policies and procedures include incorporating some flexibility to full-time enrollment requirements, faculty and staff can be better supported by being provided training to develop awareness about the manifestation of various disabilities — such as ASD — so they may be more understanding of these students' needs, and faculty can be encouraged to implement more flexible classroom policies regarding absences, and deliverable deadlines (Taylor \& Colvin, 2013). Another policy consideration that can be made is to consider developing procedures to allow more access to parents, academic/behavioral coaches, and other private support staff students may be working with. Some of the students interviewed mentioned they were working with such support options. Having an institutionally supported method of incorporating these support systems in to the on campus life of the student would be helpful since they could supplement the efforts being done on campus at home in a more cohesive manner.

Lastly, with the growth in numbers of STEM majors and its general curriculum that utilize the flipped classroom concept of self-guided learning and hands-on work when in the class session with an abundance of group work, some flexibility incorporated into these pedagogies with regard to how students with ASD and other disabilities engage 
them is also recommended (Madriaga \& Goodley, 2010; Wei, Yu, Shattuck, Mccracken, \& Blackorby, 2012). In many situations, group work is used to help students acclimate to the team-based environment found in many work places, but this is counterintuitive to the needs of some students with ASD. One of the hallmark characteristics of ASD mentioned throughout this dissertation is a deficit in the ability to communicate and socialize. The abundant use of group work in many classrooms can present a daunting task for students with ASD since they may be forced to engage multiple groups of different people during the same semester in the process of completing their course deliverables. Faculty are advised to not require so much group work and provide opportunities for individualized assignments, when possible. This would provide students with ASD the flexibility to engage groups or work on their own to complete these assignments, depending on their comfort level engaging groups at the time.

The second recommendation that will be discussed focuses on a more deliberate and purposeful effort — creating an academic and general life skills group for students with ASD. This is important since there are no provisions in current law for social and communication-based accommodations that would be created in lieu of this kind of programming (Dipeolu, Storlie, \& Johnson, 2015). This kind of program can attend to the development of some of the skills students with ASD tend to have deficits with and can help coach them when resolving them in real-time (Dillon, 2007). Although this recommendation may seem difficult and out of reach for many institutions due to funding and the variety of expertise needed to implement it properly, it may be possible, and prudent, to provide effective and high-quality support by tapping into the different resources already available on many campuses such as faculty with various academic and 
therapeutic expertise, career development offices, tutoring and writing centers, the counseling center, housing and residential life departments, and many other areas (Weiss \& Rohland, 2015). Further evidence of the feasibility of this particular recommendation is my own implementation of it in my institution. Over the last four years, my team and I have implemented this idea every semester and have been able to help dozens of students with ASD at my institution. The workgroup is known as The Blue Panthers, a name chosen by the students representing their pride of being a Panther, the school's mascot, and characterizing it as a blue colored panther, which is the color generally used to represent Autism Spectrum Disorder. Additionally, I presented this idea at the national level at the 2015 Association for Higher Education and Disability National Conference. It has since received some complimentary attention but is admittedly difficult to implement without some institutional support by way of time and meeting space and minimal funding for supplies. The primary source of support for this endeavor currently relies on networking and being able to build connections for other departments and faculty to fulfill their mission of helping students by way of collaborating with other areas of the campus (Keeling, 2004). I have done this by recruiting faculty and departments around campus to render to their expertise and services in this group's meetings, which serve as training sessions on topics such as Interviewing Skills, Engaging Authority Figures (i.e., law enforcement, demanding faculty members, bullies), Working with Classroom Groups, Conversation Ice Breakers, and more. In addition to working with faculty and other departments, some effort has been invested in building a library of resources including books, DVD's, and other media that institutional community members can use for self or professional development. 
Lastly, the third recommendation that will be discussed is that disability services offices and providers may want to develop a training video or seminar that can be presented to various departments on campus or during new employee orientations. It is imperative that training is offered to faculty and staff about students with ASD and other disabilities since this kind of training may not always be offered as part of any curriculum in many fields, and the knowledge gap of faculty and staff may be unknown by them (Cook, Rumrill, \& Tankersley, 2009). Whether an in-person or video delivery medium is chosen, on-campus disability service providers should attempt to develop a training that focuses on in and out of classroom occasions faculty and staff may be working with a student with ASD. These vignettes should include some possible scenarios and how faculty/staff members can best respond to behaviors demonstrated by students with ASD. These training tools can also be broader in scope to include other disability-related situations, thus benefiting more students with disabilities and not just those with ASD. There are some pros and cons to choosing between an in-person presentation and a video. An in-person presentation allows the presenter to personalize the training with an opportunity to do a live question and answer session and it also provides networking opportunities. Unfortunately, the in-person option is time consuming, and it may not get the widespread coverage needed to serve a large campus. The video option is able to reach a larger segment of the population in a faster and more efficient manner, but needs funding to produce, must be updated with new information when it becomes outdated, and does not provide any opportunity to be personalized with a live question and answer session or to network with others. Depending on the needs of the campus and the resources available, one of these options may be best. At my home institution, several 
videos have been made to help spread the essential information needed by faculty and staff for various topics that cover how to work with students with ASD, how to work with service animals, general disability etiquette, and other disability-related matters.

Additionally, in-person follow-up training is also offered in case the video training does not suffice and either a deeper level of training is needed on a particular topic or if a training needs to be customized to a department's niche needs.

In essence, the recommendations for practice that have been presented are dynamic in nature and may be difficult to implement depending on the resources available to the disability service provider(s) and the culture of their respective institutions. Anyone interested in implementing any of these recommendations should do more research to learn more about what resources are available to them at their institution, develop their competency regarding how students with ASD and other disabilities are served, and have detailed discussions with potential campus partners as to what resources and services can be provided towards bringing any of these ideas to fruition. It is hoped that these recommendations will serve as a springboard for conversations of what can be done campus-wide to better serve students with ASD and other disabilities.

\section{Recommendations for Future Research}

After reviewing the overall study, its findings, and its limitations, I have generated some recommendations for future studies. It is important to continue conducting research with students with ASD in higher education since there is still a small amount of research to assist them and those working with this growing population in higher education institutions. 
Moving forward, future studies should consider providing some remuneration for participating in their study. This is a fairly common practice in research and may help make the participant recruitment process more efficient and effective (Merriam, 1998).

A second recommendation for future research is to have a thoughtful discussion with some members of the host institution's community to identify the semesters that may provide the best opportunities to recruit students. At the host institution, the fall and spring semester timeframe may have yielded a significantly higher amount of participants than the summer and fall timeframe since there are more students on campus, and by the time the spring semester begins they are well accustomed enough to the routines of going to class and abiding by their obligations to be able to want to volunteer for a study.

Additionally, it may prove effective to expand the pool of participants to include students from various institutions, not just one. This may allow more students to learn of the study and possibly volunteer. Additionally, the participant pool can also be expanded to include support staff, faculty, and/or parents of students with ASD in higher education. This would obviously change the nature of this study, but it may have added more perpectives and details to the richness and depth of the experiences of students with ASD in higher education.

Another recommendation that may have improved this study is designing it to have had more interviews per participant. This may have allowed me more opportunities to speak with the participants and learn more about them and their experiences. Overall, this may have contributed a deeper and perhaps more varied understanding of the experiences the participants have had in higher education and should be considered in 
future studies. Lastly, doing multiple interviews would also have allowed me to focus on various aspects of particular issues and parts of a timeline (Seidman, 2013).

An additional aspect that could be added to this kind of study is a survey. This addition may make it possible for students to participate in the study without having to engage in the interview process. Providing such an option would add another type of data to the study and still provide an opportunity to conduct interviews since a survey can be paired with interviews under a mixed-methods study design (Creswell, 2015).

Another research topic that can be gleaned from this study is to question the origin of the unexpected high level of self-awareness. In all the interviews, the participants were keen on their needs, strengths and weaknesses, and had ideas on how to work on developing the skills they highlighted themselves with being deficient in. The participant ages ranged from 18-24 and they all spoke about receiving services in previous institutions and the K-12 environment. Could this awareness stem from them being told what their deficits and goals are by others by way of individualized education plans and therapeutic goals, or is this awareness organic and something that has been conceptualized by the person themselves? Further research on this topic could lead to novel and shifts of what is understood about this population.

Invariably there may be more aspects of this study that can be changed in order to make it more comprehensive, suited to specific purposes, allow multiple cases to be compared at once, allow interpretations to be drawn from it by different schools of thought other than Disability Theory, or it can be enhanced with resources and skillsets not available to me at the time the study was conducted. What has been presented in this section are only recommendations that may help take this line of research into new 
directions or simply add to what has been done already. The aforementioned

recommendations are not exhaustive, and other researchers may find new and/or more effective methods with which to replicate or advance this study to generate data that may help provide more robust support for students with ASD in higher education.

\section{Concluding Remarks}

This research study was conducted to help advance the foundation of knowledge currently available to help students with ASD in higher education. The five chapters presented herein provide a detailed account of why and how I went about completing this endeavor. In the first chapter, a variety of contemporary concerns were presented that called attention to the topic of students with ASD entering higher education. In the second chapter, a structured review of the available and pertinent literature was done to better understand the breadth and scope of knowledge available about the topic of students with ASD in higher education. In the third chapter, how data were collected and analyzed to assist me in answering the research questions presented was discussed with the findings of the study presented in the fourth chapter. Lastly, in the fifth chapter, how these findings help answer this study's research questions, their limitations, and how they may fit within the current and future practices in higher education to help serve students with ASD and generate future research ideas was presented.

Through this study, light has been shined on the resiliency of the students attending the host institution. As mentioned previously, this characteristic may be solely responsible for the drive and determination to successfully obtain their college degrees and develop the skills and abilities needed to conquer the challenges of living independently after graduation. It is refreshing to see the data paint a picture of a group of 
students facing the challenges one would expect a student in college to experience, but rather than to allow themselves to be overcome by these challenges, these students have faced them and further developed their skills and abilities to engage the world as independently as possible. As depicted in the interviews, facing these challenges has not been an easy task; the work has, and is, still being done.

The students interviewed are not just resilient in their pursuit of a college degree, they are also astute on how to leverage the resources available to them to further develop the skill sets they know they are deficient in. The participants shared stories acknowledging the need to socialize more, work on their oratory skills, get prepared for the variety of challenges they may face in the future world of work, and how to quickly resolve challenges that may present themselves unexpectedly. These needs were answered by a yearning to be more involved with on-campus activities and to live in oncampus student housing. These two strategies were seen as ideal in being able to expose the students to a kaleidoscope of experiences that would help reinforce skills that would be needed in the future as they will soon embark on living in the world as independent members of society. In essence, these students have managed to understand their needs, identify strategies to attend to these needs, and are actively working on implementing these strategies. As expected, all of the participants have been experiencing different levels of success at different times, but they are continually moving closer towards accomplishing their goals.

In closing, the present study has allowed me to craft an understanding of a group of students with ASD that share many of the same desires and motivations as their nuerotypical peers. The participants interviewed want to develop their socialization and 
communication skills, they want to build strong social and professional networks, and they want to develop their independent living skills. The participants interviewed in my study also want a great education and the opportunity to engage people. The findings from interviewing this group of nine students with ASD are different from what is generally reported in the literature. Moving forward, I hope my work will inspire more research, more support, and more awareness that not all people with ASD are alike. Students with ASD are a heterogenious group of people and there are still many things we as faculty and staff can do to create environments that are more universally-conducive to learning, socializing, and engaging each other. Similar to other college students, this group of individuals is simply trying to become the best versions of themselves, and we as faculty and staff in higher education, have the opportunity to help them by removing unnecessary barriers in the learning environment and facilitate their completion of their goals.

After reading this dissertation, I hope the reader asks themselves what they can start doing right now to help a student with ASD or any disability have a more positive educational experience-because we all have the power to change the learning environment. Whether we adjust our syllabi, rethink how events are produced, or how we engage the quieter members of our student group, we have that power to change these things in a positive way that will support more learning and positive collegiate experiences. 


\section{References}

Ackles, L., Fields, H., \& Skinner, R. (2013). A Collaborative Support Model for Students on the Autism Spectrum in College and University Housing. The Journal of College and University Student Housing, 40(1), 200-2012.

Adams, K. S., \& Proctor, B. E. (2010). Adaptation to college for students with and without disabilities: Group differences and predictors. Journal of Postsecondary Education and Disability, 22, 166-184.

Adreon, D., \& Durocher, J. S. (2007). Evaluating the College Transition Needs of Individuals With High-Functioning Autism Spectrum Disorders. Intervention in School and Clinic,42(5), 271-279. doi:10.1177/10534512070420050201

American Psychiatric Association (2000). Diagnostic and statistical manual of mental disorders, Fourth Edition, Text Revision. Arlington, VA: American Psychiatric Publishing, Inc.

American Psychiatric Association (2013). Diagnostic and statistical manual of mental disorders, Fifth Edition. Arlington, VA: American Psychiatric Publishing, Inc.

Anderson, C., \& Butt, C. (2017). Young Adults on the Autism Spectrum at College: Successes and Stumbling Blocks. Journal of Autism and Developmental Disorders,47(10), 3029-3039. doi:10.1007/s10803-017-3218-х

Anderson, A. H., Carter, M., \& Stephenson, J. (2017). Perspectives of University Students with Autism Spectrum Disorder. Journal of Autism and Developmental Disorders,48(3), 651-665. doi:10.1007/s10803-017-3257-3

Arana, R., \& Blanchard, S. (2017). Loyalty to Ethnic Heritage and Hispanic College Student Engagement. Journal of Hispanic Higher Education, 17(4), 332-346. doi: $10.1177 / 1538192717699519$

Astin, A. (1993). What matters in college?. San Franscisco : Jossey-Bass Inc.

Autism Speaks. (2016). DSM-V Diagnostic Criteria. Retrieved from https://www.autismspeaks.org/what-autism/diagnosis/dsm-5-diagnostic-criteria.

Barber, P. (2012). College students with disabilities: What factors influence successful degree completion? A case study. Retrieved from http://www.heldrich.rutgers.edu/sites/default/files/content/College_Students_Disa bilities_Report.pdf 
Barnhill, G. P. (2014). Supporting Students With Asperger Syndrome on College Campuses. Focus on Autism and Other Developmental Disabilities,31(1), 3-15. doi: $10.1177 / 1088357614523121$

Bennett, K. D., \& Dukes, C. (2013). Employment instruction for secondary students with Autism Spectrum Disorder: A systematic review of the literature. Education and Training in Autism and Developmental Disabilities, 48(1), 67-75.

Beytekin, O. F., \& Kadi, A. (2014). Quality of Faculty Life and Lifelong Learning Tendencies of University Students. Higher Education Studies, 4(5). doi:10.5539/hes.v4n5p28

Birds, R. (2014) Entrepreneur-managers in higher education: (how) do they exist?, Journal of Higher Education Policy and Management, 36:1, 62-73, DOI: 10.1080/1360080X.2013.844663

Bogdan, R., Biklen, S. (2007). Qualitative research for education: An introduction to theories and methods (5th ed.). Boston, MA: Pearson A \& B.

Boily, R., Kingston, S. E., \& Montgomery, J. M. (2017). Trait and Ability Emotional Intelligence in Adolescents With and Without Autism Spectrum Disorder. Canadian Journal of School Psychology, 32(3-4), 282-298. doi: $10.1177 / 0829573517717160$

Boland, W. C. (2018). The Higher Education Act and Minority Serving Institutions: Towards a Typology of Title III and V Funded Programs. Education Sciences, 8(33). doi:10.3390/educsci8010033

Boutot, A. E., \& Myles, B. S. (2011). Autism spectrum disorders: Foundations, characteristics, and effective strategies. Upper Saddle River, NJ: Pearson.

Boys, J. (2015). Building better universities: Strategies, spaces, technologies. New York: Routledge.

Brown, H. M., \& Klein, P. D. (2011). Writing, asperger syndrom and thoery of mind. Journal of Autism and Developmental Disorders, 41, 1464-1474.

Brown, K. R., \& Coomes, M. D. (2015). A spectrum of support: current and best practices for students with Autism Spectrum Disorder (ASD) at community colleges. Community College Journal of Research and Practice, 40(6), 465-479. doi:10.1080/10668926.2015.1067171

Brown, K. R., Peña, E. V., \& Rankin, S. (2017). Unwanted Sexual Contact: Students With Autism and Other Disabilities at Greater Risk. Journal of College Student Development,58(5), 771-776. doi:10.1353/csd.2017.0059 
Burgstahler, S., \& Russo-Gleicher, R. J. (2015). Applying Universal Design to Address the Needs of Postsecondary Students on the Autism Spectrum. Journal of Postsecondary Education and Disability,28(2), 199-212.

Cai, R. Y., \& Richdale, A. L. (2015). Educational Experiences and Needs of Higher Education Students with Autism Spectrum Disorder. Journal of Autism and Developmental Disorders,46(1), 31-41. doi:10.1007/s10803-015-2535-1

Carter, E. W., Lane, K. L., Cooney, M., Weir, K., Moss, C. K., \& Machalicek, W. (2013). Self-Determination Among Transition-Age Youth With Autism or Intellectual Disability: Parent Perspectives. Research and Practice for Persons with Severe Disabilities, 38(3), 129-138. doi:10.2511/027494813809330234

Causton-Theoharis, J., Ashby, C., \& DeClouette, N. (2009). Relentless Optimism: Inclusive Postsecondary Opportunities for Students with Significant Disabilities. Journal of Postsecondary Education and Disability, 22(2), 88-105.

Center for Disease Control and Prevention. (2018). Autism Spectrum Disorder. Retrieved from https://www.cdc.gov/ncbddd/autism/data.html on November $29^{\text {th }}, 2018$.

Chaidez, V., Hansen, R. L., \& Hertz-Picciotto, I. (2013). Autism spectrum disorders in Hispanics and non-Hispanics. Autism, 16(4), 381-397. doi: $10.1177 / 1362361311434787$

Charlton, J. (2010). Peripheral Everywhere. Journal of Literary \& Cultural Disability Studies, 4(2), 195-200.

Chiang, H.-M., Ni, X., \& Lee, Y.-S. (2017). Life Skills Training for Middle and High School Students with Autism. Journal of Autism and Developmental Disorders, 47(4), 1113-1121. doi: 10.1007/s10803-017-3028-1

Chukwuorji, J. C., Ifeagwazi, C. M., Nwonyi, S. K., \& Ujoatuonu, I. V. N. (2018). Sense of Community and Academic Engagement in the Seminary. Journal of Research on Christian Education, 27(1), 20-38. doi: 10.1080/10656219.2018.1447412

Cocchi, W., \& Wilson, M. (2011). Program for students on autism spectrum prepares them to navigate college life. Disability Compliance For Higher Education, $16(11)$

Collier, M., Keefe, E. B., \& Hirrel, L. A. (2015). Listening to Parents' Narratives: The Value of Authentic Experiences With Children With Disabilities and Their Families. School Community Journal, 25(2), 221-242. 
Connor, D. J., Gabel, S. L., Gallagher, D. J., \& Morton, M. (2008). Disability studies and inclusive education - implications for theory, research, and practice. International Journal of Inclusive Education, 12(5-6), 441-457.

Cote, D. L., Jones, V. L., Sparks, S. L., \& Aldridge, P. A. (2012). Designing Transition Programs for Culturally \& Linguistically Diverse Students with Disabilities. Multicultural Education, 20(1), 51-55.

Cragg, K. M., \& Schloss, P. J. (2013). Organization and administration in higher education. New York: Routledge.

Creswell, J. (2007). Qualitative Inquiry and Research Design: Choosing among Five Approaches (2nd ed.). Thousand Oaks, CA: SAGE Publications.

Creswell, J. W. (2015). A Concise introduction to mixed methods research. Thousand Oaks, CA: SAGE Publications.

Cook, L., Rumrill, P. D., \& Tankersly, M. (2009). Priorities and Understanding of Faculty Members regarding College Students with Disabilitie. Priorities and Understanding of Faculty Members Regarding College Students with Disabilitie, 21(1), 84-96.

Cullen, J. A. (2015). The Needs of College Students with Autism Spectrum Disorders and Asperger's Syndrome. Journal of Postsecondary Education and Disability,28(1), 89-101.

Dallas, B. K., Ramisch, J. L., \& McGowan, B. (2015). Students with Autism Spectrum Disorder and the Role of Family in Postsecondary Settings: A Systematic Review of the Literature. Journal of Postsecondary Education and Disability,28(2), 135147.

Daly-Cano, M., Vaccaro, A., \& Newman, B. M. (2015). College student narratives about learning and using self-advocacy skills. Journal of Postsecondary Education and Disability, 28(2), 209-223.

Danforth, S., \& Gabel, S. L. (2006). Vital questions facing disability studies in education. New York: Peter Lang.

DaDeppo, L. M. W. (2009). Integration factors related to academic success and intent to persist of college students with learning disabilities. Learning Disabilities Research \& Practice, 24, 122-131.

de los Santos, A.G., Cuamea, K.M. (2010) ChallengesFacing Hispanic-Serving Institutions in the First Decade of the 21st Century. Journal of Latinos in Education, 9:2, 90-107, DOI: 10.1080/15348431003617798 
Dillon, M. R. (2007). Creating supports for college students with Asperger Syndrome through collaboration. College Student Journal,41(2), 499-504.

Dipeolu, A. O., Storlie, C., \& Johnson, C. (2015). College Students With HighFunctioning Autism Spectrum Disorder: Best Practices for Successful Transition to the World of Work. Journal of College Counseling, 18(2), 175-190. doi:10.1002/jocc.12013

Dutta, A., Kundu, M. M., \& Schiro-Geist, C. (2009). Coordination of postsecondary transition services for students with disabilities. Journal of Rehabilitation, 75(1), $10-17$.

Elias, R., \& White, S. W. (2017). Autism Goes to College: Understanding the Needs of a Student Population on the Rise. Journal of Autism and Developmental Disorders,48(3), 732-746. doi:10.1007/s10803-017-3075-7

Elson, N. (2011). Which way next? what is the real choice for students leaving a special school?. British Journal of Learning Support, 26(4), 152-159.

Evans, N. J., Forney, D. S., Guido, F. M., Patton, L. D., \& Renn, K. A. (2010). Student development in college: Theory, research, and practice (2nd ed.). San Francisco: Jossey-Bass.

Farley, M., Cottle, K. J., Bilder, D., Viskochil, J., Coon, H., \& Mcmahon, W. (2017). Mid-life social outcomes for a population-based sample of adults with ASD. Autism Research,11(1), 142-152. doi:10.1002/aur.1897

Flanagan, J. C. (1954). The critical incident technique. Psychological Bulletin, 51(4), 327-358.

Fleischer, A. S. (2012). Support to students with Asperger syndrome in higher education - the perspectives of three relatives and three coordinators. International Journal of Rehabilitation Research,35(1), 54-61. doi:10.1097/mrr.0b013e32834f4d3b

Flores, S. M., \& Park, T. J. (2013). Race, Ethnicity, and College Success. Educational Researcher, 42(3), 115-128. doi:10.3102/0013189x13478978

Florida Department of Education - Bureau of Exceptional Education and Student Services. (2018). 2018 LEA Profile for Dade County.Miami, FL Retrieved September 25, 2018.

Freire, P. (2000). Pedagogy of the oppressed. New York: Continuum. 
Gasman, M., Nguyen, T., Samayoa, A. C., \& Corral, D. (2017). Minority Serving Institutions: A Data-Driven Student Landscape in the Outcomes-Based Funding Universe. Berkeley Review of Education, 7(1), 5-24. doi:10.5070/b87110020

Gelbar, N. W., Smith, I., \& Reichow, B. (2014). Systematic Review of Articles Describing Experience and Supports of Individuals with Autism Enrolled in College and University Programs. Journal of Autism and Developmental Disorders,44(10), 2593-2601. doi:10.1007/s10803-014-2135-5

Getzel, E. E. (2008). Addressing the persistence and retention of students with disabilities in higher education: Incorporating key strategies and supports on campus. Exceptionality, 16, 207-219.

Getzel, E. E., \& Wehman, P.(2005).Going to college: Expanding opportunities for people with disabilities. Baltimore, MD: P.H. Brookes Pub.

Gilon, S. F., \& DePoy, E. (2002). Theoretical Approaches to Disability Content in Social Work. Journal of Social Work Education, 38(1), 153-165.

Glaser, B. G., \& Strauss, A. L. (1967). The discovery of grounded theory: Strategies for qualitative research. Chicago: Aldine Pub.

Grillo, M. C., \& Leist, C. W. (2014). Academic Support as a predictor of retention to graduation: New insights on the role of tutoring, learning assistance, and supplemental instruction. Journal of College Student Retention, 15(3), 387-408. http://dx.doi.org/10.2190/CS.15.3.e

Gobbo, K., Shmulsky, S. (2012) Classroom Needs of Community College Students with Asperger's Disorder and Autism Spectrum Disorders. Community College Journal of Research and Practice, 36:1, 40-46, DOI: 10.1080/10668920903381813

Gordon, M., \& Keiser, S. (1998). Accommodation in higher education under the Americans with disabilities act (ada). DeWitt, NY: GSI Publications

Gotham, K., Marvin, A. R., Taylor, J. L., Warren, Z., Anderson, C. M., Law, P. A., ... Lipkin, P. H. (2015). Characterizing the daily life, needs, and priorities of adults with autism spectrum disorder from Interactive Autism Network data. Autism, 19(7), 794-804. doi: 10.1177/1362361315583818

Guba, E. G., \& Lincoln, Y. S. (1989). Fourth generation evaluation. Newbury Park, CA: Sage Publ.

Hadley, W. M. (2011). College students with disabilities: A student development perspective. New Directions for Higher Education, 2011(154), 77-81. 
Hansen, R. (2011). The Trifecta of Student Support Services: Helping Students with Autism Spectrum Disorders Succeed in Postsecondary Education. College and University, 86(4), 37-40.

Harper, S. R., \& Quaye, S. J. (2009). Student engagement in higher education: Theoretical perspectives and practical approaches for diverse populations. New York: Routledge Taylor \& Francis Group.

Hart, D., Grigal, M., \& Weir, C. (2010). Expanding the Paradigm: Postsecondary Education Options for Individuals with Autism Spectrum Disorder and Intellectual Disabilities. Focus on Autism and Other Developmental Disabilities,25(3), 134-150. doi:10.1177/1088357610373759

Hatfield, M., Falkmer, M., Falkmer, T., \& Ciccarelli, M. (2017). "Leaps of faith": parents and professionals viewpoints on preparing adolescents on the autism spectrum for leaving school. Journal of Research in Special Educational Needs, 17(3), 187-197. doi:10.1111/1471-3802.12377

Hendricks, D. R., \& Wehman, P. (2009). Transition From School to Adulthood for Youth With Autism Spectrum Disorders: Review and Recommendations. Focus on Autism and Other Developmental Disabilities, 24(2), 77-88. doi:10.1177/1088357608329827

Hewitt, L. E. (2011). Perspectives on Support Needs of Individuals With Autism Spectrum Disorders. Topics in Language Disorders,31(3), 273-285. doi:10.1097/tld.0b013e318227fd19

Hewitt, L. E. (2015). Assessment Considerations for College Students With Autism Spectrum Disorder. Topics in Language Disorders,35(4), 313-328. doi:10.1097/tld.0000000000000073

Host University - Digital Communications. Rankings \& Facts. Retrieved July 4, 2018, from https://www.xxx.edu/about/rankings-facts/index.html

Host University Review Board Website. (2018). Retrieved November 2, 2018, from http://research.xxx.edu/irb/

Host University Disability Services Office. (2017). 2016-2017 Annual Report. Miami, Fl: Amanda Niguidula and Martha Wong.

Host University Disability Services OfficeWebsite. (2018). Retrieved July 4, 2018, from https://studentaffairs.xxx.edu/get-support/disability-resource-center/

House, J. S. (1983). Work stress and social support. Reading, MA: Addison-Wesley. 
Hubbard, S.M., Stage, F.K. (2009) Attitudes, Perceptions, and Preferences of Faculty at Hispanic Serving and Predominantly Black Institutions. Journal of Higher Education, 80(3), 270-289

Hume, K., Loftin, R., \& Lantz, J. (2009). Increasing Independence in Autism Spectrum Disorders: A Review of Three Focused Interventions. Journal of Autism and Developmental Disorders, 39(9), 1329-1338. doi: 10.1007/s10803-009-0751-2

Jackson, S. L., Hart, L., Brown, J. T., \& Volkmar, F. R. (2017). Brief Report: SelfReported Academic, Social, and Mental Health Experiences of Post-Secondary Students with Autism Spectrum Disorder. Journal of Autism and Developmental Disorders,48(3), 643-650. doi:10.1007/s10803-017-3315-x

Jacob, S. A., \& Furgerson, S. P. (2012). Writing Interview Protocols and Conducting Interviews: Tips for Students New to the Field of Qualitative Research.The Qualitative Report, 17(42), 1-10. Retrieved from http://nsuworks.nova.edu/tqr/vol17/iss42/3

Janiga, S. J., \& Costenbader, V. (2002). The transition for high school to post-secondary education for students with learning disabilities: A survey of college service coordinators. Journal of Learning Disabilities, 35, 462-468.

Jones, T. (2016). A Historical Mission in the Accountability Era. Educational Policy,30(7), 999-1041. doi:10.1177/0895904815586852

Junco, R., \& Chickering, A. W. (2010). Civil discourse in the age of social media. About Campus, 15(4), 12-18.

Kaplin, W. A., \& Lee, B. A. (2014). The law of higher education: a comprehensive guide to legal implications of administrative decision making(7th ed.). San Francisco, CA: Jossey-Bass, a Wiley Imprint.

Keeling, R. P. (2004). Learning reconsidered. Washington, D.C.: NASPA \& ACPA

Kite, D. M., Gullifer, J., \& Tyson, G. A. (2013). Views on the Diagnostic Labels of Autism and Asperger's Disorder and the Proposed Changes in the DSM. Journal of Autism and Developmental Disorders,43(7), 1692-1700. doi:10.1007/s10803012-1718-2

Kimhi, Y. (2014). Theory of Mind Abilities and Deficits in Autism Spectrum Disorders. Topics in Language Disorders, 34(4), 329-343. doi: 10.1097/tld.0000000000000033 
Knott, F, Taylor, A. (2014) Life at university with Asperger syndrome: a comparison of student and staff perspectives. International Journal of Inclusive Education, 18:4, 411-426, DOI: 10.1080/13603116.2013.781236

Koch, T. (1996). Implementation of a hermeneutic inquiry in nursing: Philosophy, rigor and representation. Journal of Advanced Nursing, 24, 174-184.

Koegel, L. K., Ashbaugh, K., Koegel, R. L., Detar, W. J., \& Regester, A. (2013). Increasing Socialization In Adults With Aspergers Syndrome. Psychology in the Schools, 50(9), 899-909. doi: 10.1002/pits.21715

Kupfer, A. (2012) A theoretical concept of educational upward mobility, International Studies in Sociology of Education, 22:1, 57-72, DOI: $10.1080 / 09620214.2012 .682795$

Laverty, S. M. (2003). Hermeneutic phenomenology and phenomenology: A comparison of historical and methodological considerations. International Journal of Qualitative Methods, 2(3), 21-35.

Lee, G. K., \& Carter, E. W. (2012). Preparing Transition-Age Students with HighFunctioning Autism Spectrum Disorders for Meaningful Work. Psychology in the Schools, 49(10), 988-1000. doi:10.1002/pits.21651

LeGary, R. A., Jr. (2017). College Students with Autism Spectrum Disorder: Perceptions of Social Supports that Buffer College-Related Stress and Facilitate Academic Success. Journal of Postsecondary Education and Disability,,30(3), 251-268.

Lincoln, Y. S., \& Guba, E. G. (1986). But is it rigorous? Trustworthiness and authenticity in naturalistic evaluation. New Directions for Program Evaluation, 1986(30), 7384. doi:10.1002/ev.1427Loewen, G., \& Pollard18, W. (2010). The Social Justice Perspective. Journal of Postsecondary Education and Disability, 23(1), 5-18

Loewen, G., \& Pollard, W. (2010). The Social Justice Perspective. Journal of Postsecondary Education and Disability, 23(1), 5-18.

Longtin, S. E. (2014). Using the College Infrastructure to Support Students on the Autism Spectrum. Journal of Postsecondary Education and Disability,27(1), 63-72.

Luey, J. (2014). Participating, Navigating and Succeeding with Autism Spectrum Disorder in the Ontario Postsecondary Education System. College Quarterly,17(4). 
Macleod, A., Allan, J., Lewis, A., \& Robertson, C. (2017). 'Here I come again': the cost of success for higher education students diagnosed with autism. International Journal of Inclusive Education, 22(6), 683-697. doi: 10.1080/13603116.2017.1396502

Madriaga, M., \& Goodley, D. (2010). Moving beyond the minimum: socially just pedagogies and Asperger's syndrome in UK higher education. International Journal of Inclusive Education, 14(2), 115-131. doi: 10.1080/13603110802504168

Magaña, S., Lopez, K., Aguinaga, A., \& Morton, H. (2013). Access to Diagnosis and Treatment Services Among Latino Children With Autism Spectrum Disorders. Intellectual and Developmental Disabilities,51(3), 141-153. doi:10.1352/19349556-51.3.141

Mazzotti, V. L., Rowe, D. A., Sinclair, J., Poppen, M., Woods, W. E., \& Shearer, M. L. (2016). Predictors of Post-School Success: A Systematic Review of NLTS2 Secondary Analyses. Career Development and Transition for Exceptional Individuals,39(4), 196-215. doi:10.1177/2165143415588047

Menzies, J., \& Baron, R. (2013). International postgraduate student transition experiences: The importance of student societies and friends. Innovations in Education and Teaching International, 51(1), 84-94. doi:10.1080/14703297.2013.771972

Mertens, D. M. (2007). Transformative Paradigm. Journal of Mixed Methods Research,1(3), 212-225. doi:10.1177/1558689807302811

Meyers, C. A., \& Bagnall, R. G. (2015). A case study of an adult learner with ASD and ADHD in an undergraduate online learning environment. Australasian Journal of Educational Technology, 31(2), 208219. doi:10.14742/ajet.1600

Mcdonough, P. M. (1997). Choosing Colleges. How Social Class and Schools Structure Opportunity. State University of New York Press.

McKeon, B., Alpern, C. S., \& Zager, D. (2013). Promoting Academic Engagement for College Students with Autism Spectrum Disorder. Journal of Postsecondary Education and Disability,26(4), 353-366.

Michailakis, D. (2003) The Systems Theory Concept of Disability: One is not born a disabled person, one is observed to be one, Disability \& Society, 18:2, 209-229, DOI: 10.1080/0968759032000044184

Merriam, S. B. (1998). Qualitative research and case study applications in education. San Francisco: Jossey-Bass. 
Merriam, S. B. (1998). Qualitative research and case study applications in education. San Francisco: Jossey-Bass.

Mccall, Z. A. (2014). The Transition Experiences, Activities, and Supports of Four College Students With Disabilities. Career Development and Transition for Exceptional Individuals, 38(3), 162-172. doi:10.1177/2165143414537679

Morrison, J. Q., Sansosti, F. J., \& Hadley, W. M. (2009). Parent Perceptions of the Anticipated Needs and Expectations for Support for Their College-Bound Students with Asperger's Syndrome. Journal of Postsecondary Education and Disability, 22(2), 78-87.

Moustakas, C. (1994). Phenomenological research methods. Thousand Oaks: Sage Publications.

Mullen, A. L. , Baker, J. (2015) Participation without Parity in U.S. Higher Education: Gender, Fields of Study, and Institutional Selectivity, NASPA Journal About Women in Higher Education, 8:2, 172-188, DOI: 10.1080/19407882.2015.1057167

Munger, K. M., \& Mertens, D. M. (2011). Conducting research with the disability community: A rights-based approach. New Directions for Adult and Continuing Education, 2011(132), 23-33.

Ness, B. M. (2013). Supporting Self-Regulated Learning for College Students with Asperger Syndrome: Exploring the "Strategies for College Learning" Model. Mentoring \& Tutoring: Partnership in Learning, 21(4), 356-377. doi:10.1080/13611267.2013.855865

Neumeister, J. R. (2017). The Model of Transformational Change for Moral Action: A Conceptual Framework to Elevate Student Conduct Practice in Higher Education. Journal of College and Character, 18(2), 97-111. doi: 10.1080/2194587x.2017.1300097

O'Shae, A., \& Meyer, R. (2016). A Qualitative Investigation of the Motivation of College Students with Nonvisible Disabilities to Utilize Disability Services. Journal of Postsecondary Education and Disability, 29(1), 5-23.

Orsmond, G. I., Shattuck, P. T., Cooper, B. P., Sterzing, P. R., \& Anderson, K. A. (2013). Social Participation Among Young Adults With an Autism Spectrum Disorder. Journal of Autism and Developmental Disorders, 43(22), 2710-2719. doi: 10.1037/e607222013-001

Patrick, N. J. (2008). Social skills for teenagers and adults with aspergers syndrome: A practical guide to day-to-day life. Philadelphia, PA: Jessica Kingsley Publishers 
Pillay, Y., \& Bhat, C. S. (2012). Facilitating Support for Students with Asperger's Syndrome. Journal of College Student Psychotherapy,26, 140-154. doi:10.1080/87568225.2012.659161

Piven, J., \& Rabins, P. (2011). Autism spectrum disorders in older adults: toward defining a research agenda. Journal of American Geriatric Society, 59, 21512155 .

Preston, D. L. (2010). Finding Difference: Nemo and Friends Opening the Door to Disability Theory. English Journal, 100(2), 56-60.

Prince, A. M., Hodge, J., Bridges, W. C., \& Katsiyannis, A. (2018). Predictors of Postschool Education/Training and Employment Outcomes for Youth With Disabilities. Career Development and Transition for Exceptional Individuals, 41(2), 77-87. doi:10.1177/2165143417698122

Reid, D. P. (2015). From being bullied to being accepted: The lived experiences of a student with Asperger's enrolled in a Christian university. International Journal of Christianity \& Education, 19(3), 240-259. doi:10.1177/2056997115602991

Rege Colet, N. M., (2017) From content-centred to learning-centred approaches: shifting educational paradigm in higher education, Journal of Educational Administration and History, 49:1, 72-86, DOI: 10.1080/00220620.2017.1252737

Roberts, N., \& Birmingham, E. (2017). Mentoring University Students with ASD: A Mentee-centered Approach. Journal of Autism and Developmental Disorders,47(4), 1038-1050. doi:10.1007/s10803-016-2997-9

Robinson, S. (2008). Using a strategy of 'structured conversation' to enhance the quality of tutorial time. Journal of Further and Higher Education,32(1), 59-69. doi:10.1080/03098770701781457

Rocco, T. S., \& Delgado, A. (2011). Shifting Lenses: A Critical Examination of Disability in Adult Education. New Directions for Adult and Continuing Education, 132(Winter), 3-12.

Ross, J., Marcell, J., \& Williams, P. (2013). Postsecondary Education Employment and Independent Living Outcomes of Persons with Autism and Intellectual Disability. Journal of Postsecondary Education and Disability, 26(4), 337-351.

Rowe, D. A., Mazzotti, V. L., Hirano, K., \& Alverson, C. Y. (2015). Assessing Transition Skills in the 21st Century. TEACHING Exceptional Children, 47(6), 301-309. doi:10.1177/0040059915587670 
Rubin, H., Rubin, I. (2012). Qualitative interviewing: The art of hearing data (3rd ed.). Thousand Oaks, CA: Sage.

Saldana, J. (2013). The coding manual for qualitative researchers (2nd ed.). Los Angeles, CA: SAGE Publications.

Sampson, V. (2008). Dear Colleague Letter: The Higher Education Opportunity Act (pgs. 1-2). Retrieved from https://ifap.ed.gov/dpcletters/GEN0812FP0810.html on November 12, 2018.

Sanford, T., Hunter, J. M. (2011) Impact of Performance-funding on Retention and Graduation Rates Education Policy Analysis Archives, 19(33). Retrieved August $27^{\text {th }}, 2017$, from http://epaa.asu.edu/ojs/article/view/949

Sarrett, J. C. (2017). Autism and Accommodations in Higher Education: Insights from the Autism Community. Journal of Autism and Developmental Disorders, 48(3), 679-693. doi:10.1007/s10803-017-3353-4

Schlossberg, N. K. (2011). The challenge of change: The transition model and its applications. Journal of Employment Counseling, 48(4), 159-162.

Scott, S. S., McGuire, J. M., \& Shaw, S. F. (2003). Universal design for instruction: a new paradigm for adult instruction in postsecondary education. Remedial and Special Education, 24(6), 369-379.

Seidman, I. (2013). Interviewing as qualitative research: A guide for researchers in education and the social sciences (4th ed.). New York, NY: Teachers College Press.

Siebers, T. (2011). Disability theory. Ann Arbor: University of Michigan Press.

Simon, J. A. (2011). Legal issues in serving students with disabilities in postsecondary education. New Directions for Student Services, 134, 95-107. doi:10.1002/ss.397

Shattuck, P.T.,Wagner, M.,Narendorf, S., Sterzing, P.,\&Hensley, M. (2011). Post-high school service use among young adults with autism. Archives of Pediatrics and Adolescent Medicine, 165, 141 - 146. doi:10.1001/archpediatrics.2010.279

Shattuck, P. T., Narendorf, S. C., Cooper, B., Sterzing, P. R., Wagner, M., \& Taylor, J. L. (2012). Postsecondary Education and Employment Among Youth With an Autism Spectrum Disorder. Pediatrics, 129(6), 1042-1049.

Shenton, A. (2004). Strategies for ensuring trustworthiness in qualitative research projects. Education for Information, 22, 63-75.Sinek, S. (2009). Start with why. New York, NY: Penguin Books Ltd. 
Shogren, K. A., \& Plotner, A. J. (2012). Transition Planning for Students With Intellectual Disability, Autism, or Other Disabilities: Data from the National Longitudinal Transition Study-2. Intellectual and Developmental Disabilities, 50(1), 16-30. doi:10.1352/1934-9556-50.1.16

Skaff, L. F., Kemp, J. N., Mcgovern, L. A., \& Fantacone, J. M. (2016). Educator and Parent Views of the Effectiveness of Individualized Learning Plans for Students With Disabilities. Career Development and Transition for Exceptional Individuals,39(2), 68-78. doi:10.1177/2165143414546131

Shmulsky, S. \& Gobbo, K. (2013) Autism Spectrum in the College Classroom: Strategies for Instructors, Community College Journal of Research and Practice, 37:6, 490495, DOI: $10.1080 / 10668926.2012 .716753$

Shmulsky, S., Gobbo, K., \& Donahue, A. (2015). Groundwork for Success: A College Transition Program for Students with ASD. Journal of Postsecondary Education and Disabilitylity,28(2), 235-241.

Smith, C. P. (2007). Support services for students with Asperger's Syndrome in higher education. College Student Journal,41(3), 515-531.

Smith, F. \& Lucas, J., 2010. Vocational Rehabilitation (VR) Employment Outcomes for Transition-age Youth with Autism, and Other Disabilities. Data Series, Data Note XXVI. Boston, MA: Institute for Community Inclusion

Sosnowy, C., Silverman, C., \& Shattuck, P. (2017). Parents' and young adults' perspectives on transition outcomes for young adults with autism. Autism, 22(1), 29-39. doi: 10.1177/1362361317699585

Spencer, L., Lyketsos, C. G., Samstad, E., Dokey, A., Rostov, D., \& Chisolm, M. (2011). American journal of psychiatry. A suicidal adult in crisis: an unexpected diagnosis of autism spectrum disorder, 168(9), 890-892.

Stebleton, M. J., Soria, K. M., Huesman, R. L., \& Torres, V. (2014). Recent Immigrant Students at Research Universities: The Relationship Between Campus Climate and Sense of Belonging. Journal of College Student Development,55(2), 196-202. doi:10.1353/csd.2014.0019

Stodden, R., Yamamoto, K., Folk, E., Kong, E., \& Otsuji, D. (2013). Pursuing Quality Evidence: Applying Single-Subject Quality Indicators to Non-experimental Qualitative Educational Research. Education and Training in Autism and Developmental Disabilities, 48(4), 491-503. Retrieved from http://www.jstor.org/stable/24232506 
Tager-Flusberg, H. (2007). Evaluating the Theory-of-Mind Hypothesis of Autism. Current Directions in Psychological Science, 16(6), 311-315. doi: 10.1111/j.1467-8721.2007.00527.x

Taylor, C. M., \& Colvin, K. L. (2013). Universal Design: A Tool to Help College Students With Aspergers Syndrome Engage on Campus. About Campus, 18(3), 915. doi: $10.1002 / a b c .21118$

Taylor, J. L., \& Henninger, N. A. (2014). Frequency and Correlates of Service Access Among Youth with Autism Transitioning to Adulthood. Journal of Autism and Developmental Disorders, 45(1), 179-191. doi: 10.1007/s10803-014-2203-x

Test, D. W. (2008). Seamless Transition for All. Research and Practice for Persons with Severe Disabilities, 33(3), 98-99. doi:10.2511/rpsd.33.3.98

Test, D. W., Smith, L. E., \& Carter, E. W. (2014). Equipping Youth With Autism Spectrum Disorders for Adulthood: Promoting Rigor, Relevance, and Relationships. Remedial and Special Education, 35(2), 80-90. doi:10.1177/0741932513514857

Tinto, V. (1988). Stages of student departure: Reflections on the longitudinal character of student leaving. The Journal of Higher Education, 59(4), 438-455.

Tinto, V. (2012). Completing college: Rethinking institutional action. Chicago: The University of Chicago Press.

Thelin, J. R. (2011). A history of American higher education(2nd ed.). Baltimore (Md.): Johns Hopkins University Press.

Thomas, K. C., Ellis, A. R., Mclaurin, C., Daniels, J., \& Morrissey, J. P. (2007). Access to Care for Autism-Related Services. Journal of Autism and Developmental Disorders,37(10), 1902-1912. doi:10.1007/s10803-006-0323-7

Thomas, P., Zahorodny, W., Peng, B., Kim, S., Jani, N., Halperin, W., \& Brimacombe, M. (2012). The association of autism diagnosis with socioeconomic status. Autism, 16(2), 201-213. doi:10.1177/1362361311413397

Tracy, S. J. (2010). Qualitative Quality: Eight "Big-Tent" Criteria for Excellent Qualitative Research. Qualitative Inquiry, 16(10), 837-851.

Trautwein, C., \& Bosse, E. (2016). The first year in higher education-critical requirements from the student perspective. Higher Education, 73(3), 371-387. doi: 10.1007/s10734-016-0098-5 
U.S. Department of Education. (2011, April 1). Statement by Assistant Secretary Alexa Posny on the Fourth Annual World Autism Awareness Day on Saturday, April 2. Retrieved on August 3, 2016, from http://www.ed.gov/news/pressreleases/statement-assistant-secretary-alexa-posny-fourth-annual-world-autismawareness-d

U.S. Department of Education, National Center for Education Statistics. (2016).The Condition of Education 2016. NCES2016-144, Washington, D.C. Retrieved on August 19, 2017, from https://nces.ed.gov/pubs2016/2016144.pdf

Vanbergeijk, E., Klin, A., \& Volkmar, F. (2008). Supporting More Able Students on the Autism Spectrum: College and Beyond. Journal of Autism and Developmental Disorders, 38(7), 1359-1370.

Van Hees, V., Moyson, T., \& Roeyers, H. (2014). Higher Education Experiences of Students with Autism Spectrum Disorder: Challenges, Benefits and Support Needs. Journal of Autism and Developmental Disorders,45(6), 1673-1688. doi:10.1007/s10803-014-2324-2

Van Manen, M. (1997). Researching lived experience: Human science for an action sensitive pedagogy(2nd ed.). New York: Routledge.

Watson, N. (2012). Theorising the Lives of Disabled Children: How Can Disability Theory Help? Children \& Society, 26, 192-202. doi:10.1111/j.10990860.2012.00432.x

Webster, D. D. (2004). Giving voice to students with disabilities who have successfully transitioned to college. Career Development for Exceptional Individuals, 27, $151-175$.

Wehman, P., Schall, C., Carr, S., Targett, P., West, M., \& Cifu, G. (2014). Transition from High School to Adulthood for Adolescents and Young Adults with Autism Spectrum Disorders: What We Know and What We Need to Know. Adolescents and Adults with Autism Spectrum Disorders, 24(I), 30-40, 41-60. doi:10.1007/978-1-4939-0506-5_3

Wei, X., Yu, J. W., Shattuck, P., Mccracken, M., \& Blackorby, J. (2012). Science, Technology, Engineering, and Mathematics (STEM) Participation Among College Students with an Autism Spectrum Disorder. Journal of Autism and Developmental Disorders, 43(7), 1539-1546. doi: 10.1007/s10803-012-1700-z

Weiss, A. L., \& Rohland, P. (2015). Implementing a Communication Coaching Program for Students with Autism Spectrum Disorders in Postsecondary Education. Topics in Language Disorders, 35(4), 345-361. doi: 10.1097/tld.0000000000000071 
Wessel, R. D., Jones, J. A., Markle, L., \& Westfall, C. (2009). Retention and Graduation of Students with Disabilities: Facilitating Student Success. Journal of Postsecondary Education and Disability, 21(3), 116-125.

Wilkinson, L. (2017). A best practice guide to assessment and intervention for autism spectrum disorder in schools (2nd ed.). London, UK: Jessica Kingsley Publisher.

White, S. W., Ollendick, T. H., \& Bray, B. C. (2011). College students on the autism spectrum. Autism, 15(6), 683-701. doi:10.1177/1362361310393363

White, S. W., Richey, J. A., Gracanin, D., Coffman, M., Elias, R., LaConte, S., \& Ollendick, T. H. (2016). Psychosocial and Computer-Assisted Intervention for College Students with Autism Spectrum Disorder: Preliminary Support for Feasibility. Education and Training in Autism and Developmental Disabilities,51(3), 307-317.

Wolf, L. E. (2006). College Students with ADHD and Other Hidden Disabilities. Annals of the New York Academy of Sciences, 931(1), 385-395. doi:10.1111/j.17496632.2001.tb05792.x

Wolf, L. E., Brown, J. T., \& Bork, G. R. K. (2009). Students with asperger syndrome: A guide for college personnel. Shawnee Mission, KA: Autism Asperger Publishing Co.

Yazan, B. (2015). Three Approaches to Case Study Methods in Education: Yin, Merriam, and Stake.The Qualitative Report,20(2),134-152.

Yin, R. K. (2018). Case study research and applications: design and methods (6th ed.). Los Angeles, CA: SAGE.

Yin, R.K. (2006). Case Study Methods. In Green, J. L., Camilli, G., \& Elmore, P. B. (Ed.), Handbook of complementary methods in education research (3rd ed.). Mahwah, NJ: Routledge.

Zeedyk, S. M., Tipton, L. A., \& Blacher, J. (2016). Educational Supports for High Functioning Youth With ASD. Focus on Autism and Other Developmental Disabilities, 31(1), 37-48. doi:10.1177/1088357614525435

Zhang, D., Landmark, L., Grenwelge, C., \& Montoya, L. (2010). Culturally Diverse Parents' Perspectives on Self-Determination. Education and Training in Autism and Developmental Disabilities,45(2), 175-186. 


\section{APPENDICES}

\section{$\underline{\text { Appendix A }}$}

\section{Interview Questions}

\section{Bio-Demographic Questions}

*The first question of the interview will first be asked without the audio recorder on. It will be asked again when the recording starts in order to document it was asked and what their response was. The interviewee will be made aware of this.

1. For confidentiality, what is the pseudonym/nickname you wish to be referred to as during this interview?

2. What is your age?

3. What is your ethnicity?

4. What is your race?

5. What is the gender you identify as?

\section{Higher Education Experience Questions}

1. So tell me when you started going to college/

\section{?}

a. (Only if student started their higher education experience at another institution) How long have you been at

2. Tell me about your time at regarding faculty, student and general staff experiences?

a. Do any particular events or experiences stand out since you started at

?

b. What would you say was positive about those events?

c. What would you say was negative about those events?

d. How did you react or respond to those events?

e. What did you learn from those experiences?

3. Tell me a bit about your experiences with support services at ?(if needed, different support services can be named, such as advising, disability services, tutoring, counseling, health services, etc to help the interviewee understand the question).

a. Do any particular events or experiences stand out since you started at

?

b. What would you say was positive about those events?

c. What would you say was negative about those events?

d. How did you react or respond to those events?

e. What did you learn from those experiences?

4. Can you tell me about how prepared you feel you are/are getting to live on your own after graduation?

a. Do any particular events or experiences stand out since you started at ?

b. What would you say was positive about those events?

c. What would you say was negative about those events?

d. How did you react or respond to those events? 
e. What did you learn from those experiences?

5. If you went to any college or university before _ can you talk about your support service experiences there?

a. Do any particular events or experiences stand out since you started at ?

b. What would you say was positive about those events?

c. What would you say was negative about those events?

d. How did you react or respond to those events?

e. What did you learn from those experiences?

6. What would you say was especially helpful in supporting you in college?

7. What would you say was not helpful in supporting you in college?

8. If forced to choose something, what would you change about your experience?

a. How would this change benefit you?

b. How would this change benefit other people?

9. How would you compare the support you had in high school with the support you have now in college?

10. How did you hear about of the support services available at

11. How confident are you that you know who and where to go to for help with anything you need at

12. So, at this point, we are done with all the questions I have. Is there anything you want to add that we haven't covered yet today? 


\section{Appendix B}

\section{Participants Needed for a Study on the Experiences of University Students with Autism Spectrum Disorder}

We are looking for current students with Autism Spectrum Disorder (ASD) to participate in a study. This study has been approved by the Institutional Review Board at

The purpose of this study is to learn of the experiences that university students with ASD have had with transitioning to

support services at and how well-prepared they feel for life after graduation.

If you agree to be a part of the study, you will be asked to participate in a private, in-person interview. The interview will be audio recorded, and it will take about 60- to 90-minutes to complete. This will be followed by an in-person review of that interview's transcript, which will take about another 60-minutes of your time.

The study will be conducted in private offices at the

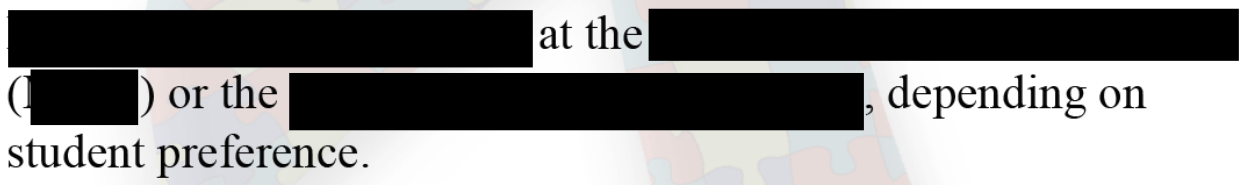

If you are interested in participating or need more information, please call Stephen P. Loynaz at 786-326-4498 or e-mail at loynazs@,fiu.edu. 


\section{Appendix C}

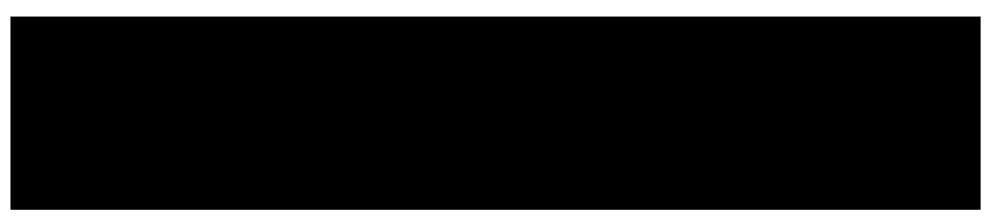

\section{ADULT CONSENT TO PARTICIPATE IN A RESEARCH STUDY}

\section{Experiences of College Students with Autism Spectrum Disorder at}

\section{SUMMARY INFORMATION}

Much of the current research on students with Autism Spectrum Disorders (ASD) has been centered on children and adolescents in the K-12 population. This case study will use in-person interviews for gaining an understanding of the experiences of students with ASD at $\quad$ The researcher expects that the data collected in this study will help faculty and staff in higher education work more effectively with students with ASD or a related disability.

Things you should know about this study:

- Purpose: The purpose of the study is to gain a deeper understanding of the needs of students with ASD or a related disability in a university.

- Procedures: If you choose to participate, you will be asked to take part in an interview and later review the transcript of that interview for accuracy and recommend needed updates, at your discretion.

- Duration: The interview will take about 60-90 minutes. The review and approval of the interview transcript will be done during a second interview, and this should take about 60 additional min.

- Risks: The main risk or discomfort from this research is remembering and discussing challenging experiences at $\square$ as well as discussing and anticipating future success, challenges, and the ability to live, work, and recreate independently.

- Benefits: A possible benefit to you from this research is obtaining referrals to based resources for any unmet need that is discussed during the interview. Also, the information you share will help inform how colleges and universities can better serve college students with ASD.

- Alternatives: Other than choosing not to participate, you can talk with staff members of the to learn about their services.

- Participation: Taking part in this research project is voluntary.

Please carefully read the entire document before agreeing to participate. 


\section{PURPOSE OF THE STUDY}

The purpose of this study is to learn more about the experiences of students with ASD in regard to support services offered in higher education.

\section{NUMBER OF STUDY PARTICIPANTS}

If you decide to be in this study, you will be one of up to 20 people in this research study.

\section{DURATION OF THE STUDY}

Your participation will involve up to two interactions with the researcher. The first will be a scheduled in-person interview. This interview is expected to last 60-90 minutes. The second interaction will take place in person, if the participant chooses to verify the accuracy of the original interview's transcript. If you choose to participate in the second interaction, you will receive a copy of the interview transcript so you may make editing recommendations and confirm its accuracy. This second interview will take about 60 $\min$.

\section{PROCEDURES}

If you agree to be in the study, we will ask you to do the following things:

1. You will participate in one audio recorded in-person interview for approximately 6090 minutes. During this interview, you will be assigned a four-digit reference ID number to protect your identity and you will be asked questions about your experiences at (and any other college/university you attended), your experiences with (or other university's) student support services, and how well-prepared you feel to live independently now or after graduation.

2. If you choose to participate in the second meeting, you will participate in reviewing your interview's transcript for accuracy and make any editing recommendations that are needed to make it accurately reflect what you said during the interview. This second meeting will occur after the interview via an in-person meeting depending on the participant's preference. This meeting will be set-up upon completion of the interview's transcript via the participant's preferred contact method, such as a phone number or e-mail. This second meeting will take about $60 \mathrm{~min}$.

\section{RISKS AND/OR DISCOMFORTS}

The study has the following possible risks to you: First, you will be asked to remember and discuss challenging experiences at Second, you will be asked to anticipate and 
discuss future successes, challenges, and the ability to live, work, and recreate independently.

\section{BENEFITS}

The study has the following possible benefits to you: First, as an individual, you will be discussing your experiences at with a higher education professional that will be able to provide referrals for any unmet needs you may have. Second, society may benefit from this interview by having more information about what adult college students with ASD need to be successful in college and after college.

\section{ALTERNATIVES}

Other than choosing not to participate, you can talk with staff members of the to learn about their services. Any significant new findings developed during the course of the research which may relate to your willingness to continue participation will be provided to you.

\section{CONFIDENTIALITY}

The records of this study will be kept private and will be protected to the fullest extent provided by law. In any report we might publish, we will not include any information that will make it possible to identify you. Research records will be stored securely, and only the researcher team will have access to the records. However, your records may be inspected by authorized University or other agents who will also keep the information confidential.

\section{USE OF YOUR INFORMATION}

Your information collected as part of the research will not be used or distributed for future research studies even if identifiers are removed.

\section{COMPENSATION \& COSTS}

There are no costs or compensation to you for participating in this study. 


\section{RIGHT TO DECLINE OR WITHDRAW}

Your participation in this study is voluntary. You are free to participate in the study or withdraw your consent at any time during the study. You will not lose any benefits if you decide not to participate or if you quit the study early. The investigator reserves the right to remove you without your consent at such time that he/she feels it is in the best interest.

\section{RESEARCHER CONTACT INFORMATION}

If you have any questions about the purpose, procedures, or any other issues relating to this research study you may contact Stephen Peter Loynaz at via phone at 305-348-7617, or via e-mail at loynazs@ fiu.edu. You can also contact Dr. Kyle D. Bennett at 3641, or via email at kyle.bennett@fiu.edu.

\section{IRB CONTACT INFORMATION}

If you would like to talk with someone about your rights of being a subject in this research study or about ethical issues with this research study, you may contact the by phone at 305-348-2494 or by email at ori@ fiu.edu.

\section{PARTICIPANT AGREEMENT}

I have read the information in this consent form and agree to participate in this study. I have had a chance to ask any questions I have about this study, and they have been answered for me. I understand that I will be given a copy of this form for my records.

Signature of Participant

Date

Printed Name of Participant

Signature of Person Obtaining Consent

Date 
VITA

\section{STEPHEN PETER LOYNAZ}

\section{BORN, NEW YORK, NY}

$2003-2005$

Activity leader

Tropical Elementary School

Mimai, FL

$2000-2005$

B.A. Psychology

Florida International University

Miami, FL

2006

Case Manager

Children's Psychiatric Center

Miami, FL

$2006-2007$

Coordinator

Barry University

Miami Shores, FL

$2007-2011$

Coordinator

Florida International University

Miami, FL

$2009-2020$

Online Instructor

American Medical Academy

Miami, FL

2010

Intern

Swithcboard of Miami

Miami, FL

2010

Intern

Coordinated Victim's Assistance Center (CVAC)

Miami, FL

2010

M.S. Mental Health Counseling

Florida International University

Miami, FL 
$2011-2020$

Lecturer

Florida International University

Miami, FL

$2011-2020$

Associate Director \& Access Consultant Manager

Florida International University

Miami, FL

2014

Graduate Certificate in Public Management

Florida International University

Miami, FL

2015

Division of Student Affairs Leadership Award

Florida International University

Miami, FL

2020

Doctor of Philosophy in Higher Education

Florida International University

Miami, FL

\section{PRESENTATIONS}

Loynaz, S. (2016). AHEAD National Conference - Blue Pathways: An adaptable group program for students on the Autism Spectrum

Loynaz, S. (2016). AHEAD National Conference-Expanding Access: The narrative intake technique for students without documentation 